\title{
WestVirginiaUniversity
}

THE RESEARCH REPOSITORY @ WVU

Graduate Theses, Dissertations, and Problem Reports

2019

\section{Three Essays on Applied Semiparametric Methods}

Qinling Lu

West Virginia University, qilu@mix.wvu.edu

Follow this and additional works at: https://researchrepository.wvu.edu/etd

Part of the Economics Commons

\section{Recommended Citation}

Lu, Qinling, "Three Essays on Applied Semiparametric Methods" (2019). Graduate Theses, Dissertations, and Problem Reports. 3881.

https://researchrepository.wvu.edu/etd/3881

This Dissertation is protected by copyright and/or related rights. It has been brought to you by the The Research Repository @ WVU with permission from the rights-holder(s). You are free to use this Dissertation in any way that is permitted by the copyright and related rights legislation that applies to your use. For other uses you must obtain permission from the rights-holder(s) directly, unless additional rights are indicated by a Creative Commons license in the record and/ or on the work itself. This Dissertation has been accepted for inclusion in WVU Graduate Theses, Dissertations, and Problem Reports collection by an authorized administrator of The Research Repository @ WVU.

For more information, please contact researchrepository@mail.wvu.edu. 


\title{
Three Essays on Applied Semiparametric Methods
}

\section{Qinling Lu}

\author{
Dissertation submitted \\ to the College of Business and Economics \\ at West Virginia University
}

in partial fulfillment of the requirements for the degree of

\author{
Doctor of Philosophy \\ in \\ Economics
}

\author{
Feng Yao, Ph.D., Chair \\ Joshua Hall, Ph.D. \\ Arabinda Basistha, Ph.D. \\ Xiaoli Etienne, Ph.D. \\ Department of Economics
}

Morgantown, West Virginia

2019

Keywords: Semiparametric Panel Data Model; Stochastic Production Frontier; Technical Efficiency; Environmental Policy

Copyright 2019 Qinling Lu 


\section{ABSTRACT \\ Three Essays on Applied Semiparametric Methods \\ Qinling Lu}

The first chapter studies a varying coefficient panel data model with different smoothing variables and fixed effects using a two-step estimation approach. The first-step pilot estimator is constructed by approximating the varying coefficients with B-spline functions. The pilot estimator is then used to perform a one-step backfitting to obtain the second-step efficient estimator with kernel local linear estimation. The second-step estimator is efficient in the sense of being equivalent to a procedure knowing the other components of the varying coefficient. The asymptotic properties of both the pilot and efficient estimators are obtained. A Monte Carlo simulation indicates that the proposed estimator performs well with finite sample size.

The second chapter investigates the production efficiency of the U.S. coal-burning power plants that are covered under the Acid Rain Program from 2001 to 2005. To account for the influence of the Acid Rain Program on technical efficiency and the impact of environment variables on the marginal product of inputs, I introduce a panel data stochastic production frontier model with fixed effects and varying coefficients. The varying coefficients capture the relationship between power plant characteristics and the marginal return on inputs. Besides, the proposed model allows the inefficiency to depend on the environment variables, such as environmental policies. This set up enables the identification of the existence and magnitude of inefficiency. The proposed model relaxes the functional form assumption on coefficient functions and distribution assumption on the error terms. The empirical results reveal that the Acid Rain Program improves production efficiency for some power plants based on their operation and maintenance costs on sulfur removal equipment per unit of generating capacity. In addition, the marginal return on capital is affected by the years of operation of a power plant.

The third chapter studies the performance of water utilities in China. Water shortage is of great concern in China. Improving water delivery efficiency is the direct and efficient method to alleviate the water crisis. This paper performs an efficiency analysis of 56 water utilities during the period from 2009 to 2013. A semiparametric stochastic production frontier model with smooth coefficient is introduced to evaluate the magnitude of technical inefficiency and to examine the impact of institutional and operational conditions, such as customer density, non-household user rate, non-revenue water ratio, average water pressure in pipes, and the percentage of internal staff among all the employees. The discussion focuses on the impact of the internal staff ratio since the benefits of being an internal staff drive their incentives to work. The empirical results reveal that a water utility with higher internal staff ratio has a lower marginal return on the technical staff. The finding supports that the internal staff ratio changes the technical efficiency and a large internal staff ratio reduces technical inefficiency at a decreasing rate. 


\section{Acknowledgments}

First and foremost, I would like to express my sincere gratitude to my advisor, Dr. Feng Yao, for his generous help and support. It was his extensive knowledge of econometrics and enthusiasm for research that inspired me in my research. I appreciate all his generous help and guidance along the way.

I would also like to thank the faculty at the West Virginia University for their courses that influenced my research substantially. I would particularly like to acknowledge the members of my dissertation

committee, Dr. Joshua Hall, Dr. Arabinda Basistha, and Dr. Xiaoli Etienne, for their support and valuable feedbacks.

Lastly, I would like to thank my family. I am deeply thankful to my parents for their love and encouragement in all my pursuit. I also appreciate the support of my loving and patient husband along the way. 


\section{Contents}

1 Efficient estimation in varying coefficient panel data model with different smoothing variables and fixed effects

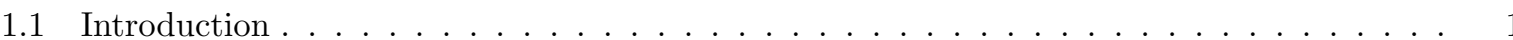

1.2 Estimation of the varying coefficient panel data model with fixed effects and different

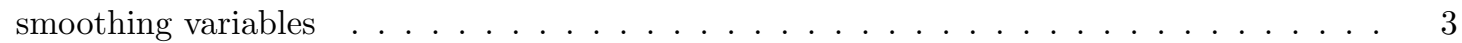

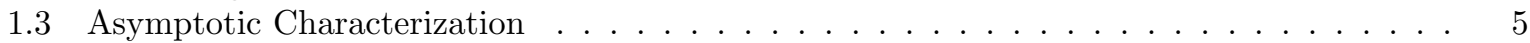

1.4 Monte Carlo Simulation . . . . . . . . . . . . . . . . . . . . . . . . 7

1.4.1 Estimation Procedure . . . . . . . . . . . . . . . . . . . . . 7

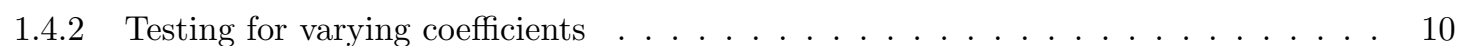

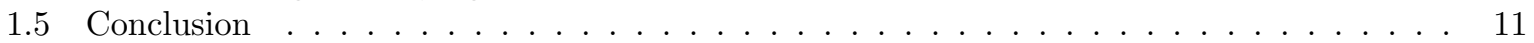

2 Does Emissions Trading Affect Power Plant Productivity? A Semiparametric Anal$\begin{array}{ll}\text { ysis on the Stochastic Production Frontier } & 17\end{array}$

2.1 Introduction . . . . . . . . . . . . . . . . . . . . . . . . . 17

2.2 Background and Literature Review . . . . . . . . . . . . . . . . . . . 20

2.2.1 Coal-fired Power plants and the Acid Rain Program . . . . . . . . . . . . . . 20

2.2.2 The Stochastic Production Frontier . . . . . . . . . . . . . . . . . . . . . . . . 21

2.3 Methodology and Model Specification . . . . . . . . . . . . . . . . . . . . 22

2.4 The U.S. Coal-fired Power Plants Production Efficiency Analysis . . . . . . . . . . . . . 24

2.4.1 Empirical Model . . . . . . . . . . . . . . . . . . . . . . . . . . . . . 24

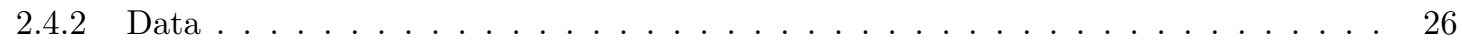

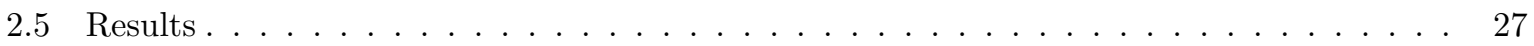

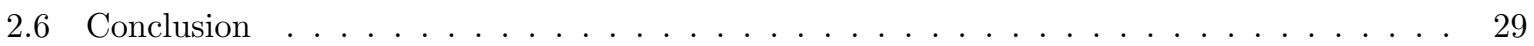

3 Production Efficiency of Chinese Urban Water Utilities 39

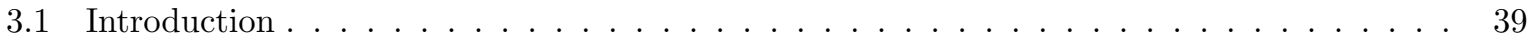

3.2 Background and Literature Review . . . . . . . . . . . . . . . . . . . . 41

3.3 Model . . . . . . . . . . . . . . . . . . . . . . . . . . . . . 44

3.3.1 The Semiparametric Smooth Coefficient Stochastic Frontier Model . . . . . . . . . 44

$3.3 .2 \quad$ Data . . . . . . . . . . . . . . . . . . . . . . . . . 47

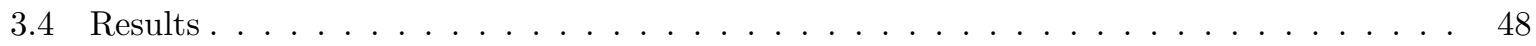

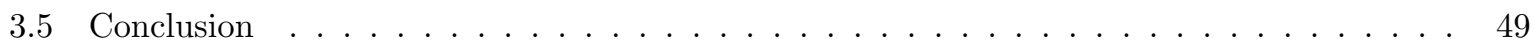

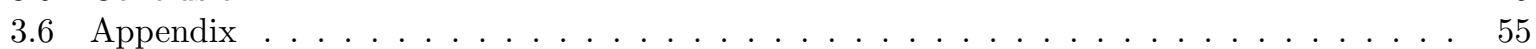




\section{List of Figures}

1.1 Plots of smooth coefficient functions against environment variables, where $\beta_{1}\left(z_{1, i t}\right)=(2$. $\left.z_{1, i t}\right)^{3}, \beta_{2}\left(z_{2, i t}\right)=1+e^{2 \cdot z_{2, i t}-1}, \beta_{3}\left(z_{3, i t}\right)=0.5 \cdot e^{-2 \cdot z_{3, i t}}, \beta_{4}\left(z_{4, i t}\right)=\ln \left(5 \cdot z_{4, i t}\right), \beta_{5}\left(z_{5, i t}\right)=$ $1+z_{5, i t}+z_{5, i t}^{2}$, and $\beta_{6}\left(z_{6, i t}\right)=\sin \left(\pi \cdot z_{6, i t}\right) \ldots \ldots \ldots \ldots \ldots$

2.1 Plots of estimated $\beta_{L}\left(\right.$ Number $\left._{i t}\right), \beta_{K}\left(\operatorname{Age}_{i t}\right), \beta_{F}\left(\right.$ Number $\left._{i t}\right)$, and $-g\left(W_{i t}\right)$ against envi-

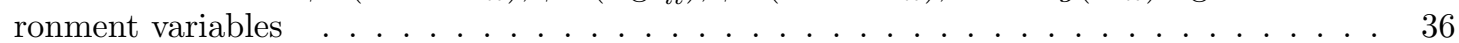

2.2 Plot of technical efficiency score $\mathrm{TE}_{i t}$ against $W_{i t} \ldots \ldots \ldots \ldots \ldots \ldots$. . . . . . . . . 37

2.3 Plot of technical efficiency $\mathrm{TE}_{i t}$ against $W_{i t} / K_{i t} \ldots \ldots \ldots \ldots \ldots$. . . . . . . . . 38

3.1 Plots of $\alpha\left(\operatorname{Staff}_{i t}\right), \beta_{L T}\left(\operatorname{Staff}_{i t}\right), \beta_{L N T}\left(\operatorname{Staff}_{i t}\right), \beta_{K}\left(\operatorname{Staff}_{i t}\right)$, and $\beta_{E}\left(\operatorname{Staff}_{i t}\right)$ against $\operatorname{Staff}_{i t} \quad 53$

3.2 Plots of direct effect, efficiency changes, and overall effects against $\mathrm{Staff}_{i t} \ldots$. . . . . . . . 54

3.3 Plots of $\alpha\left(\operatorname{Cusden}_{i t}\right), \beta_{L T}\left(\operatorname{Cusden}_{i t}\right), \beta_{L N T}\left(\operatorname{Cusden}_{i t}\right), \beta_{K}\left(\operatorname{Cusden}_{i t}\right)$, and $\beta_{E}\left(\operatorname{Cusden}_{i t}\right)$ against $\mathrm{Cusden}_{i t} \ldots \ldots \ldots \ldots \ldots \ldots \ldots \ldots \ldots$

3.4 Plots of direct effect, efficiency changes, and overall effects against Cusden $_{i t} \ldots \ldots$. . . . . 59

3.5 Plots of $\alpha\left(\right.$ Nonrevr $\left._{i t}\right), \beta_{L T}\left(\right.$ Nonrevr $\left._{i t}\right), \beta_{L N T}\left(\right.$ Nonrevr $\left._{i t}\right), \beta_{K}\left(\right.$ Nonrevr $\left._{i t}\right)$, and $\beta_{E}\left(\operatorname{Nonrevr}_{i t}\right)$ against Nonrevr $_{i t} \ldots \ldots \ldots \ldots \ldots \ldots$. . . . . . . . . . . . . . . . 60

3.6 Plots of direct effect, efficiency changes, and overall effects against Nonrevr $r_{i t} \quad \ldots \ldots$. . . . 61

3.7 Plots of $\alpha\left(\right.$ Nonhhdr $\left._{i t}\right), \beta_{L T}\left(\right.$ Nonhhdr $\left._{i t}\right), \beta_{L N T}\left(\operatorname{Nonhhdr}_{i t}\right), \beta_{K}\left(\operatorname{Nonhhdr}_{i t}\right)$, and $\beta_{E}\left(\operatorname{Nonhhdr}_{i t}\right)$ against $\mathrm{Nonhhdr}_{i t}$. . . . . . . . . . . . . . . . . . . . . . . . 62

3.8 Plots of direct effect, efficiency changes, and overall effects against Nonhhdr $\mathrm{N}_{i t} \ldots \ldots$. . . . 63

3.9 Plots of $\alpha\left(\right.$ Pressure $\left._{i t}\right), \beta_{L T}\left(\right.$ Pressure $\left._{i t}\right), \beta_{L N T}\left(\right.$ Pressure $\left._{i t}\right), \beta_{K}\left(\right.$ Pressure $\left._{i t}\right)$, and $\beta_{E}\left(\right.$ Pressure $\left._{i t}\right)$

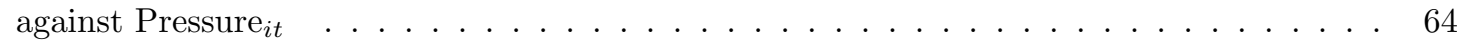

3.10 Plots of direct effect, efficiency changes, and overall effects against Pressure Pt $_{i t}$. . . . . . 65 


\section{List of Tables}

1.1 The average mean squared error (AMSE), average bias (ABIAS), and average standard deviation (ASTD) of the two-step estimator with bandwidth $h_{j}=c_{j} z_{j, s d}(n * t)^{-1 /\left(4+p_{j}\right)}$ and $c_{j}=1.5$.

1.2 The average mean squared error (AMSE), average bias (ABIAS), and average standard deviation (ASTD) of the two-step estimator with bandwidth $h_{j}=c_{j} z_{j, s d}(n * t)^{-1 /\left(4+p_{j}\right)}$ and $c_{j}=1.7 \ldots \ldots \ldots \ldots \ldots \ldots \ldots \ldots \ldots \ldots$

1.3 The average mean squared error (AMSE), average bias (ABIAS), and average standard deviation (ASTD) of the two-step estimator with bandwidth $h_{j}=c_{j} z_{j, s d}(n * t)^{-1 /\left(4+p_{j}\right)}$ and $c_{j}=2 \ldots \ldots \ldots \ldots \ldots \ldots \ldots \ldots \ldots \ldots \ldots \ldots$

1.4 Empirical rejection frequency of $V_{n t} \ldots \ldots \ldots \ldots \ldots \ldots \ldots$

2.1 The AMSE of two-step estimator in the stochastic production frontier . . . . . . . . . . 31

2.2 Estimation results of the two-step estimator in the stochastic production frontier . . . . . 32

2.3 Summary statistics . . . . . . . . . . . . . . . . . . . . . . . . 33

2.4 Estimation of the semiparametric model with varying coefficient . . . . . . . . . . . . . 34

2.5 Estimation of the parametric model with linear coefficient functions . . . . . . . . . . 35

3.1 Summary Statistics . . . . . . . . . . . . . . . . . . . . . . 51

3.2 Estimation of the Semiparametric Smooth Coefficient Stochastic Frontier with Staff $i t \quad$. . 52

3.3 Estimation of the Semiparametric Smooth Coefficient Stochastic Frontier with Environment Variables . . . . . . . . . . . . . . . . . . . . . . . 57 


\section{Chapter 1}

\section{Efficient estimation in varying coefficient panel data model with different smoothing variables and fixed effects}

\subsection{Introduction}

The availability of panel data allows researchers to track individual information over time, thus estimation and inference may be conducted on models with more complexity than those in purely time-series or crosssection data (see Arellano (2003), Baltagi (2013) and Hsiao (2014) for excellent review of parametric panel data analysis). As parametric panel data models may be misspecified, their analysis may give misleading inferences. To address this issue, nonparametric and semiparametric methods have been introduced in the panel data analysis, and recent studies include those on random effects (Li and Stengos (1996), Ullah and Roy (1998), Ruckstuhl et al. (2000), Wang (2003), Henderson and Ullah (2005), Lin and Carroll (2006), Martins-Filho and Yao (2009)), and fixed effects (Su and Ullah (2006), Henderson et al. (2008)). Since estimation of random effect model is appropriate only when the individual effects are not correlated with regressors, we focus on the fixed effects models.

A purely nonparametric function with multivariate regression cannot be estimated with reasonable accuracy due to the so-called "curse of dimensionality." A useful structural regression, the varying coefficient model, including the purely nonparametric, additive and partially linear regression models as special cases, allows the regression coefficients to depend on smoothing variables. It inherits simplicity and easy interpretation of traditional linear models yet is intrinsically nonparametric. Sun et al. (2009) propose an interesting estimator for the varying coefficient panel data model with fixed effects by removing the fixed effects with a kernel-based weight. 
The traditional varying coefficient model restricts the coefficient function of each regressor, though there could be many, to depend on the same smoothing variables. An important extension is to allow the coefficient functions to depend on different smoothing variables, so the partial impact of the regressors can be driven by different variables. For example, this arises naturally in a production frontier estimation. In terms of modelling for real dataset, this is more flexible than the traditional varying coefficient model (Park et al. (2015), section 3). However, the estimation methods for traditional varying coefficient model and varying coefficient model with different smoothing variables are totally different. A pointwise kernel weighted local polynomial fit gives direct estimators of the coefficient functions in the traditional case, but for the different smoothing variable case, the procedure gives multivariate functions of the whole smoothing vectors, losing the structure of different smoothing variables. Two approaches have been proposed to estimate the coefficient function with different smoothing variables. First approach applies marginal integration technique of Linton and Nielsen (1995) to recover each individual coefficient function, including Yang et al. (2006), Zhang and Li (2007), Feng et al. (2012), and Xue and Yang (2006). The other approach is based on the smooth backfitting introduced by Mammen et al. (1999), including Lee et al. (2012b), Lee et al. (2012a), and Roca-Pardinas and Sperlich (2010). To our knowledge, we are not aware of any estimation of the varying coefficient panel data model with different smoothing variables and fixed effects.

We propose a two-step estimator for the varying coefficients. In the first step, we model the fixed effects as in Su and Ullah (2006) and Sun et al. (2009), but construct a pilot estimator by approximating the varying coefficients with series based estimator. The pilot step consistently estimates the varying coefficients and it is computationally straightforward to implement. Inspired by Linton (1997), in the second step we use the pilot estimates to perform a one-step kernel-based backfitting. We obtain the asymptotic distributions of the proposed estimators, and we are glad to show that the second-step estimator has the oracle property, in the sense that each varying coefficient can be estimated with the same asymptotic accuracy as if all the other varying coefficients in the regression model were known.

The rest of this paper is organized as follows. Section 2 introduces the proposed model and estimator. The asymptotic properties of proposed estimators are included in Section 3. Monte Carlo simulation of the model is in Section 4. Section 5 concludes the paper. 


\subsection{Estimation of the varying coefficient panel data model with fixed effects and different smoothing variables}

Let's consider the following varying coefficient panel data model with fixed effects and different smoothing variables,

$$
Y_{i t}=\alpha_{i}+X_{1 i t}^{\prime} \beta_{1}\left(Z_{1 i t}\right)+\cdots+X_{d i t}^{\prime} \beta_{d}\left(Z_{d i t}\right)+\epsilon_{i t}, \quad i=1, \cdots, n, t=1, \cdots, T .
$$

Here, for $j=1, \cdots, d, X_{j i t} \in \Re^{r_{j}}, Z_{j i t} \in \Re$. We allow $Z_{j i t}$ in $\beta_{j}(\cdot)$ to change with $j$; thus, the smoothing variables are different. We denote the $l-t h$ element in $X_{j i t}$ by $X_{j i t, l}$. Correspondingly, $\beta_{j}\left(Z_{j i t}\right)=$ $\left(\beta_{j 1}\left(Z_{j i t}\right), \cdots, \beta_{j r_{j}}\left(Z_{j i t}\right)\right)$, where $\beta_{j l}(\cdot): \Re \rightarrow \Re$. We denote $r=\sum_{j=1}^{d} r_{j}$. With $E\left(\epsilon_{i t} \mid X_{i t}, Z_{i t}, \alpha_{i}\right)=0$, we assume that $E\left(\alpha_{i} \mid X_{i t}, Z_{i t}\right)=\alpha_{i}$, which introduces statistical dependence between the heterogeneity term, or the fixed effects $\alpha_{i}$ and the explanatory variables. In practice, we envision that the dimension of $X_{j i t}$ can be large, and that of $Z_{j i t}$ should be relatively small so that the curse-of-dimensionality issue will not be of severe concern. Here, we simply consider $Z_{j i t}$ to be univariate.

Without the fixed effects and without the panel data, the structure displayed in equation (1) is the same as model (I) of Yang et al. (2006). Different from Sun et al. (2009), we allow for different smoothing variables $Z_{j i t}$ for different coefficient $\beta_{j}(\cdot)$, thus the marginal impact of $X_{j i t}$ can be driven by different variables. One strategy would be performing a backfitting or a smooth backfitting, extending the method in Henderson et al. (2008) to the varying coefficient set-up, though its asymptotic property can be difficult to study. As mentioned in the introduction, estimation of $\beta_{j}(\cdot)$ directly as in Sun (2009) can be misleading, as the procedure delivers multivariate functions of the whole smoothing vector $Z_{i t}$, losing the structure of different smoothing variables. Another strategy will be performing a multivariate smoothing first on all $\beta_{j}(\cdot)$ 's, then utilize the marginal integration idea as in Linton and Nielsen (1995) and Yang et al. (2006) to obtain estimates for each $\beta_{j}(\cdot)$. We do not pursue this idea here, as the marginal integration estimator may not maintain the oracle property and the associated multivariate smoothing can be very demanding when $d$ is large.

In estimating additive models, Horowitz and Mammen (2004) pioneered a two-step estimation procedure. They perform a series estimation of the nonparametric additive components, followed by a kernel based backfitting step, and the resulted estimators are oracle efficient and free of the curse of dimensionality. This two-step estimation is attractive due to the simplicity in the estimation which reduces the computation burden, besides it has attractive asymptotic properties. This idea appears also in Wang and Yang (2007) in additive autoregression model, and is adapted in several papers that deal with endogeneity with a control function approach (Ozabaci et al. (2014), Delgado et al. (2018)). 
Inspired by this idea, we propose a two-step estimation. The first step is a series-based pilot estimator for each $\beta_{j}(\cdot)$. Let $\left\{\phi_{l}(\cdot), l=1,2, \cdots\right\}$ be a sequence of basis functions (B-slpine series) and $L_{n}$ be some integer such that $L_{n} \rightarrow \infty$ as $n \rightarrow \infty$. With $\Phi_{L n}(v)=\left[\phi_{1}(v), \cdots, \phi_{L_{n}}(v)\right]^{\prime}$, we approximate $\beta_{j l}\left(z_{j}\right)$ with $\Phi_{L n}(v)^{\prime} \lambda_{j l}$, where $\lambda_{j l}$ is a $L_{n} \times 1$ vector for each $l=1, \cdots, r_{j}$, and $j=1, \cdots, d$. Then for $\lambda_{j}=$ $\left(\lambda_{j 1}^{\prime}, \cdots, \lambda_{j r_{j}}^{\prime}\right)^{\prime}$, an $\left(L_{n} * r_{j}\right) \times 1$ vector, we approximate $X_{j i t^{\prime}} \beta_{j}\left(Z_{j i t}\right)$ with $\left[X_{j i t} \otimes \Phi_{L_{n}}\left(Z_{j i t}\right)\right]^{\prime} \lambda_{j} \equiv \chi_{j i t}^{\prime} \lambda_{j}$, where $\chi_{j i t}$ is also an $\left(L_{n} * r_{j}\right) \times 1$ vector. Thus,

$$
Y_{i t} \approx \alpha_{i}+\sum_{j=1}^{d} \chi_{j i t}^{\prime} \lambda_{j}+\epsilon_{i t}=\alpha_{i}+\chi_{i t}^{\prime} \lambda+\epsilon_{i t}
$$

where $\chi_{i t}=\left[\chi_{1 i t}, \cdots, \chi_{d i t}^{\prime}\right]^{\prime}, \lambda=\left[\lambda_{1}^{\prime}, \cdots, \lambda_{d}^{\prime}\right]^{\prime}$, each is an $L_{n} * r \times 1$ vector.

Following Sun et al. (2009), we impose the assumption that $\sum_{i=1}^{n} \alpha_{i}=0$ for the fixed effects, which implies that $\alpha_{1}=-\sum_{i=2}^{n} \alpha_{i}$. We let $\alpha_{0}=\left(-\sum_{i=2}^{n} \alpha_{i}, \alpha_{2}, \cdots, \alpha_{n}\right)^{\prime}, \alpha_{-1}=\left(\alpha_{2}, \cdots, \alpha_{n}\right)^{\prime}$. $I_{n}$ is a $n \times n$ identity matrix, $e_{T}$ is a $T \times 1$ column vector of ones, and $D_{M}=\left[-e_{n-1}, I_{n-1}\right]^{\prime} \otimes e_{T}$. We express the assumption on the fixed effects through $D_{M} \alpha_{-1}=\alpha_{0} \otimes e_{t}$. For notation purpose, we let $Y_{i}^{\prime}=$ $\left(Y_{i 1}, \cdots, Y_{i T}^{\prime}\right)^{\prime}, Y=\left(Y_{1}^{\prime}, \cdots, Y_{n}^{\prime}\right)^{\prime}$, and $\chi=\left\{\left\{\chi_{i t}^{\prime}\right\}_{t=1}^{T}\right\}_{i=1}^{n}$. We estimate

$$
\left(\hat{\alpha}_{-1}, \hat{\lambda}\right)=\operatorname{argmin}_{\alpha_{-1}, \lambda}\left[Y-D_{M} \alpha_{-1}-\chi \lambda\right]^{\prime}\left[Y-D_{M} \alpha_{-1}-\chi \lambda\right]
$$

It is easy to see that for $M_{D}=I_{n T}-D_{M}\left(D_{M}^{\prime} D_{M}\right)^{-1} D_{M}^{\prime}, \hat{\lambda}=\left(\chi^{\prime} M_{D} \chi\right)^{-1} \chi^{\prime} M_{D}$. We like to comment that the first step is very easy to carry through computations. Thus, we estimate $\beta_{j l}\left(z_{j}\right)$ and $\beta_{j}\left(z_{j}\right)$ with

$$
\hat{\beta}_{j l}\left(z_{j}\right)=\Phi_{L_{n}}\left(z_{j}\right)^{\prime} \hat{\lambda}_{j l}, \hat{\beta}_{j}\left(z_{j}\right)=\left[I_{r_{j}} \otimes \Phi_{L_{n}}\left(z_{j}\right)\right]^{\prime} \hat{\lambda}_{j} .
$$

Second, we propose our one-step back-fitting estimation inspired by Linton (1997), based on the pilot estimation defined in (1.2). We utilize $h$ as the bandwidth in the one-step backfitting estimation. Let's define $\left(X^{\prime} \hat{\beta}\right)_{(-j)}=\left\{\left\{X_{(-j) i t}^{\prime} \hat{\beta}_{(-j)}\left(Z_{(-j) i t}\right)\right\}_{t=1}^{T}\right\}_{i=1}^{n}$, where

$$
X_{(-j) i t}^{\prime} \hat{\beta}_{(-j)}\left(Z_{(-j) i t}\right)=\sum_{q=1, q \neq j}^{d} X_{q i t}^{\prime} \hat{\beta}_{q}\left(Z_{q i t}\right)=\sum_{q=1, q \neq j}^{d} \sum_{l=1}^{r_{q}} X_{q i t, l}^{\prime} \hat{\beta}_{q l}\left(Z_{q i t}\right) .
$$

We approximate $\beta_{j l}\left(Z_{j i t}\right) \approx \beta_{j l}\left(z_{j 0}\right)+\left(Z_{j i t}-z_{j 0}\right) \beta_{j l}^{(1)}\left(z_{j 0}\right)$. We define $b_{j l}\left(z_{j 0}\right)=\left(\beta_{j l}\left(z_{j 0}\right), \beta_{j l}^{(1)}\left(z_{j 0}\right)\right)$ to be a $2 \times 1$ vector, $b_{j}\left(z_{j 0}\right)=\left(b_{j 1}\left(z_{j 0}\right), \cdots, b_{j r_{j}}\left(z_{j 0}\right)\right)^{\prime}$ to be a $r_{j} \times 2$ matrix, and $R_{j i t}=\left(1,\left(Z_{j i t}-z_{j 0}\right)\right)^{\prime}$. Then with $X_{(-j) i t}^{\prime} \beta_{(-j)}\left(Z_{(-j) i t}\right)$ defined similarly with a true $\beta_{q l}(\cdot)$,

$$
\begin{aligned}
Y_{i t}-X_{(-j) i t}^{\prime} \beta_{(-j)}\left(Z_{(-j) i t}\right)=\alpha_{i}+X_{j i t}^{\prime} \beta_{j}\left(Z_{j i t}\right)+\epsilon_{i t} \approx & \alpha_{i}+X_{j i t}^{\prime} b_{j}\left(z_{j 0}\right) R_{j i t}+\epsilon_{i t} \\
& =\alpha_{i}+\left(R_{j i t}^{\prime} \otimes X_{j i t}^{\prime}\right) \operatorname{vec}\left(b_{j}\left(z_{j 0}\right)\right)+\epsilon_{i t} .
\end{aligned}
$$


Here $\operatorname{vec}\left(b_{j}\left(z_{j 0}\right)\right.$ denotes a vector created by stacking columns of $b_{j}\left(z_{j 0}\right)$ on tops of one another. Note that the first $r_{j}$ elements in $\operatorname{vec}\left(b_{j}\left(z_{j 0}\right)\right)$ is $\beta_{j}\left(z_{j 0}\right)$. Let $R_{j i}\left(z_{j 0}\right)=\left[\left(R_{j i 1}^{\prime} \otimes X_{j i 1}^{\prime}\right)^{\prime}, \cdots,\left(R_{j i T}^{\prime} \otimes X_{j i T}^{\prime}\right)^{\prime}\right]^{\prime}$ be a $T \times\left(2 r_{j}\right)$ matrix, $R_{j}\left(z_{j 0}\right)=\left[R_{j 1}\left(z_{j 0}\right)^{\prime}, \cdots, R_{j n}\left(z_{j 0}\right)^{\prime}\right]^{\prime}$ be a $n T \times\left(2 r_{j}\right)$ matrix. We define

$$
M_{h}\left(z_{j 0}\right)=I_{n T}-D_{M}\left(D_{M}^{\prime} W_{h}\left(z_{j 0}\right) D_{M}\right)^{-1} D_{M}^{\prime} W_{h}\left(z_{j 0}\right), S_{h}\left(z_{j 0}\right)=M_{h}\left(z_{j 0}\right)^{\prime} W_{h}\left(z_{j 0}\right) M_{h}\left(z_{j 0}\right),
$$

where $W_{h}\left(z_{j 0}\right)=\operatorname{diag}\left\{\left\{K\left(\frac{Z_{j i t}-z_{j 0}}{h}\right)\right\}_{t=1}^{T}\right\}_{i=1}^{n}$ is a $n T \times n T$ matrix, $\left.K_{j}\left(\frac{Z_{j i}-z_{j 0}}{h_{1}}\right)\right)=\operatorname{diag}\left\{K_{j}\left(\frac{Z_{j i 1}-z_{j 0}}{h_{1}}\right)\right.$, where $K(\cdot)$ is a univariate kernel function. We define the backfitting estimator as

$$
\begin{array}{r}
\left(\operatorname{vec}\left(\check{b}_{j}\left(z_{j 0}\right)\right), \check{\alpha}_{-1}\right)=\underset{\operatorname{vec}\left(b_{j}\left(z_{j 0}\right)\right), \alpha_{-1}}{\operatorname{argmax}}\left[Y-\left(X^{\prime} \hat{\beta}\right)_{(-j)}-R_{j}\left(z_{j 0}\right) \operatorname{vec}\left(b_{j}\left(z_{j 0}\right)\right)-D_{M} \alpha_{-1}\right]^{\prime} W_{h}\left(z_{j 0}\right) \\
\times\left[Y-\left(X^{\prime} \hat{\beta}\right)_{(-j)}-R_{j}\left(z_{j 0}\right) \operatorname{vec}\left(b_{j}\left(z_{j 0}\right)\right)-D_{M} \alpha_{-1}\right] .
\end{array}
$$

We obtain

$$
\begin{gathered}
\check{\alpha}_{-1}=\left[D_{M}^{\prime} W_{h}\left(z_{j 0}\right) D_{M}\right]^{-1} D_{M}^{\prime} W_{h}\left(z_{j 0}\right)\left[Y-\left(X^{\prime} \hat{\beta}\right)_{(-j)}-R_{j}\left(z_{j 0}\right) \operatorname{vec}\left(b_{j}\left(z_{j 0}\right)\right)\right], \\
\operatorname{vec}\left(\check{b}_{j}\left(z_{j 0}\right)\right)=\left[R_{j}^{\prime}\left(z_{j 0}\right) S_{h}\left(z_{j 0}\right) R_{j}\left(z_{j 0}\right)\right]^{-1} R_{j}^{\prime}\left(z_{j 0}\right) S_{h}\left(z_{j 0}\right)\left[Y-\left(X^{\prime} \hat{\beta}\right)_{(-j)}\right] .
\end{gathered}
$$

Specifically, for $e_{l, 2 r_{j}}$ a $2 r_{j} \times 1$ vector of zeros, except that the $l-t h$ position is one,

$$
\check{\beta}_{j l}\left(z_{j 0}\right)=e_{l, 2 r_{j}}^{\prime}\left[R_{j}^{\prime}\left(z_{j 0}\right) S_{h}\left(z_{j 0}\right) R_{j}\left(z_{j 0}\right)\right]^{-1} R_{j}^{\prime}\left(z_{j 0}\right) S_{h}\left(z_{j 0}\right)\left[Y-\left(X^{\prime} \hat{\beta}\right)_{(-j)}\right] .
$$

In our first step, there is no need to impose the restriction that $\sum_{i=1}^{n} \alpha_{i}=0$, since $\chi_{j i t}=\left[X_{j i t} \otimes\right.$ $\left.\Phi_{L n}\left(Z_{j i t}\right)\right]$ are not time invariant. However, in the case that $X_{j i t}$ contains a constant, we need to impose the restriction to make the second step feasible since we perform a local linear expansion on the varying coefficient (see pp. 169 of Lin et al. (2014) for a similar comment). Thus, we impose the restriction in both steps and we comment later that imposing this restriction changes the asymptotic result of $\hat{\beta}_{j l}(\cdot)$.

\subsection{Asymptotic Characterization}

The Asymptotic properties of our proposed two-step estimator $\hat{\beta}(z)$ and $\check{\beta}(z)$ are derived in this section with the following assumptions. We use $C$ to represent a generic constant throughout this paper, which can have different value in different places.

\section{Assumption 1.}


(1) $\left\{X_{1 i t}, \cdots, X_{d i t}\right\},\left\{Z_{1, i t}, \cdots, Z_{d i t}\right\}$, and $\epsilon_{i t}$ are identically and independently distributed (IID) across i.

(2) Denote marginal density of $Z_{j i t}$ as $f_{z_{j i t}}\left(z_{j i t}\right) \in C^{2}$ and $\inf _{Z_{j i t} \in G_{j}} f_{z_{j i t}}\left(z_{j i t}\right)>0$ for $G_{j}$ as a compact subset of $\Re^{1}$.

(3) The conditional density of $Z_{j i t}$ given $X_{j i t}$ is $f_{Z_{j i t} \mid X_{j i t}}\left(Z_{j i t} \mid X_{j i t}\right)<C$, and it is also continuous at $Z_{j i t}$.

(4) The joint density of $\left(Z_{j i t}, Z_{j i \tau}\right)$ conditioning on $\left(X_{j i t}, X_{j i \tau}\right)$ is $f_{Z_{j i t}, Z_{j i \tau} \mid X_{j i t}, X_{j i \tau}}\left(Z_{j i t}, Z_{j i \tau}\right)<C$.

(5) $\Sigma_{j_{0}}\left(Z_{j 0}\right)=\frac{1}{d} \sum_{t=1}^{T} E K_{j i t}\left(1-\frac{K_{j i t}}{K_{i}}\right)\left(\widetilde{R}_{j i t} \widetilde{R}_{j i t}^{T} \otimes X_{j i t} X_{j i t}^{T}\right)$ is a nonsingular matrix with $\lambda_{\text {min }}\left(\Sigma_{j 0}\left(Z_{j 0}\right)\right)>$ $C>0$.

\section{Assumption 2.}

$K(\psi): \Re_{d} \rightarrow \Re$ is a product kernel. $K(\psi)=\prod_{j=1}^{d} k\left(\psi_{j}\right)$, with symmetric $k(\psi): \Re \rightarrow \Re$ such that,

(1) $\left|k(z) z^{i}\right| \leq C$ for all $z \in \Re$ and $j=0,1,2,3$.

(2) $\int\left|z^{j} k(z)\right| d z \leq C$ for $j=0,1,2,3$.

(3) $\int k(z) d z=1, \int z k(z) d z=0, \int z^{2} k(z) d z=\mu_{k, 2}<\infty$.

(4) $k(z)$ is continuously differentiable on $\Re$ with $\left|z^{j} \frac{d}{d z} k(z)\right| \leq C \forall z \in \Re$ and $j=0,1,2,3$.

(5) (i) $\left|k(z) z^{j}\right| \rightarrow 0$ as $z \rightarrow 0 \forall j=0,1,2,3$. (ii) specifically, $\|z\|>c_{k}$ for some $c_{k}>0$, then $k(z) z^{j}=o\left(h^{d}\right)$.

(6) $\left|\frac{1}{\sqrt{k(z)}} \frac{d}{d z} k(z) z^{j}\right| \leq C j=0,1,2,3$.

(7) $\forall i, T, K_{i} .=\sum_{t=1}^{T} K_{i t}>c_{0}>0$.

\section{Assumption 3.}

(1) Let $\nu_{l l^{\prime}, j t}\left(Z_{j i t}\right)=E\left(X_{j i t, l}, X_{j i t, l^{\prime}} \mid Z_{j i t}\right)$ be in $C^{2}, \forall t, j$ and $l, l^{\prime}=1, \cdots, r_{j} . E\left(X_{j i t, l} X_{j i t, l^{\prime}} \mid Z_{j i t}, Z_{j i s}\right)$ is continuous at $Z_{j i t}, Z_{j i s}$, for $t \neq s$.

(2) $E\left(\left|X_{j i t, l} X_{j i t, l^{\prime}}\right|^{s} \mid Z_{j i t}\right)<C$ for some $s>2, \forall t$ and $\forall l, l \in 1, \cdots, r_{j}$.

\section{Assumption 4.}

(1) $n h^{3} \rightarrow \infty, h \rightarrow 0$ as $n \rightarrow \infty$.

(2) Let $L n$ be some integers such that $L n \rightarrow \infty$ as $n \rightarrow \infty$.

\section{Assumption 5.}

(1) $\beta_{j l}\left(Z_{j 0}\right) \in C^{2}$.

(2) $\epsilon_{i t}$ is i.i.d. with $E\left(\epsilon_{i t}\right)=0, v\left(\epsilon_{i t}\right)=\sigma_{\epsilon}^{2}$ and independent of $X_{i t}, Z_{i t} . E\left[\epsilon_{i t}\right]^{2+\delta}<C$.

(3) $\alpha_{i}$ is i.i.d. with zero mean and finite variance, $\alpha_{i}$ can be correlated with $X_{i t}, Z_{i t}$. 
Assumption 1 requires observation $X_{i t}, Z_{i t}$, and $\epsilon_{i t}$ to be i.i.d. across i. The marginal density and conditional density of $z$ are bounded and smooth. Assumption 2 states the standard moments and smoothness of kernel function. Assumption 3 specifies that $E\left(X_{j i t, l} X_{j i t, l^{\prime}} \mid Z_{j i t}, Z_{j i s}\right)$ is continuous and bounded. Assumption 5 indicates that the coefficient function is twice differentiable.

Theorem 1. With Assumptions, we have

$$
\begin{aligned}
& \text { (i) }\|\hat{\lambda}-\lambda\|=O_{p}\left(\sqrt{\frac{L_{n}}{n}}+L_{n}^{-\xi}\right) . \\
& \text { (ii) } \sup _{z_{j} \in G_{j}}\left\|\hat{\beta}_{j}\left(z_{j}\right)-\beta_{j}\left(z_{j}\right)\right\|=O_{p}\left(\mathcal{S}_{0 L_{n}}\left(\sqrt{\frac{L_{n}}{n}}+L_{n}^{-\xi}\right)\right) \text {, for } j=1, \cdots, d \text {. }
\end{aligned}
$$

Next, we consider the infeasible estimator $\check{\beta}_{j l}\left(z_{j 0}\right)$ assuming the knowledge of true values of $\left(X^{\prime} \beta\right)_{-j}$. Using the notations before, we define

$$
\tilde{\beta}_{j l}\left(z_{j 0}\right)=e_{l, 2 r_{j}}^{\prime}\left[R_{j}^{\prime}\left(z_{j 0}\right) S_{h}\left(z_{j 0}\right) R_{j}\left(z_{j 0}\right)\right]^{-1} R_{j}^{\prime}\left(z_{j 0}\right) S_{h}\left(z_{j 0}\right)\left[Y-\left(X^{\prime} \beta\right)_{(-j)}\right]
$$

In Theorem 2 below, we first establish the asymptotic distribution of $\tilde{\beta}_{j}\left(z_{j 0}\right)=\left(\tilde{\beta}_{j 1}\left(z_{j 0}\right), \cdots, \tilde{\beta}_{j r_{j}}\left(z_{j 0}\right)\right)^{\prime}$, and then we show that the difference between $\tilde{\beta}_{j}\left(z_{j 0}\right)$ and $\check{\beta}_{j}\left(z_{j 0}\right)$ is negligible; thus, $\check{\beta}_{j}\left(z_{j 0}\right)$ inherits the asymptotic characterization of $\tilde{\beta}_{j}\left(z_{j 0}\right)$ and is oracle.

Theorem 2. With assumptions A1(1)-(5), A2(1)-(4), (7), A3(1), (2), A4(1), and A5(1)-(3), we have

(i) $\sqrt{n h}\left[\tilde{\beta}_{j}\left(z_{j 0}\right)-\beta_{j}\left(z_{j 0}\right)-\left(B_{n 0}\left(z_{j 0}\right)+o_{p}\left(h^{2}\right)\right)\right] \stackrel{d}{\rightarrow} N\left(0, e_{2 r_{j}}^{\prime} \Sigma_{j 0}^{-1}\left(z_{j 0}\right) \Sigma_{j}\left(z_{j 0}\right) \Sigma_{j 0}^{-1}\left(z_{j 0}\right) e_{2 r_{j}}\right)$, where $e_{2 r_{j}}=\left[e_{1,2 r_{j}}, \cdots, e_{r_{j}, 2 r_{j}}\right], B_{n 0}\left(z_{j 0}\right), \Sigma_{j 0}\left(z_{j 0}\right)$ and $\Sigma_{j}\left(z_{j 0}\right)$ are defined in the assumptions.

(ii) With assumptions, we have $\sqrt{n h}\left(\check{\beta}_{j}\left(z_{j 0}\right)-\tilde{\beta}_{j}\left(z_{j 0}\right)\right)=o_{p}(1)$.

\subsection{Monte Carlo Simulation}

\subsubsection{Estimation Procedure}

In this section, a Monte Carlo simulation is presented to examine the finite sample performance of the proposed estimator. The simulation is designed to evaluate two aspects of our estimators. Firstly, the consistency of estimator is investigated at different sample size for both the series-based estimator and the kernel-based estimator; secondly, we compare the estimation accuracy of the two-step estimators and evaluate whether the second-step estimator is oracle efficient. The data-generating process (DGP) is as follows:

$$
\text { DGP : } y_{i t}=\alpha_{i}+\sum_{j=1}^{d} x_{j, i t} \cdot \beta_{j}\left(z_{j, i t}\right)+\epsilon_{i t} \quad i=1, \ldots, n ; \quad t=1, \ldots, T
$$

Let $x_{j, i t}$ be i.i.d. and drawn from standard normal distribution $N(0,1)$ for each $j$, independently. The smoothing variable $z_{j, i t}$ is i.i.d. uniformly distributed with $\operatorname{Unif}(0,1)$ for each $j$. In this simulation, 
we let $d=6$ and all of the coefficient functions to be non-linear. The varying coefficient functions are specified as $\beta_{1}\left(z_{1, i t}\right)=\left(2 \cdot z_{1, i t}\right)^{3}, \beta_{2}\left(z_{2, i t}\right)=1+e^{2 \cdot z_{2, i t}-1}, \beta_{3}\left(z_{3, i t}\right)=0.5 \cdot e^{-2 \cdot z_{3, i t}}, \beta_{4}\left(z_{4, i t}\right)=\ln \left(5 \cdot z_{4, i t}\right)$, $\beta_{5}\left(z_{5, i t}\right)=1+z_{5, i t}+z_{5, i t}^{2}$, and $\beta_{6}\left(z_{6, i t}\right)=\sin \left(\pi \cdot z_{6, i t}\right)$. To give a better ideal of the shape of the coefficient functions, we report the plots of the smooth coefficients in Figure 1.1. Each panel in the figure exhibits nonlinearity which is ideal for the estimation of different smooth coefficients. The random error term $\epsilon_{i t}$ is assumed to be i.i.d. $N(0,1)$, which is consistent with the assumption $E\left(\epsilon_{i t} \mid X_{i t}, Z_{i t}, \alpha_{i}\right)=0$. To satisfy the condition $E\left(\alpha_{i} \mid X_{i t}, Z_{i t}\right)=\alpha_{i}$, we let $\alpha_{i}=\frac{1}{T} \sum_{t=1}^{T} z_{2, i t}$.

The coefficient estimation requires selection of smoothing parameters in both steps, which are knots in the first step and bandwidth in the second step. In the first step, we use the third-order B-splines which is based on the De Boor's algorithm. The number of total knots $L_{n}$ in series estimation requires that as $n * t \rightarrow \infty, L_{n} \rightarrow \infty$ and $\frac{L_{n}}{n * t} \rightarrow 0$ (Li and Racine (2007)). Followed Wang and Yang (2007), the number of evenly spaced interior $\operatorname{knots}$ is $N=\min \left(\left[c(n * t)^{2 / 5} \log (n * t)\right],\left[((n * t) / 2-1) d^{-1}\right]\right)$, where the bracket [ ] represents integer part of the number; $c=0.5$ is a tuning constant. To ensure the base functions of the third-order splines near the boundary are lined in the unit interval, three knots are added at both ends of the knots interval, which leads to the total number of knots $L n=N+6$. In the second-step local linear regression, the selection of bandwidth for kernel-based estimator follows the rule-of-thumb method. Also, we choose the Gaussian kernel in the second-step estimation. Define bandwidth $h=\left(h_{1}^{\prime}, \ldots, h_{d}^{\prime}\right)^{\prime}$ and $h_{j}=c_{j} z_{j, s d}(n * t)^{-1 /\left(4+p_{j}\right)}$, where $c_{j}$ is constant and chosen to be $1.5^{1} . ; z_{j, s d}$ represents sample standard deviation of $z_{j, i t}$ for each $j ; p_{j}=1$ for all $\mathrm{j}$ in this case. The bandwidth can also be selected from other data-driven methods, and we use the rule-of-thumb method for computation simplicity.

Three experiments are conducted to evaluate the performance of the proposed estimator. In each experiment, let $t=3$, and $n$ takes value 100, 200, and 400 separately. Each experiment is repeated for 500 times.

The main criterion for evaluation is the average mean squared error (AMSE) across 500 repetitions. We also report the average bias (ABIAS) and the average standard deviation (ASTD) for illustration purpose. The estimation is performed on 100 fixed grid points which are evenlly distributed on the support of $z_{j, i t}(0,1)$ for both steps ${ }^{2}$

$$
A M S E\left[\hat{\beta}_{j}\right]=\frac{1}{100} \sum_{k=1}^{100}\left[\hat{\beta}_{j}\left(\operatorname{grid}_{k}\right)-\beta_{j}\left(\operatorname{grid}_{k}\right)\right]^{2}
$$

\footnotetext{
${ }^{1}$ In general, the rule-of-thumb constant $c$ is close to 1 , when the Gaussian kernel is used. We let $c_{j}=1.5$ in the simulation. When the constant is chosen to be 1 for large sample size, it would make the diagonal matrix with kernels to be singular due to small bandwidth selection.

${ }^{2}$ The upper and lower $2.5 \%$ on the support of $z_{j, i t}$ are cut to avoid boundary bias.
} 


$$
\operatorname{AMSE}\left[\check{\beta}_{j}\right]=\frac{1}{100} \sum_{k=1}^{100}\left[\check{\beta}_{j}\left(\operatorname{grid}_{k}\right)-\beta_{j}\left(\operatorname{grid}_{k}\right)\right]^{2}
$$

where $j=1, \cdots, d ; \operatorname{grid}_{k}$ represents the sequence of 100 selected grid points; $\hat{\beta}_{j}\left(\operatorname{grid}_{k}\right)$ and $\check{\beta}_{j}\left(\operatorname{grid}_{k}\right)$ are the first-step and the second-step estimators; $\beta_{j}\left(\right.$ grid $\left._{k}\right)$ is the true coefficient function at the 100 fixed grid points.

Table 1.1 reports the AMSE, ABIAS, and ASTD at different sample size for each coefficient function. In the first panel of Table 1.1, the AMSE decreases when $n$ increases in both the first-step and secondstep estimators. It reveals that the performance of the proposed estimator improves with large sample size and it is robust across different types of coefficient functions. We then compare the AMSE of the two-step estimators; the kernel-based estimator overall has smaller AMSE at each experiment design for all coefficient functions, which illustrates that the second-step estimator is oracle efficient. The gain in AMSE reduction is substantial, especially for $\beta_{2}, \beta_{3}$, and $\beta_{5}$.

The ASTD is reported in the third panel in Table 1.1. The pattern of the change in ASTD for each coefficient functions at different sample size roughly matches that in the AMSE. However, the ABIAS reported in the second panel in Table 1.1 is slightly different. The first-step estimator has a relatively smaller average bias than that of the second-step. The ABIAS of the kernel-based estimator decrease with large $n$ across different coefficient functions except for $\beta_{3}$. The difference between ABIAS in two steps can be explained by the distinct nature of the series-based and kernel-based estimators. In the first step estimation, the B-splines are constructed to approximate coefficient functions globally which are computationally convenient. In contrast, the kernel-based estimator in the second step performs a local approximation on the coefficient function. Besides, the selection of smoothing parameters (knots and bandwidth) are different. The gain in the AMSE is mainly attributed to the decrease in the ASTD across all three experiments.

Next, we evaluate the robustness of the proposed estimator. In Theorem 2, the convergence rate is associated with the bandwidth $h$, which converges to zero as $n \rightarrow \infty$. The selection of bandwidth in above simulation is based on the rule-of-thumb method $h_{j}=c_{j} z_{j, s d}(n * t)^{-1 /\left(4+p_{j}\right)}$ and $c_{j}$ is set to be 1.5. To test the robustness of the second-step estimator, simulation is performed when $c_{j}=1.7$ and $c_{j}=2$ and the results are reported in Table 1.2 and Table 1.3. It is observed that the AMSE decreases with large sample size and the second-step estimator in general has smaller AMSE than the first-step ones. We also noticed that larger value of constant $c_{j}$ is related to relatively higher AMSE, such as the AMSE for $\check{\beta}_{6}$ with sample size $n=400$ which is estimated to be $0.0138,0.0270$, and 0.0295 with $c_{j}$ being 1.5 , 1.7, and 2. Since the convergence rate $\sqrt{n h}$ in Theorem 2 is directly related to the bandwidth $h$ which changes with constant $c_{j}$, the estimator $\check{\beta}_{j}$ converges to its true value at a slower rate with a larger $c_{j}$. 


\subsubsection{Testing for varying coefficients}

In this section, we test whether the coefficient function changes with smoothing variables. Because of the presence of fixed effects, we introduce a hypothesis test that is motivated by Yang et al. (2006). The null hypothesis is in equation (1.5).

$$
H_{0}: \beta_{j}\left(z_{j}\right) \equiv c
$$

where $\beta_{j}\left(z_{j}\right)$ can be any coefficient functions in above DGP. In this hypothesis test, we start with the constant $c$ which is the simplest parametric function. The test statistics is constructed in equation (1.6). When the null hypothesis is $\operatorname{true}^{3}, \min _{\alpha} E\left[\beta_{j}\left(z_{j}\right)-c\right]^{2} \cdot w_{j}\left(z_{j}\right)=0$. The solution for the minimization problem is $\check{c_{j}}=\frac{1}{n \cdot T} \sum_{i=1}^{n} \sum_{t=1}^{T} \check{\beta}_{j}\left(z_{j, i t}\right)$.

$$
V_{n t, j}=\frac{1}{n \cdot T} \sum_{i=1}^{n} \sum_{t=1}^{T} \check{\beta}_{j}\left(z_{j, i t}\right)^{2}-\frac{1}{(n \cdot T)^{2}}\left(\sum_{i=1}^{n} \sum_{t=1}^{T} \check{\beta}_{j}\left(z_{j, i t}\right)\right)^{2}
$$

The sampling distribution of the test statistics under the null is constructed by using the wild bootstrap procedure in Yang et al. (2006). Denote $\tilde{m}(x, z)=x_{j, i t} \cdot \check{c_{j}}+\sum_{k \neq j}^{d} \check{\beta}_{j}\left(z_{k, i t}\right) \cdot x_{k, i t}$. The empirical distribution of $V_{n t}$ is obtained from the following steps.

1. Obtain the residuals $\tilde{\epsilon}_{i t}=Y_{i t}-\tilde{m}(x, z)$ for $i=1, \cdots, n$ and $t=1, \cdots, T$.

2. Construct residual $\epsilon_{i t}^{*}=\tilde{\epsilon}_{i t} \cdot G_{i t}$ where $G_{i t}$ has a two-point distribution. Once $\epsilon_{i t}^{*}$ is obtained, we have $Y_{i t}^{*}=\tilde{m}(x, z)+\epsilon_{i t}^{*}$.

3. Compute bootstrap statistics $V_{n t, j}^{*}$ using $\left\{\left\{\left(Y_{i t}^{*}, x_{i}, z_{i}\right)\right\}_{t=1}^{T}\right\}_{i=1}^{n}$.

4. Repeat step 2 and $3 \mathrm{M}$ times to obtain the empirical distribution of $V_{n t, 1}^{*}, \cdots, V_{n t, M}^{*}$.

$\mathrm{M}$ is 100 in the simulation. $G_{i t}=(1-\sqrt{5}) / 2$ with probability $(5+\sqrt{5}) / 10$ and $G_{i t}=(1+\sqrt{5}) / 2$ with probability $(5-\sqrt{5}) / 10$. Once the empirical distribution of the $V_{n t}$ is obtained, it is straightforward to identify its value at $95 \%$ quantile.

The number of knots and bandwidth are selected by using the same method as in the previous subsection. In Table 1.4, we report the empirical rejection frequency for the bootstrap test statistics $V_{n t}$ at different sample size. The results show that the empirical powers are 1 across all sample sizes, and the empirical size decreases with large sample size.

\footnotetext{
${ }^{3}$ The arbitrary positive weight function $w_{j}$ in Yang et al. (2006) is set to one.
} 


\subsection{Conclusion}

In this paper, we propose a varying coefficient panel data model with different smoothing variables and fixed effects. It is a generalization of the traditional varying coefficient model, which allows the partial impact of regressor to depend on different smoothing variable. Meanwhile, no functional form assumption is imposed on the coefficients and no restriction is on the distribution of error terms.

The presence of fixed effects and different smoothing variables make the one-step smoothing estimation method not applicable. Therefore, we propose a two-step estimation method to recover the coefficient functions as well as the conditional mean of inefficiency. The first-step estimation adopts a series-based estimator to estimate different coefficient functions simultaneously. We then use the first-step pilot estimator to perform one-step backfitting and estimate each coefficient function using kernel based local linear estimation technique. The asymptotic analysis indicates that our proposed efficient estimator converges at a rate which is same as that of traditional kernel-based local linear estimator. The Monte Carlo simulations show encouraging results that the second-step estimator is oracle efficient. 
Table 1.1: The average mean squared error (AMSE), average bias (ABIAS), and average standard deviation (ASTD) of the two-step estimator with bandwidth $h_{j}=c_{j} z_{j, s d}(n * t)^{-1 /\left(4+p_{j}\right)}$ and $c_{j}=1.5$.

\begin{tabular}{|c|c|c|c|c|c|c|}
\hline \multirow[t]{2}{*}{$\mathrm{t}=3$} & \multicolumn{6}{|c|}{ AMSE } \\
\hline & $\hat{\beta}_{1}$ & $\hat{\beta}_{2}$ & $\hat{\beta_{3}}$ & $\hat{\beta_{4}}$ & $\hat{\beta}_{5}$ & $\hat{\beta}_{6}$ \\
\hline $\mathrm{n}=100$ & 0.1897 & 0.1834 & 0.1872 & 0.1903 & 0.1893 & 0.1888 \\
\hline $\mathrm{n}=200$ & 0.0947 & 0.0984 & 0.0972 & 0.0978 & 0.0984 & 0.0960 \\
\hline \multirow[t]{2}{*}{$\mathrm{n}=400$} & 0.0620 & 0.0623 & 0.0617 & 0.0615 & 0.0618 & 0.0619 \\
\hline & $\tilde{\beta}_{1}$ & $\tilde{\beta}_{2}$ & $\tilde{\beta}_{3}$ & $\tilde{\beta}_{4}$ & $\tilde{\beta}_{5}$ & $\tilde{\beta}_{6}$ \\
\hline $\mathrm{n}=100$ & 0.1466 & 0.0380 & 0.0323 & 0.0776 & 0.0359 & 0.0467 \\
\hline $\mathrm{n}=200$ & 0.0912 & 0.0197 & 0.0159 & 0.0473 & 0.0156 & 0.0233 \\
\hline$n=400$ & 0.0598 & 0.0099 & 0.0078 & 0.0344 & 0.0081 & 0.0138 \\
\hline \multirow[t]{2}{*}{$\mathrm{t}=3$} & \multicolumn{6}{|c|}{ ABIAS } \\
\hline & $\hat{\beta}_{1}$ & $\hat{\beta}_{2}$ & $\hat{\beta_{3}}$ & $\hat{\beta_{4}}$ & $\hat{\beta_{5}}$ & $\hat{\beta}_{6}$ \\
\hline $\mathrm{n}=100$ & -0.0042 & -0.0039 & -0.0039 & -0.0022 & -0.0015 & 0.0059 \\
\hline $\mathrm{n}=200$ & 0.0030 & -0.0035 & -0.0040 & 0.0020 & -0.0004 & -0.0032 \\
\hline \multirow[t]{2}{*}{$\mathrm{n}=400$} & 0.0035 & -0.0009 & -0.0008 & 0.0024 & -0.0021 & -0.0011 \\
\hline & $\tilde{\beta}_{1}$ & $\check{\beta}_{2}$ & $\ddot{\beta}_{3}$ & $\tilde{\beta}_{4}$ & $\check{\beta}_{5}$ & $\check{\beta}_{6}$ \\
\hline $\mathrm{n}=100$ & 0.2253 & 0.0358 & 0.0069 & -0.1169 & 0.0150 & -0.0695 \\
\hline $\mathrm{n}=200$ & 0.2036 & 0.0336 & 0.0035 & -0.1068 & 0.0156 & -0.0716 \\
\hline $\mathrm{n}=400$ & 0.1738 & 0.0287 & 0.0040 & -0.0980 & 0.0129 & -0.0593 \\
\hline \multirow[t]{2}{*}{$\mathrm{t}=3$} & \multicolumn{6}{|c|}{ ASTD } \\
\hline & $\hat{\beta}_{1}$ & $\hat{\beta}_{2}$ & $\hat{\beta}_{3}$ & $\hat{\beta_{4}}$ & $\hat{\beta}_{5}$ & $\hat{\beta_{6}}$ \\
\hline $\mathrm{n}=100$ & 0.4117 & 0.4039 & 0.4070 & 0.4110 & 0.4091 & 0.4091 \\
\hline $\mathrm{n}=200$ & 0.2959 & 0.3008 & 0.2995 & 0.2994 & 0.3023 & 0.2978 \\
\hline \multirow{2}{*}{$\mathrm{n}=400$} & 0.2431 & 0.2434 & 0.2424 & 0.2423 & 0.2422 & 0.2428 \\
\hline & $\dot{\beta}_{1}$ & $\dot{\beta}_{2}$ & $\tilde{\beta}_{3}$ & $\tilde{\beta}_{4}$ & $\dot{\beta}_{5}$ & $\tilde{\beta}_{6}$ \\
\hline $\mathrm{n}=100$ & 0.2748 & 0.1409 & 0.1307 & 0.2095 & 0.1368 & 0.1571 \\
\hline $\mathrm{n}=200$ & 0.2046 & 0.1029 & 0.0969 & 0.1675 & 0.0940 & 0.1079 \\
\hline $\mathrm{n}=400$ & 0.1609 & 0.0754 & 0.0691 & 0.1457 & 0.0689 & 0.0832 \\
\hline
\end{tabular}


Table 1.2: The average mean squared error (AMSE), average bias (ABIAS), and average standard deviation (ASTD) of the two-step estimator with bandwidth $h_{j}=c_{j} z_{j, s d}(n * t)^{-1 /\left(4+p_{j}\right)}$ and $c_{j}=1.7$.

\begin{tabular}{|c|c|c|c|c|c|c|}
\hline \multirow[t]{2}{*}{$t=3$} & \multicolumn{6}{|c|}{ AMSE } \\
\hline & $\hat{\beta_{1}}$ & $\hat{\beta_{2}}$ & $\hat{\beta_{3}}$ & $\hat{\beta_{4}}$ & $\hat{\beta_{5}}$ & $\hat{\beta_{6}}$ \\
\hline$n=100$ & 0.5034 & 0.4777 & 0.4917 & 0.4866 & 0.5079 & 0.5677 \\
\hline $\mathrm{n}=200$ & 0.1838 & 0.1873 & 0.1920 & 0.1844 & 0.1957 & 0.1932 \\
\hline \multirow[t]{2}{*}{$\mathrm{n}=400$} & 0.0932 & 0.0963 & 0.0966 & 0.0959 & 0.0979 & 0.0979 \\
\hline & $\check{\beta_{1}}$ & $\check{\beta}_{2}$ & $\check{\beta_{3}}$ & $\check{\beta}_{4}$ & $\check{\beta_{5}}$ & $\check{\beta}_{6}$ \\
\hline$n=100$ & 0.3028 & 0.1150 & 0.0954 & 0.1625 & 0.1025 & 0.1183 \\
\hline$n=200$ & 0.1742 & 0.0368 & 0.0324 & 0.0763 & 0.0325 & 0.0482 \\
\hline $\mathrm{n}=400$ & 0.1190 & 0.0172 & 0.0148 & 0.0517 & 0.0155 & 0.0270 \\
\hline \multirow[t]{2}{*}{$t=3$} & \multicolumn{6}{|c|}{ ABIAS } \\
\hline & $\hat{\beta_{1}}$ & $\hat{\beta_{2}}$ & $\hat{\beta}_{3}$ & $\hat{\beta_{4}}$ & $\hat{\beta}_{5}$ & $\hat{\beta_{6}}$ \\
\hline $\mathrm{n}=100$ & 0.0103 & 0.0004 & -0.0023 & -0.0113 & 0.0014 & 0.0060 \\
\hline $\mathrm{n}=200$ & -0.0068 & -0.0099 & 0.0026 & 0.0095 & -0.0049 & 0.0016 \\
\hline \multirow[t]{2}{*}{$\mathrm{n}=400$} & 0.0009 & 0.0007 & 0.0008 & 0.0015 & 0.0025 & 0.0000 \\
\hline & $\check{\beta}_{1}$ & $\check{\beta_{2}}$ & $\check{\beta_{3}}$ & $\check{\beta}_{4}$ & $\check{\beta_{5}}$ & $\check{\beta_{6}}$ \\
\hline $\mathrm{n}=100$ & 0.2644 & 0.0429 & -0.0040 & -0.1290 & 0.0246 & -0.0827 \\
\hline$n=200$ & 0.2399 & 0.0352 & 0.0064 & -0.1117 & 0.0131 & -0.0809 \\
\hline $\mathrm{n}=400$ & 0.2286 & 0.0407 & 0.0084 & -0.1130 & 0.0206 & -0.0791 \\
\hline \multirow[t]{2}{*}{$t=3$} & \multicolumn{6}{|c|}{ ASTD } \\
\hline & $\hat{\beta_{1}}$ & $\hat{\beta_{2}}$ & $\hat{\beta_{3}}$ & $\hat{\beta}_{4}$ & $\hat{\beta_{5}}$ & $\hat{\beta_{6}}$ \\
\hline $\mathrm{n}=100$ & 0.6443 & 0.6291 & 0.6384 & 0.6314 & 0.6428 & 0.6519 \\
\hline $\mathrm{n}=200$ & 0.4034 & 0.4078 & 0.4141 & 0.4050 & 0.4155 & 0.4139 \\
\hline \multirow[t]{2}{*}{$\mathrm{n}=400$} & 0.2928 & 0.2988 & 0.2985 & 0.2968 & 0.3006 & 0.2988 \\
\hline & $\check{\beta_{1}}$ & $\check{\beta_{2}}$ & $\check{\beta_{3}}$ & $\check{\beta}_{4}$ & $\check{\beta_{5}}$ & $\check{\beta}_{6}$ \\
\hline$n=100$ & 0.4132 & 0.2297 & 0.2059 & 0.2864 & 0.2098 & 0.2411 \\
\hline$n=200$ & 0.3124 & 0.1356 & 0.1268 & 0.2120 & 0.1263 & 0.1583 \\
\hline $\mathrm{n}=400$ & 0.2426 & 0.0946 & 0.0893 & 0.1750 & 0.0887 & 0.1157 \\
\hline
\end{tabular}


Table 1.3: The average mean squared error (AMSE), average bias (ABIAS), and average standard deviation (ASTD) of the two-step estimator with bandwidth $h_{j}=c_{j} z_{j, s d}(n * t)^{-1 /\left(4+p_{j}\right)}$ and $c_{j}=2$.

\begin{tabular}{|c|c|c|c|c|c|c|}
\hline \multirow[t]{2}{*}{$\mathrm{t}=3$} & \multicolumn{6}{|c|}{ AMSE } \\
\hline & $\hat{\beta_{1}}$ & $\hat{\beta}_{2}$ & $\hat{\beta}_{3}$ & $\hat{\beta_{4}}$ & $\hat{\beta}_{5}$ & $\hat{\beta}_{6}$ \\
\hline $\mathrm{n}=100$ & 0.5116 & 0.4675 & 0.5099 & 0.4876 & 0.5118 & 0.4896 \\
\hline $\mathrm{n}=200$ & 0.1953 & 0.1878 & 0.1897 & 0.1866 & 0.1794 & 0.1789 \\
\hline \multirow[t]{2}{*}{$\mathrm{n}=400$} & 0.0969 & 0.0951 & 0.0950 & 0.0968 & 0.0971 & 0.0986 \\
\hline & $\check{\beta_{1}}$ & $\check{\beta_{2}}$ & $\check{\beta_{3}}$ & $\check{\beta}_{4}$ & $\check{\beta}_{5}$ & $\check{\beta_{6}}$ \\
\hline $\mathrm{n}=100$ & 0.3394 & 0.0928 & 0.0896 & 0.1621 & 0.0961 & 0.1103 \\
\hline $\mathrm{n}=200$ & 0.2320 & 0.0357 & 0.0306 & 0.0843 & 0.0296 & 0.0531 \\
\hline $\mathrm{n}=400$ & 0.1622 & 0.0173 & 0.0128 & 0.0577 & 0.0135 & 0.0295 \\
\hline \multirow[t]{2}{*}{$\mathrm{t}=3$} & \multicolumn{6}{|c|}{ ABIAS } \\
\hline & $\hat{\beta_{1}}$ & $\hat{\beta_{2}}$ & $\hat{\beta_{3}}$ & $\hat{\beta_{4}}$ & $\hat{\beta}_{5}$ & $\hat{\beta_{6}}$ \\
\hline $\mathrm{n}=100$ & -0.0054 & -0.0150 & 0.0135 & 0.0080 & 0.0076 & 0.0147 \\
\hline $\mathrm{n}=200$ & -0.0020 & 0.0018 & 0.0066 & -0.0019 & -0.0001 & -0.0077 \\
\hline \multirow[t]{2}{*}{$\mathrm{n}=400$} & -0.0035 & 0.0027 & -0.0001 & 0.0011 & 0.0023 & 0.0022 \\
\hline & $\check{\tilde{\beta}_{1}}$ & $\check{\beta}_{2}$ & $\check{\tilde{\beta}_{3}}$ & $\check{\beta}_{4}$ & $\check{\beta_{5}}$ & $\check{\tilde{\beta}_{6}}$ \\
\hline $\mathrm{n}=100$ & 0.2204 & 0.0185 & 0.0164 & -0.1109 & 0.0268 & -0.0738 \\
\hline $\mathrm{n}=200$ & 0.2434 & 0.0457 & 0.0148 & -0.1259 & 0.0174 & -0.0945 \\
\hline $\mathrm{n}=400$ & 0.2399 & 0.0449 & 0.0087 & -0.1250 & 0.0191 & -0.0828 \\
\hline \multirow[t]{2}{*}{$t=3$} & \multicolumn{6}{|c|}{ ASTD } \\
\hline & $\hat{\beta}_{1}$ & $\hat{\beta_{2}}$ & $\hat{\beta}_{3}$ & $\hat{\beta}_{4}$ & $\hat{\beta}_{5}$ & $\hat{\beta}_{6}$ \\
\hline $\mathrm{n}=100$ & 0.6543 & 0.6262 & 0.6432 & 0.6357 & 0.6443 & 0.6360 \\
\hline $\mathrm{n}=200$ & 0.4136 & 0.4083 & 0.4111 & 0.4066 & 0.3991 & 0.4002 \\
\hline \multirow[t]{2}{*}{$\mathrm{n}=400$} & 0.2994 & 0.2966 & 0.2954 & 0.2986 & 0.2989 & 0.3007 \\
\hline & $\check{\beta_{1}}$ & $\check{\beta_{2}}$ & $\check{\beta_{3}}$ & $\check{\beta_{4}}$ & $\check{\beta_{5}}$ & $\check{\beta_{6}}$ \\
\hline $\mathrm{n}=100$ & 0.4834 & 0.2094 & 0.1905 & 0.2955 & 0.1972 & 0.2396 \\
\hline $\mathrm{n}=200$ & 0.3894 & 0.1316 & 0.1139 & 0.2212 & 0.1189 & 0.1656 \\
\hline $\mathrm{n}=400$ & 0.3111 & 0.0930 & 0.0795 & 0.1861 & 0.0828 & 0.1225 \\
\hline
\end{tabular}


Table 1.4: Empirical rejection frequency of $V_{n t}$

\begin{tabular}{lll}
\hline \multicolumn{3}{c}{$H_{0}: \beta_{1}\left(z_{1 i t}\right) \equiv 2$} \\
\hline $\mathrm{n}=50$ & Empirical Size & Empirical Power \\
$\mathrm{n}=100$ & 0.08 & 1 \\
$\mathrm{n}=150$ & 0.05 & 1 \\
\hline
\end{tabular}



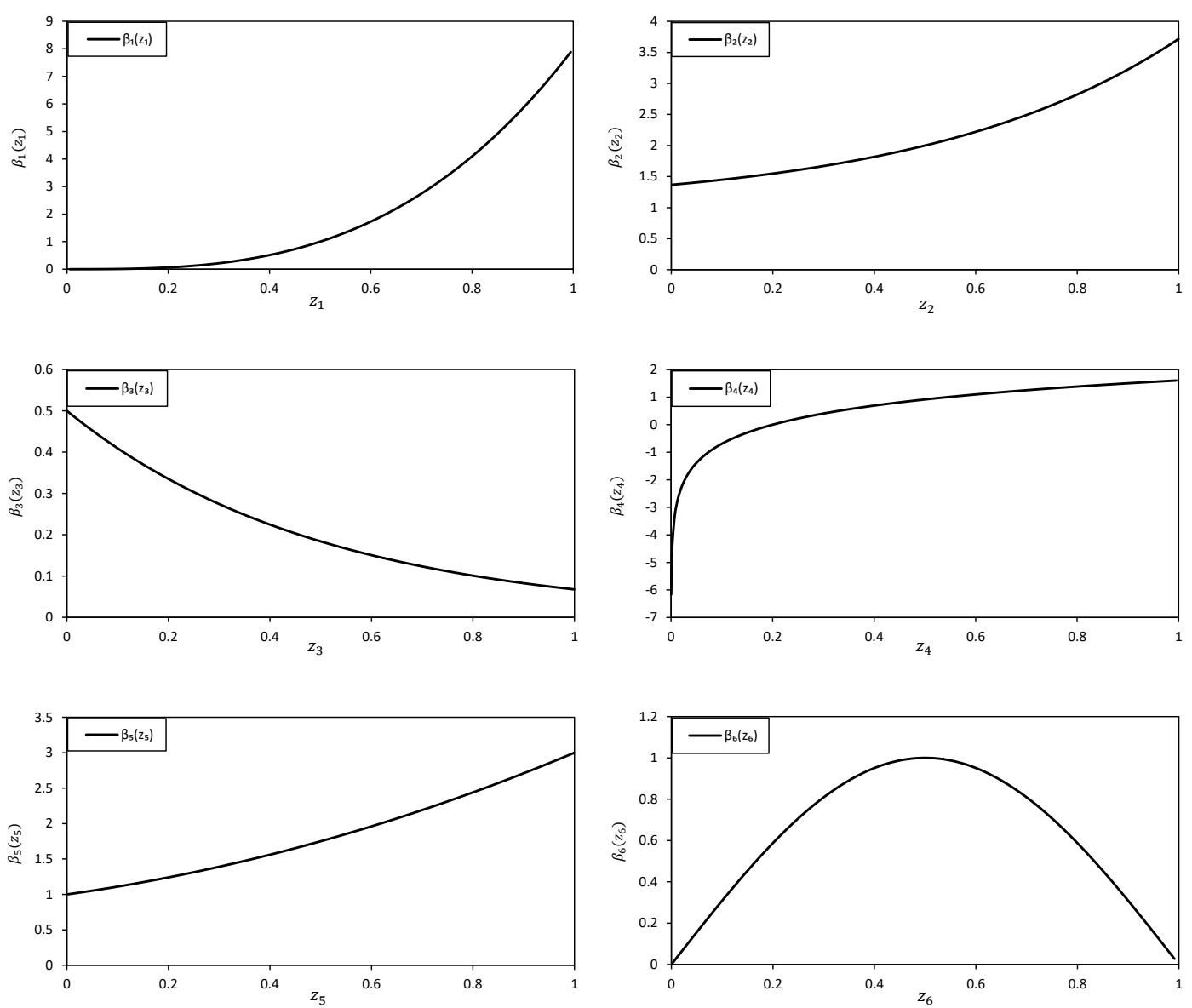

Figure 1.1: Plots of smooth coefficient functions against environment variables, where $\beta_{1}\left(z_{1, i t}\right)=(2$. $\left.z_{1, i t}\right)^{3}, \beta_{2}\left(z_{2, i t}\right)=1+e^{2 \cdot z_{2, i t}-1}, \beta_{3}\left(z_{3, i t}\right)=0.5 \cdot e^{-2 \cdot z_{3, i t}}, \beta_{4}\left(z_{4, i t}\right)=\ln \left(5 \cdot z_{4, i t}\right), \beta_{5}\left(z_{5, i t}\right)=1+z_{5, i t}+z_{5, i t}^{2}$, and $\beta_{6}\left(z_{6, i t}\right)=\sin \left(\pi \cdot z_{6, i t}\right)$. 


\section{Chapter 2}

\section{Does Emissions Trading Affect Power Plant Productivity? A Semiparametric Analysis on the Stochastic Production Frontier}

\section{$2.1 \quad$ Introduction}

The Acid Rain Program (ARP) was introduced by the Environmental Protection Agency (EPA) in 1995 as the first national cap-and-trade program, which is designed to reduce the overall level of air pollution, such as sulfur dioxide $\left(\mathrm{SO}_{2}\right)$ and nitrogen oxide $\left(\mathrm{NO}_{x}\right)^{1}$. Because of human health and air quality concern, efforts have been taken to control $\mathrm{SO}_{2}$ emission, such as introducing the market-oriented environmental programs. As a market-based pollution control approach, the ARP allows power plants to purchase and sell emission permits based on their needs and costs.

Since properly designed environmental policy encourages innovation and improves the production process, the market-based environmental program enables electricity generating units to offset costs of compliance and improve their efficiency (Porter and van der Linde (1995)). The inefficiency in this paper refers to the shortfall of actual electricity generation from the maximum output given the same labor, capital, and fuel. The electricity generation is a comprehensive process in which fossil fuel is burned in the boiler to generate steam, and the steam passes through the turbine and spins the generator. This system operates automatically at some degree, but it still requires monitoring and adjustment by power plant operators. Inefficiency can potentially arise from different sources, such as the performance of plant operators, plant management efficiency, operational condition of generators, and environmental policies. As a market-based policy, the Acid Rain Program can change production efficiency by affecting a plant's

\footnotetext{
${ }^{1}$ The Acid Rain Program includes both the $\mathrm{SO}_{2}$ program and the $\mathrm{NO}_{x}$ program. Since this paper evaluates the influence of the Acid Rain $\mathrm{SO}_{2}$ program on productivity, the discussion focuses on the $\mathrm{SO}_{2}$ program.
} 
choice on emission control technology.

The strategies of emission control include switching to low-sulfur coal, installing scrubber (FGD units) ${ }^{2}$, and purchasing emission permits from other regulated units (Hancevic (2016)). It is one of the most crucial choices of planning to select a cost-effective emission control method and meet compliance requirement. In general, a power plant chooses emission abatement approach by comparing the marginal costs. Besides, different emission control methods affect production efficiency at varying degree. When a plant switches high-sulfur content coal to low-sulfur ones, it requires technology updates and this process can lower the electricity generation. On the other hand, the operation of FGD units consumes electricity and in turn reduces net generation. The last approach keeps net electricity unaffected by allowing power plants to purchase permits to cover excess emission when initially allocated permits are insufficient. It is crucial to identify a power plant's choice among the three options and find out the balance between emission control and production efficiency. It offers information on the improvement of environmental policy when considering electricity generation efficiency.

Besides inefficiency, other factors that are known as environment variables can potentially change the output level indirectly. Ignoring environment variables in productivity analysis may lead to unreliable inference due to possible model misspecification. The environment variables are different from traditional inputs which change output level through the marginal product of inputs. Firm characteristics are a typical example of environmental variables, such as the average age of generators and the total number of generators in a power plant. The age of a generator indicates current production technology and the time that a generator has worked for. Therefore, it changes the capital utilization and marginal product of physical capital. Mathematically, this relationship between the marginal product of input and environment variables can be represented by a coefficient function of environment variables.

The empirical tool that is widely used in power plant efficiency analysis is the directional output distance function which models the production technology with multiple outputs and inputs. (Färe et al. (2005); Färe et al. (2012); Färe et al. (2013)). In the literature, the output is categorized as good output (electricity generated) and bad ones (air pollution). Since they are modeled jointly, environmental efficiency is realized as the expansion of electricity generation and contraction of air pollutant. Although it is an attractive approach, the random shock and firm heterogeneity are not permitted in this model setup. To avoid potential model misspecification and account for plant fixed effects, I propose to use a panel data stochastic production frontier model with fixed effects.

The production frontier analysis is firstly motivated by the seminar work of Aigner et al. (1977) and Meeusen and van Den Broeck (1977), which offers a benchmark model on frontier analysis. A stochastic

\footnotetext{
${ }^{2}$ Scrubber is also called Flue-gas desulfurization (FGD), which is a technology used to remove end-of-pipe $\mathrm{SO}_{2}$ emission.
} 
production frontier model consists of a production function and the composite error. The composite error has two components which are the random noise that is out of control of a firm and the inefficiency term that captures the shortfall of actual production from the maximum output. Since the model identifies the presence and magnitude of inefficiency, it gains more popularity recently. Efficiency estimation offers information on factors that lead to under-performance of a plant. Recent research focuses on the model where the distribution of inefficiency depends on a set of environment variables, such as determinant of inefficiency and firm characteristics. This model setup enables the estimation of the influence of the Acid Rain Program on inefficiency by allowing the inefficiency term to be a function of the measurement of the Acid Rain Program.

To further evaluate the influence of power plant characteristics on the marginal return on labor and capital, I introduce the varying coefficient structure in the proposed frontier model. That is to say, the shape of coefficient of labor can vary with the number of generators in a power plant. Similarly, the marginal product of capital is possibly related to the years that a generator has been used. Since the functional form of the coefficient functions is unknown, no assumption is imposed to avoid model misspecification. Besides, the varying coefficient model potentially alleviates the "curse of dimensionality," since the regressors and environmental variables are modeled separately.

The proposed empirical model is a panel data stochastic production frontier model with fixed effects and varying coefficients. No restriction is imposed on the shape of coefficient functions. To facilitate the influence of power plant characteristics on the marginal product of labor and physical capital, each coefficient can change with a different variable. Meanwhile, to allow the data itself to recover the shape of the inefficiency term, no distribution or functional form assumption is imposed on error terms. This interesting model setup is not touched before. Related work is found in Parmeter et al. (2017), which also relaxes distribution assumption in the model but the authors focus on a cross-sectional stochastic frontier.

As a flexible varying coefficient model, the one-step local maximum likelihood in Cai et al. (2000) for the traditional varying coefficient model is not feasible, due to the presence of different smoothing functions and no assumption on error terms. To estimate the marginal product of labor and capital consistently, I propose to use the two-step estimation method in Yao et al. (2018a) to dealing with different coefficient functions and taking care of fixed effects. The proposed estimation method is different from traditional two-step methods in the production frontier literature that suffers from the omitted variable problem in their first step estimation and gives biased estimates. In this paper, the first-step estimator is a series-based estimator, which estimates all the coefficient function simultaneously. In the second step, a one-step backfitting is performed, and then the kernel-based estimator recovers the coefficient functions 
efficiently.

The rest of this paper is organized as follows. Section 2 introduces the background of the Acid Rain Program and the related literature on the stochastic production frontier. In section 3, a detailed discussion on the proposed stochastic production frontier model with fixed effects and varying coefficients is presented. Section 4 introduces the application of the proposed model on efficiency analysis of U.S. coal-burning power plants. Estimation results are reported in section 5. Section 6 concludes the paper.

\subsection{Background and Literature Review}

\subsubsection{Coal-fired Power plants and the Acid Rain Program}

The electricity generating power plants rely heavily on the consumption of fossil fuel (coal, natural gas, and petroleum). Among different types of fossil fuel, coal was the primary energy source for electricity generation as of $2010^{3}$. According to the EPA, burning fossil fuel is the largest source of Sulfur dioxide $\left(\mathrm{SO}_{2}\right)$ in the atmosphere (EPA, 2018). $\mathrm{SO}_{2}$ is harmful to the human respiratory system and the culprits to blame for the formation of acid rain and particulate matter (PM) pollution. Therefore, the Acid Rain Program was introduced by the EPA to reduce $\mathrm{SO}_{2}$ and $\mathrm{NO}_{x}$ from major sources such as power plants.

The Acid Rain Program was established in 1995 under Title IV of the 1990 Clean Air Act Amendments. It aims to reduce the emission of $\mathrm{SO}_{2}$ and $\mathrm{NO}_{x}$. The Acid Rain $\mathrm{SO}_{2}$ program sets a cap on $\mathrm{SO}_{2}$ emission by EPA and emission permits are allocated among electric generating units (EGU). An Emission permit represents the right to emit pollution. The program is designed to be phased in which includes two phases. Phase I began in 1995, and it targeted coal-burning power plants in eastern and midwestern states. Phase II expanded the coverage and tightened the final cap to be 8.95 million tons of $\mathrm{SO}_{2}$ which is one half of the emission level in 1980 (EPA). It is a flexible way to reduce overall pollution level since the EPA only requires a total reduction on $\mathrm{SO}_{2}$ emission and allows power plants to choose the most cost-effective method to control pollution ${ }^{4}$. Some power plants have relatively lower emission abatement cost, and they can reduce $\mathrm{SO}_{2}$ to a lower level and have a surplus of emission permits. These surpluses can be banked for future use or traded in the market. In contrast, some plants face high costs of $\mathrm{SO}_{2}$ removal. When initially allocated permits are not enough to cover the $\mathrm{SO}_{2}$ emission, power plants have two choices. They either pay the penalties for any excess $\mathrm{SO}_{2}$ emission or to purchase permits from other sources. Napolitano et al. (2007) state that power plants always choose the most cost-efficient way to deal with emission.

\footnotetext{
${ }^{3}$ According to the Energy Information Administration (EIA), natural gas became the largest source (32\%) for U.S. electricity generation in 2017. Coal is the second largest energy source for electricity generation (30\%).

${ }^{4}$ The emission abatement techniques among power plants are fuel switching and installation of Flue-gas desulfurization (FGD) units (Ellerman (2003)).
} 
Ideally, well designed environmental policy encourages innovation and reduces emission. Market-based environmental policy can help electricity generating units to offset costs of compliance and improve their efficiency ( Porter and van der Linde (1995)). Recent research examined the performance of power plants from different aspects. The primary interest falls on the influence of environmental policies on production efficiency, which evaluate the generation to emission ratio and emission abatement efficiency (Hampf and Rødseth (2015) and Hampf (2014)). Another approach is via a stochastic production frontier model. Knittel (2002) investigates the impact of regulatory environment on power plants efficiency by introducing the measurement of regulation into the inefficiency term. This frontier model incorporates the influence of determinants of technical inefficiency into production function.

In Knittel (2002), it focuses on efficiency analysis, but the influence of firm characteristics is not considered. Recent work by Heshmati et al. (2014) finds out that plant characteristics affect capital utilization and worker's performance, however they focus on the panel data model but not the production frontier. In addition, the neoclassical production reveals the relationship between output and classical inputs, but it does not consider the impact of operational environments such as the number of generators and the average age of generators in each plant. To account for the influence of environment variable, Heshmati et al. (2014) estimate the productivity of the Korean electric power plant and include environmental variables via the smoothing coefficient function. Since their work mainly focuses on smoothing coefficient function in a panel data model, it does not include the measure of technical inefficiency as in the stochastic production frontier analysis.

\subsubsection{The Stochastic Production Frontier}

The development of frontier estimation starts with parametric methods which require functional form assumption on production functions, such as Cobb-Douglas and translog production function. Also, the popular estimation approach is maximum likelihood which relies on the distribution assumption on the error terms, such as half normal, exponential, truncated normal, or gamma distribution on the one-side

inefficiency (Aigner et al. (1977), Meeusen and van Den Broeck (1977), Stevenson (1980), and Greene $(1980))$.

Recently, nonparametric and semiparametric approaches are proposed to tackle the heavily parametric problem in frontier analysis. Since purely nonparametric estimation suffers from the so-called "curse of dimensionality," semiparametric estimation becomes popular by reducing the dimension of parameters. Besides, it allows unspecified functional form of coefficient function and additive structure. Fan et al. (1996) proposed a kernel based semiparametric approach to estimate production frontier, and the joint work of Martins-Filho and Yao (2015) further extended the work. Another concern falls on the specifica- 
tion of composite error terms. Existing literature relies on distribution assumption of the composite error term, such as normal distribution on the random error and truncated normal distribution on technical inefficiency (Fan et al. (1996); Martins-Filho and Yao (2015); Horrace and Parmeter (2011)). It would potentially limit the application of the model when the distribution assumption is not satisfied. Recent research on cross-sectional stochastic production frontier by Parmeter et al. (2017) relaxes distribution assumptions on composite error terms and estimates the conditional mean of inefficiency.

A growing literature focuses on the frontier model where the distribution of inefficiency is correlated with environmental parameters, such as firm characteristics or determinant of inefficiency. The common estimation approach is maximum likelihood (Kumbhakar et al. (1991); Battese and Coelli (1995); Caudill et al. (1995) ). To facilitate maximum likelihood estimation, the parametric assumption on the distribution of inefficiency term is required. Recent work by Alvarez et al. (2006) introduces scaling property of inefficiency which requires no assumption on distribution, however, scaling function still needs to be specified.

This paper adds to the production frontier literature by introducing a panel data model with fixed effects and varying coefficients. Each of the coefficient functions can depend on different environment variables. Also, considering fixed effects potentially alleviate endogeneity concern in the panel data model. The varying coefficient setup accounts for the influence of firm characteristic on marginal product of inputs. Meanwhile, no parametric assumption is imposed on the functional form of coefficient function or the distribution of error terms. The model enables data itself to recover the shape of coefficient function.

\subsection{Methodology and Model Specification}

This section introduces the stochastic production frontier model with varying coefficient and fixed effects as in (2.1),

$$
Y_{i t}=\alpha_{i}+X_{i t}^{\prime} \beta\left(Z_{i t}\right)+v_{i t}-u_{i t} \quad i=1, \ldots, n ; t=1, \ldots, T
$$

Where $Y_{i t}$ is output; $\alpha_{i}$ is unobserved firm-specific fixed effects that could be correlated with $X_{i t}, Z_{i t}$, or $W_{i t}^{5} ; X_{i t} \in \Re^{r}$ is the explanatory variable which refers to traditional inputs, such as labor, physical capital, and fuel; $Z_{i t} \in \Re^{p}$ is environment variable which could potentially affect production indirectly, such as the operational condition in a power plant; the varying coefficient function $\beta\left(Z_{i t}\right)$ for each input is allowed to depend on different environment variables; $v_{i t}$ represents statistic random error, which is assumed to be i.i.d. with zero mean and finite variance $\sigma_{v}^{2} ; u_{i t}>0$ with zero mean and finite variance

\footnotetext{
${ }^{5} W_{i t}$ is determinant of inefficiency which is introduced in the following paragraphs.
} 
$\sigma_{u}^{2}$ represents technical inefficiency that leads to the shortfall of actual production from the frontier.

The distribution of inefficiency term $u_{i t}$ is allowed to depend on environment variables such as firm characteristics or determinant of inefficiency. Since interest is on the influence of the Acid Rain Program on firm productivity, the inefficiency term is considered to depend on determinants of inefficiency $W_{i t} \in \Re^{s}$, which could be a measurement of the Acid Rain Program. Let $E\left(u_{i t} \mid X_{i t}, Z_{i t}, W_{i t}\right)=$ $g\left(W_{i t}\right)$. Since $v_{i t}$ represents random noise that is beyond the control of power plants, it is assumed that $E\left(v_{i t} \mid X_{i t}, Z_{i t}, W_{i t}\right)=0$. No distribution assumption is imposed on neither $v_{i t}$ nor $u_{i t}$. Based on the above assumptions on error terms, it is straightforward to reveal that $E\left(\left(v_{i t}-u_{i t}\right) \mid X_{i t}, Z_{i t}, W_{i t}\right) \neq 0$. Therefore, (2.1) could not be estimated directly because of the nonzero conditional mean of composite error. Let there be another composite error term $\epsilon_{i t}=v_{i t}-\left(u_{i t}-g\left(W_{i t}\right)\right)$, which satisfies $E\left(\epsilon_{i t} \mid X_{i t}, Z_{i t}, W_{i t}\right)=0$. (2.1) is transformed into (2.2).

$$
Y_{i t}=\alpha_{i}+X_{i t}^{\prime} \beta\left(Z_{i t}\right)-g\left(W_{i t}\right)+\epsilon_{i t}
$$

Model (2.2) is essentially a varying coefficient panel data model with different smoothing variables $\beta\left(Z_{i t}\right)$ and fixed effects, in which the last regressor is a vector of ones and coefficient function is $-g\left(W_{i t}\right)$. It can be estimated using the two-step estimation approach in Yao et al. (2018a) ${ }^{6}$.

It is noticed that the varying coefficient model in Yao et al. (2018a) has no restriction on the smoothing functions. That being said, $g\left(W_{i t}\right)>0$ in (2.2) is not imposed when using estimators proposed by Yao et al. (2018a). Before proceeding to empirical estimation, a simple simulation is introduced to evaluate performance of the estimator when $-g\left(W_{i t}\right)$ exists in the model. Ideally, the estimator should give consistent estimation.

The data-generating process is,

$$
D G P: \quad Y_{i t}=\alpha_{i}+x_{1, i t} \beta_{1}\left(z_{1, i t}\right)+x_{2, i t} \beta_{2}\left(z_{2, i t}\right)-g\left(z_{3, i t}\right)+\epsilon_{i t}
$$

where $i=1, \ldots, n ; t=1, \ldots, T$. Let $x_{1, i t}, x_{2, i t}$ and $x_{3, i t}$ distribute normally with $N(0,1)$ independently. The smoothing variables $z_{1, i t}, z_{2, i t}$, and $z_{3, i t}$ are uniformly distributed with $\operatorname{Unif}(0,1)$ independently. The error term $\epsilon_{i t}$ has $N(0,1)$. The coefficient functions are generated as $\beta_{1}\left(z_{1, i t}\right)=e^{z_{1, i t}-1}, \beta_{2}\left(z_{2, i t}\right)=e^{z_{2, i t}}$, and $-g\left(z_{3, i t}\right)=-0.5 * e^{z_{3, i t}}$ to ensure $-g\left(z_{3, i t}\right)=-0.5 * e^{z_{3, i t}}<0$ is imposed. The fixed effects $\alpha_{i}=\frac{1}{T} \sum_{t=1}^{T} z_{1, i t}$. Let $t=3$, and $n$ takes value 50,100 , and 200 .

The selection of smoothing parameters, bandwidth and knots, follows the method in Yao et al. (2018a). The average means squared error (AMSE) in equation (2.3) evaluates performance of the two-step esti-

\footnotetext{
${ }^{6} \mathrm{~A}$ detailed discussion on the two-step estimation method can be found in Yao et al. (2018a).
} 
mator, where $\hat{\beta}_{j}(\cdot)$ denotes first-step series-based estimator and $\check{\beta}_{j}(\cdot)$ is second-step kernel-based oracle efficient estimator. The coefficients are estimated at 100 equally-spaced fixed grid points on $[0,1]$. Estimation results are reported in Table 2.1. As sample size increases, the AMSE decreases in all three coefficient functions. When the true coefficient function $-g\left(z_{3, i t}\right)$ is below zero, the estimates at 25th, 50th, and 75th percentiles are all negative numbers in Table 2.2. Therefore, the two-step approach estimates conditional mean of inefficiency consistently, when the inefficiency is truly a function of $W_{i t}$.

$$
\begin{aligned}
& A M S E\left[\hat{\beta}_{j}\right]=\frac{1}{100} \sum_{k=1}^{100}\left[\hat{\beta}_{j}\left(\operatorname{grid}_{k}\right)-\beta_{j}\left(\operatorname{grid}_{k}\right)\right]^{2} \\
& A M S E\left[\check{\beta}_{j}\right]=\frac{1}{100} \sum_{k=1}^{100}\left[\check{\beta}_{j}\left(\operatorname{grid}_{k}\right)-\beta_{j}\left(\operatorname{grid}_{k}\right)\right]^{2}
\end{aligned}
$$

\subsection{The U.S. Coal-fired Power Plants Production Efficiency Anal- ysis}

\subsubsection{Empirical Model}

In this section, model (2.2) is estimated to evaluate technical efficiency and the marginal product of inputs in the coal-burning power plants from 2001 to $2005^{7}$. The conditional mean of inefficiency $-g\left(W_{i t}\right)$ measures the shortfall of actual electricity generation from the optimal level, and it is affected by the Acid Rain Program. The shape of the coefficient functions changes with the operational conditions of power plants, such as the total number of generators and the average years of operation. In previous stochastic frontier literature, the relationship between coefficient function and operational condition is not revealed. Therefore, this paper contributes to the literature to investigate the impact of plant characteristics on the marginal return on inputs, which can potentially be a linear or nonlinear function. Meanwhile, the coefficient functions of labor, capital, and fuel are allowed to depend on different parameters.

One output and three inputs are chosen in this paper by following the literature on power plant analysis. The output is net electricity generation (Megawatt hour). Three inputs are labor, physical capital, and coal (Knittel (2002); Kleit and Terrell (2001); Färe et al. (2007); Hampf (2014); Färe et al. (2005); Färe et al. (2014)). Two environment variables are the average age of generators and the total number of generators in each power plant. Since these two parameters are associated with the utilization of capital and worker experience, they change the shape of coefficient functions(Heshmati et al. (2014)).

\footnotetext{
${ }^{7}$ The coal-burning power plant is defined as the plant in which at least one boiler consumes coal as the primary fuel (Chan et al. (2018)). Fuels, other than coal, are mainly used to heat the boiler instead of generating steam for electricity generation in a coal-burning power plant.
} 
The functional form of the varying coefficient is unknown, and it is allowed to be recovered by data itself without imposing functional form assumptions.

The selection of determinant of inefficiency $W_{i t}$ is crucial for consistent estimation of the Acid Rain Program's impact on production. The operation and maintenance costs on FGD technology is selected as the measurement of the Acid Rain Program. The Acid Rain Program changes power plants pollution control methods mainly through three channels, which are shifting to lower-sulfur coal, purchasing permits for excess emission, and installing FGD units to remove end-of-pipe sulfur content(Hancevic (2016)). An emission control technology lowers production efficiency when it reduces actual net electricity generation. Among those three approaches, FGD technology and switching fuel both decrease net electricity generation, in contrast, purchasing or selling emission permit has no direct impact on output. Regarding fuel switching, the typical types of coal used in the power plants are Subbituminous (SUB) and Bituminous (BIT) coal. According to the EPA's report, the SUB has lower heating value but emits less $\mathrm{SO}_{2}$ than that of BIT (Pechan et al. (1993)). When a power plant shifts to a different type of fuel, it requires adjustment on combustion technology and can reduce production efficiency. It is noticed that only 2 power plants out of 36 in the observations switched from BIT to SUB, therefore the impact of fuel switching is negligible in this paper. The discussion focuses on permits purchasing and FGD technology. The operation of FGD units consumes electricity, which in turn reduces net electricity generation and raises inefficiency. Therefore, the impact of the Acid Rain Program on efficiency is determined by a plant's choice between utilizing more of the FGD units and purchasing permits, when initially allocated permits are not enough.

A power plant chooses emission control method with lower marginal costs between purchasing permits and relying on FGD technology. When initially allocated emission permits are sufficient to cover a power plant's $\mathrm{SO}_{2}$ emission in a compliance year, the production efficiency is unaffected by the Acid Rain Program in this scenario. If a plant's $\mathrm{SO}_{2}$ emission is beyond permits endowment, this power plant chooses from purchasing additional permits or utilizing FGD units after comparing marginal costs between them ${ }^{8}$.

The proposed empirical stochastic production frontier model is in (2.4).

$$
\ln \mathrm{Y}_{i t}=\alpha_{i}+\ln \mathrm{L}_{i t} \cdot \beta_{L}\left(\mathrm{Z}_{1, i t}\right)+\ln \mathrm{K}_{i t} \cdot \beta_{K}\left(\mathrm{Z}_{2, i t}\right)+\ln \mathrm{F}_{i t} \cdot \beta_{F}\left(\mathrm{Z}_{3, i t}\right)-g\left(\mathrm{~W}_{i t}\right)+e_{i t}
$$

where $Y_{i t}$ is the annual net electricity generation $(\mathrm{MWh}) ; \alpha_{i}$ captures fixed effects; $L_{i t}, K_{i t}$, and $F_{i t}$ are labor, capital, and coal consumption, respectively; $Z_{1, i t}, Z_{2, i t}$, and $Z_{3, i t}$ are environment variables

\footnotetext{
${ }^{8}$ The penalty for each ton of excess $\mathrm{SO}_{2}$ is $\$ 3042$ in 2005 and no penalty is levied according to EPA (2005). Power plants either obtain permits from other regulated sources or relying on FGD technology to remove $\mathrm{SO}_{2}$ in exhaust.
} 
which can either be the average age of generators $\left(\mathrm{Age}_{i t}\right)$ or the total number of generators in a power plant $\left(\right.$ Number $\left._{i t}\right) ; W_{i t}$ represents determinant of inefficiency and it is measured as the total operation and maintenance costs on FGD units in a year; $e_{i t}=v_{i t}-\left(u_{i t}-g\left(W_{i t}\right)\right)$ is composite error with zero mean; $v_{i t}$ is stochastic error and $u_{i t}$ is inefficiency.

The smoothing coefficient function $\beta_{L}(\cdot), \beta_{K}(\cdot)$, and $\beta_{F}(\cdot)$ can depend on the same or different environment variables. In the panel data model of Heshmati et al. (2014), the age of the generators is positively related to the return on capital. Therefore, $\beta_{K}\left(\mathrm{Age}_{i t}\right)$ is also proposed in this model. The number of generators gives information on the size of power plants and is also an indicator of capital utilization. Thus, $\beta_{L}\left(\right.$ Number $\left._{i t}\right)$ and $\beta_{F}\left(\right.$ Number $\left._{i t}\right)$ are included in the model (2.5). The selection of smoothing parameters, bandwidth and number of knots, is followed from Yao et al. (2018a).

$\ln \mathrm{Y}_{i t}=\alpha_{i}+\ln \mathrm{L}_{i t} \cdot \beta_{L}\left(\right.$ Number $\left._{i t}\right)+\ln \mathrm{K}_{i t} \cdot \beta_{K}\left(\mathrm{Age}_{i t}\right)+\ln \mathrm{F}_{i t} \cdot \beta_{F}\left(\right.$ Number $\left._{i t}\right)-g\left(\mathrm{~W}_{i t}\right)+e_{i t}$

The technical efficiency score (TE) based on the empirical model (2.5) is calculated in (2.6), which follows Li and Phillips (2017). TE is always between 0 and 1, with 0 being least efficient and 1 being fully efficient. It gives a better understanding on the overall performance of power plants

$$
\mathrm{TE}_{i t}=\exp \left(-g\left(W_{i t}\right)\right)
$$

For illustration purpose, a parametric model in (2.7) is introduced by assuming each coefficient function is a linear function of an environment variable. The coefficient functions are $\beta_{L}\left(\right.$ Number $\left._{i t}\right)=c_{1}+a_{1} *$ $\operatorname{Number}_{i t}, \beta_{K}\left(\mathrm{Age}_{i t}\right)=c_{2}+a_{2} * \mathrm{Age}_{i t}, \beta_{F}\left(\right.$ Number $\left._{i t}\right)=c_{3}+a_{3} *$ Number $_{i t}$, and $-g\left(\mathrm{~W}_{i t}\right)=c_{4}+a_{4} * \mathrm{~W}_{i t}$.

$\ln \mathrm{Y}_{i t}=\alpha_{i}+c_{1} \ln \mathrm{L}_{i t}+c_{2} \ln \mathrm{K}_{i t}+c_{3} \ln \mathrm{F}_{i t}+c_{4}+a_{1}$ Number $_{i t} \ln \mathrm{L}_{i t}+a_{2} \mathrm{Age}_{i t} \ln \mathrm{K}_{i t}+a_{3}$ Number $_{i t} \ln \mathrm{F}_{i t}+a_{4} \mathrm{~W}_{i t}+e_{i t}$

\subsubsection{Data}

The total observation is 180, which includes 36 coal-burning power plants from 2001 to 2005 . The data is obtained from the Energy Information Administration (EIA), the Federal Energy Regulatory Commission (FERC), and the EPA. Since data are reported at different levels (boiler-level, generator-level, and plantlevel) from the above sources, it is aggregated to plant level for consistency. Summary statistics are reported in Table 2.3 . 
The output is measured as the annual net generation of electricity (MWh) in each power plant. The data is obtained from EIA form 767, which collects power plant operating data, such as electricity generation at generator-level and fuel consumption at boiler-level. The yearly plant-level data is obtained by summing up monthly data and then aggregating to plant level.

The generating capacity (MW) is introduced as a measurement of capital (Hampf and Rødseth (2015)). The data is collected from EIA form 860 which reports generator-level data. The plant-level generating capacity is obtained by aggregating generator-level data from generators that use coal as primary energy source $^{9}$. Since not all the generators in a power plant are included, data on labor and fuel should also

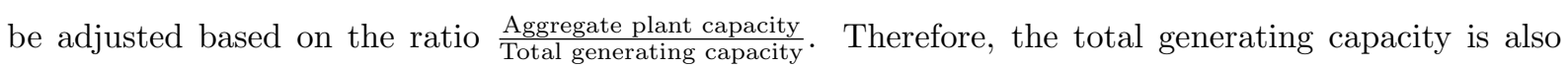
collected.

The average number of employees in each plant is used as the measurement of labor. The data is obtained from FERC Form 1, which collects data on the financial and operating status of electric utilities. Since Form 1 reports the total number of employees, the plant-level data is adjusted based on generating capacity using the formula Average Number of Employees $=$ Average number of employees ${ }_{F o r m 1} \times$ $\frac{\text { Aggregate plant capacity }}{\text { Total generating capacity }}$

The measurement of Fuel is the annual heat content (MMBtu) from coal, which is collected from EIA form 767. Coal combustion heats pressured water to steam, which passes through the turbine and spins the generator. The heat content is an indicator of the total amount of coal being used for electricity generation.

The average age of generators and the total number of generators are obtained from EIA form 860 . Only generators that use coal as a primary fuel are counted. The determinant of inefficiency is measured as the total operation and maintenance costs on sulfur removal units FGD which is obtained from EIA 767. A list of power plants that are covered under the Acid Rain Program is obtained from the EPA Air Markets Program Data (AMPD).

\subsection{Results}

The estimation results of the semiparametric stochastic frontier model (2.5) are reported in Table 2.4, which includes the 25th, 50th, and 75 th percentiles of the parameter estimates. The parametric estimates are in Table 2.5. The coefficient functions $\beta_{L}\left(\right.$ Number $\left._{i t}\right), \beta_{K}\left(\mathrm{Age}_{i t}\right)$, and $\beta_{F}\left(\mathrm{Number}_{i t}\right)$ are plotted against the smoothing variables in Figure 2.1. For comparison purpose, a plot of parametric coefficient function is also included in each panel in Figure 2.1. Overall, the parametric coefficient functions

\footnotetext{
${ }^{9}$ In this paper, the discussion focuses on the coal-burning power plant; therefore, the generating capacity only accounts for generators use coal as the primary energy source.
} 
fall out of the confidence intervals of the semiparametric alternatives, which indicates potential model misspecification in the linear coefficient functions.

In Figure 2.1, the marginal product of labor is negatively related to the total number of generators in a power plant. This may be attributed to reduced capital utilization in large power plants. Although the operation of a power plant is complex, but it works automatically to some degree. The plant operators are mainly responsible for monitoring and adjusting the operation process (Bushnell and Wolfram (2009)). When available generators are not fully operated, the marginal return on the operator is relatively low.

The plot of marginal return on capital $\beta_{K}\left(\mathrm{Age}_{i t}\right)$ has an inverse $\mathrm{U}$ shape. The age of generators has a positive impact on the marginal product of capital when generators are new. It is explained by the learning-by-doing and improved capital utilization. This improvement is also observed in Korean electricity generating units (Heshmati et al. (2014)). When the operation reaches 30 years, the wear and tear decrease marginal return on capital. It is also noticed that the parametric coefficient function does not offer useful information since the plot of parametric estimates is below zero.

The plot of coefficient function of fuel is relatively flat. However, the estimates of $\check{\beta}_{F}\left(\mathrm{Number}_{i t}\right)$ in Table 2.4 increase with number of generators. Comparing the parametric and semiparametric model, the parametric model underestimates the influence of total number of generators on the marginal return of fuel. Large power plants tend to have better coal utilization.

Combining the information in Table 2.4, Figure 2.1, and the calculated technical efficiency score in Figure 2.2, the influence of the Acid Rain Program on efficiency is revealed. In Table 2.4, the average conditional mean of inefficiency is -0.2667 , which indicates that net electricity generation is reduced by $23.4 \%\left(\left(1-e^{-0.2667}\right) \times 100 \%\right)$ on average. It reduces net electricity generation by $1,141,645 \mathrm{MWh}$, if considering the average electricity generation $(4,876,801 \mathrm{MWh})$. In Figure 2.2, the technical efficiency changes with operation and maintenance costs of FGD nonlinearly. The efficiency score ranges from 0.65 to 0.9 . When the costs $W_{i t}$ is below 20 (thousand dollars), the technical efficiency decreases with increasing FGD costs. The efficiency has an upward trend when the cost on FGD units is between 20 and 60 . When the cost on FGD is higher than 80, the efficiency stays around 0.775.

Since a large power plant tends to generate more $\mathrm{SO}_{2}$ than the small ones because it burns more coal and generates more electricity. To control for this size effect, the unit FGD cost is calculated as $W_{i t} / K_{i t}$ which is based on the generating capacity of a power plant. In Figure 2.3, the technical efficiency is plotted against the unit cost of FGD. When the unit FGD cost is relatively low (below 4 US dollars/MW), higher technical efficiency is associated with lower emission removal costs. Also, only high-efficient plants ${ }^{10}$

\footnotetext{
${ }^{10}$ For comparison purpose and ease of notation, the power plants are categorized into two groups which are high-efficient and low-efficient ones. The threshold is based on the average conditional mean of inefficiency $\left(T E_{i t}=\exp (-0.2667)=0.76\right)$. A power plant has an efficiency score higher than 0.76 is high-efficient ones in this paper.
} 
are observed in this range. However, when unit cost is in the range from $4 \$ / \mathrm{MW}$ to $10 \$ / \mathrm{MW}$, both higher-efficient and low-efficient plants present. It reveals that low-efficient power plants benefit more from the Acid Rain Program. Assuming a hypothetical situation where the Acid Rain Program was not established, the only emission control method is FGD technology. The technical efficiency would be negatively related to the unit cost on FGD. This reason is that higher costs on FGD units indicates inefficient utilization of coal and lower net electricity generation. However, in Figure 2.3 plants which have unit FGD cost ranging from $4 \$ / \mathrm{MW}$ to $10 \$ / \mathrm{MW}$ tend to have higher efficiency score (above 0.76). It should be noticed that power plants rely on FGD units to remove most of $\mathrm{SO}_{2}$ emission at the beginning. To further reduce emission, a power plant then faces choices between purchasing permits and relying more heavily on FGD technology. There are 41 observations in the sample which have higher efficiency score and their unit FGD costs are beyond $4 \$$ MW. It can be explained by a firm's decision on purchasing extra permits after comparing the marginal costs of permits and adjustment on FGD units.

\subsection{Conclusion}

$\mathrm{SO}_{2}$ has drawn people's attention because of health and environmental concern. As the most significant sources of $\mathrm{SO}_{2}$ pollution, the coal-burning power plants have been the target of the Acid Rain Program which is established under Title IV of the 1990 Clean Air Act. As a cost-effective environmental program, the Acid Rain Program effectively reduces ambient $\mathrm{SO}_{2}$ level and allows power plants to choose their emission control technology with the lowest costs. The emission abatement methods include switching to low-sulfur coal, purchasing emission permits, and implementing FGD technology. This paper serves to evaluate the technical efficiency change in a power plant which is covered by the Acid Rain Program.

Besides, it is observed that power plants characteristics potentially affect the marginal return on labor, capital, and fuel. Therefore, a stochastic production frontier model with varying coefficient is introduced to capture the impact of operating conditions on the marginal product of inputs. To avoid model misspecification, the functional form assumptions on the coefficient function are relaxed. The estimation result reveals that the operational conditions change the marginal return on labor and capital. To improve the marginal productivity of labor, it requires better utilization of capital in large power plants. Also, a plant reaches the highest marginal return on physical capital when the generator works for approximate 30 years. When a generator gets older, the wear and tear drive down its efficiency.

The existence and magnitude of production inefficiency are evaluated by the inefficiency term in the stochastic production frontier. Since inefficiency in the model can depend on the environment variables, it captures the influence of environmental program on technical inefficiency. In this paper, the operation 
and maintenance costs on FGD units is considered as the determinant of inefficiency. Sulfur removal using FGD units consumes electricity and reduces the net electricity generation, which increases the gap between actual production and the efficient level. In contrast, purchasing permits to offset excess $\mathrm{SO}_{2}$ emission keeps efficiency unaffected. A power plant makes decision based on the marginal cost of each approach. The empirical results indicate that the Acid Rain Program improves technical efficiency for power plants with unit FGD cost ranging from $4 \$ / \mathrm{MW}$ to $10 \$ / \mathrm{MW}$. 
Table 2.1: The AMSE of two-step estimator in the stochastic production frontier

\begin{tabular}{llll}
\hline $\mathrm{t}=3$ & \multicolumn{3}{c}{ AMSE } \\
\hline \hline & $\hat{\beta}_{1}\left(z_{1, i t}\right)$ & $\hat{\beta}_{2}\left(z_{2, i t}\right)$ & $-\hat{g}\left(z_{3, i t}\right)$ \\
$\mathrm{n}=50$ & 0.1865 & 0.1783 & 0.3930 \\
$\mathrm{n}=100$ & 0.0954 & 0.0971 & 0.3302 \\
$\mathrm{n}=200$ & 0.0616 & 0.0553 & 0.2944 \\
\hline & $\check{\beta}_{1}\left(z_{1, i t}\right)$ & $\check{\beta}_{2}\left(z_{2, i t}\right)$ & $-\check{g}\left(z_{3, i t}\right)$ \\
$\mathrm{n}=50$ & 0.0428 & 0.0453 & 0.2726 \\
$\mathrm{n}=100$ & 0.0248 & 0.0255 & 0.2537 \\
$\mathrm{n}=200$ & 0.0149 & 0.0136 & 0.2494 \\
\hline
\end{tabular}


Table 2.2: Estimation results of the two-step estimator in the stochastic production frontier

\begin{tabular}{lllll}
\hline & $\mathrm{Q}(25 \%)$ & Median & $\mathrm{Q}(75 \%)$ & Mean \\
\hline$\beta_{1}\left(z_{1, i t}\right)$ & $1.4256^{* * *}$ & $1.6257^{* * *}$ & $1.9241^{* * *}$ & $1.6374^{* * *}$ \\
& $(0.1124)$ & $(0.1316)$ & $(0.1645)$ & $(0.2029)$ \\
$\beta_{2}\left(z_{2, i t}\right)$ & $1.7258^{* * *}$ & $1.9513^{* * *}$ & $2.4909^{* * *}$ & $2.1004^{* * *}$ \\
& $(0.0941)$ & $(0.2139)$ & $(0.1680)$ & $(0.1799)$ \\
$-g\left(z_{3, i t}\right)$ & $-1.6214^{* * *}$ & $-1.2924^{* * *}$ & $-1.2099^{* * *}$ & $-1.4220^{* * *}$ \\
& $(0.1288)$ & $(0.1018)$ & $(0.0962)$ & $(0.1755)$ \\
\hline
\end{tabular}

$* * *, * *, *$ represent the significant level at the $1 \%, 5 \%$, and $10 \%$ respectively. 
Table 2.3: Summary statistics

\begin{tabular}{llllll}
\hline Variable & Def. & Mean & Std Dev & Min & Max \\
\hline $\ln \mathrm{Y}_{i t}$ & Log of Net Electricity Generation (MWh) & 15.40 & 0.81 & 13.34 & 16.93 \\
$\ln \mathrm{L}_{i t}$ & Log of Average Number of Employees & 4.83 & 0.76 & 2.40 & 6.33 \\
$\ln \mathrm{K}_{i t}$ & Log of Nameplate Capacity (MW) & 6.70 & 0.80 & 4.75 & 8.11 \\
$\ln \mathrm{F}_{i t}$ & Log of Heat Content of Coal (MMBtu) & 12.58 & 0.63 & 11.00 & 13.85 \\
$\mathrm{Age}_{i t}$ & 31 & 10 & 12 & 53 \\
Number $_{i t}$ & Average Age of Generators & 2.7 & 1.4 & 1 & 7 \\
$\mathrm{~W}_{i t}$ & Total Number of Generators & 6.61 & 11.88 & 0 & 106.31 \\
\hline Number of observations & O\&M Costs on FGD Units (thousand dollars) & \multicolumn{5}{c}{} \\
\hline
\end{tabular}


Table 2.4: Estimation of the semiparametric model with varying coefficient

\begin{tabular}{lllll}
\hline & $\mathrm{Q}(25 \%)$ & Median & $\mathrm{Q}(75 \%)$ & Mean \\
\hline$\check{\beta_{L}}\left(\mathrm{Number}_{i t}\right)$ & 0.1415 & 0.2628 & 0.2628 & 0.2213 \\
& $(0.1018)$ & $(0.5113)$ & $(0.5113)$ & $(0.4242)$ \\
$\check{\beta_{K}}\left(\mathrm{Age}_{i t}\right)$ & 0.0508 & $0.0875^{*}$ & $0.0955^{* *}$ & 0.0669 \\
$\check{\beta_{F}}\left(\right.$ Number $\left._{i t}\right)$ & $(0.0606)$ & $(0.0492)$ & $(0.0426)$ & $(0.0580)$ \\
& $1.1076^{* * *}$ & $1.1076^{* * *}$ & $1.1336^{* * *}$ & $1.1162^{* * *}$ \\
$-\check{g}\left(\mathrm{~W}_{i t}\right)$ & $(0.1888)$ & $(0.1888)$ & $(0.0553)$ & $(0.1633)$ \\
& $(0.1646)$ & -0.2469 & -0.2297 & $-0.2667^{*}$ \\
\hline$* * * * * * *$ & $(0.1590)$ & $(0.1591)$ & $(0.1610)$ \\
\hline
\end{tabular}


Table 2.5: Estimation of the parametric model with linear coefficient functions

\begin{tabular}{ll}
\hline & Estimates \\
\hline $\ln \mathrm{L}$ & -0.0638 \\
& $(10.2051)$ \\
Number $_{i t} \ln \mathrm{L}_{i t}$ & 0.0145 \\
& $(3.0452)$ \\
& -0.3386 \\
$\ln \mathrm{K}_{i t}$ & $(55.3382)$ \\
& 0.0024 \\
Age $_{i t} \ln \mathrm{K}_{i t}$ & $(0.1155)$ \\
& 0.2996 \\
$\ln \mathrm{F}_{i t}$ & $(10.4417)$ \\
& -0.0008 \\
Number $_{i t} \ln \mathrm{F}_{i t}$ & $(1.3117)$ \\
& 0.0004 \\
$\mathrm{~W}_{i t}$ & $(0.1581)$ \\
& ******* represent the significant level at the $1 \%, 5 \%$, and $10 \%$ respectively.
\end{tabular}



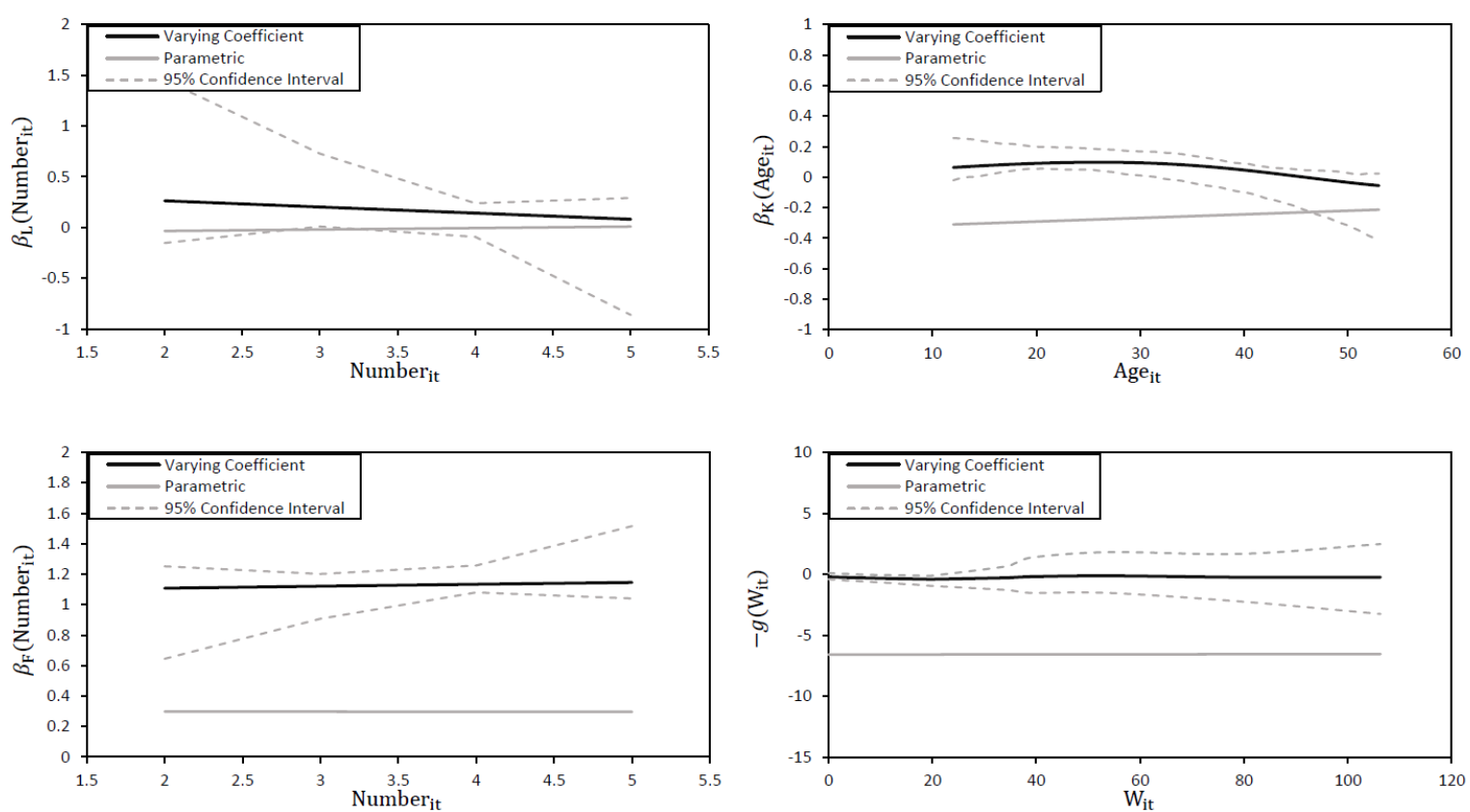

Figure 2.1: Plots of estimated $\beta_{L}\left(\right.$ Number $\left._{i t}\right), \beta_{K}\left(\mathrm{Age}_{i t}\right), \beta_{F}\left(\mathrm{Number}_{i t}\right)$, and $-g\left(W_{i t}\right)$ against environment variables 


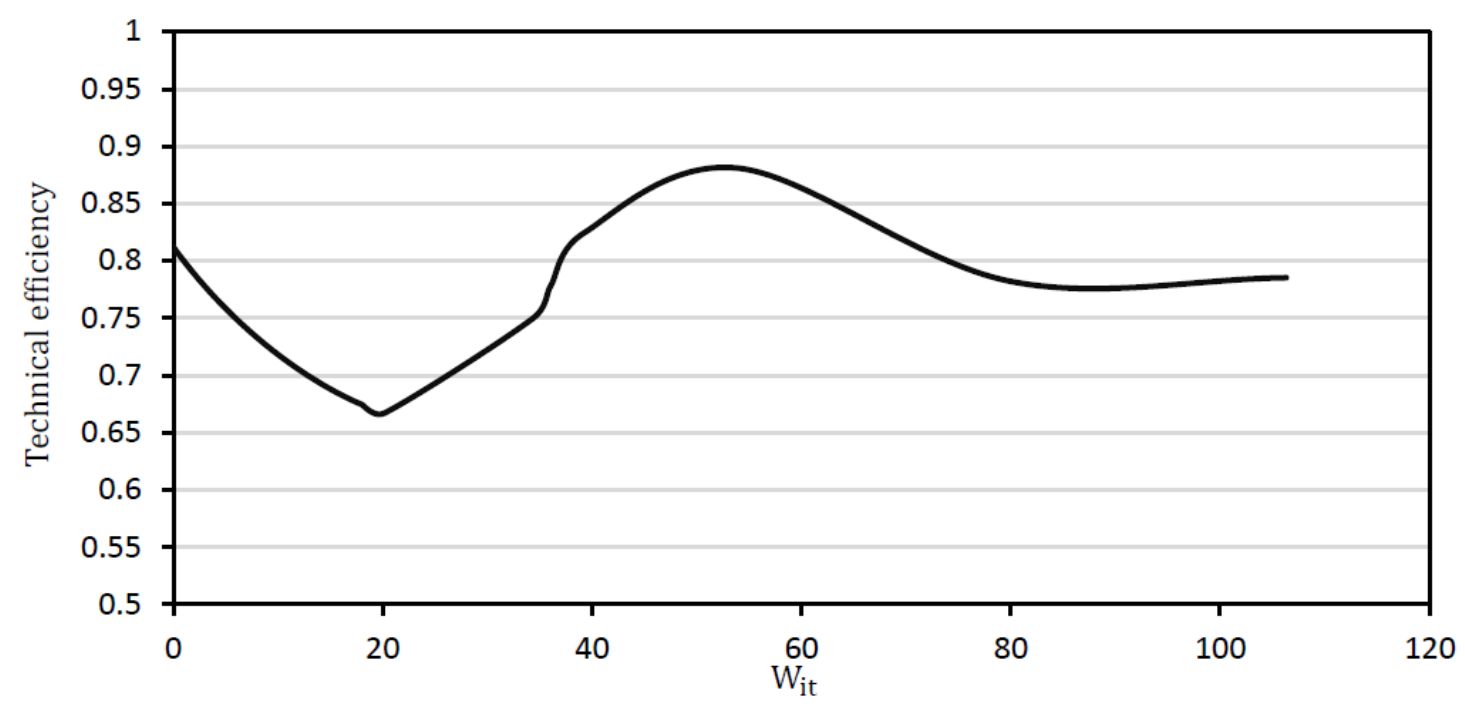

Figure 2.2: Plot of technical efficiency score $\mathrm{TE}_{i t}$ against $W_{i t}$ 


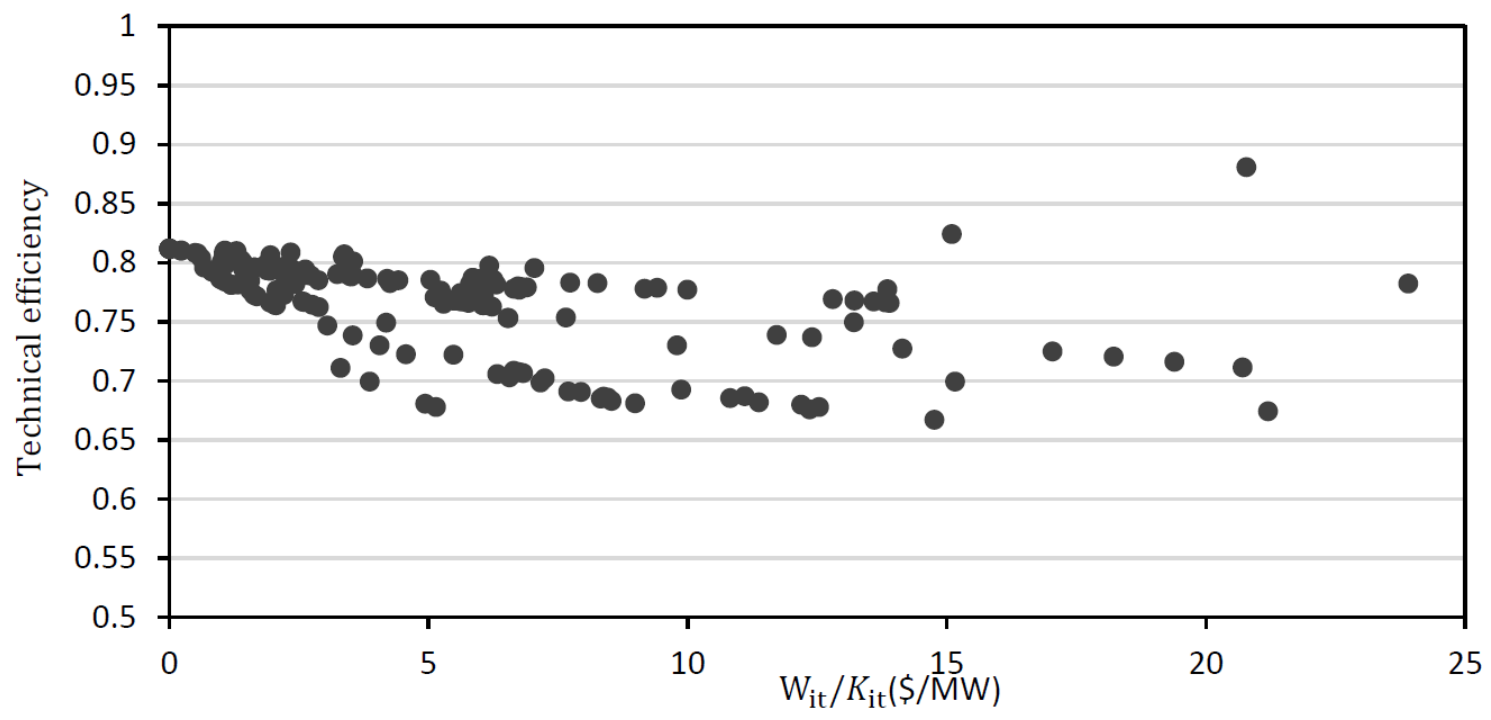

Figure 2.3: Plot of technical efficiency $\mathrm{TE}_{i t}$ against $W_{i t} / K_{i t}$ 


\section{Chapter 3}

\section{Production Efficiency of Chinese Urban Water Utilities}

\subsection{Introduction}

Water shortage has been a severe issue in China which results from the geographically uneven distribution of water resource, fast economic growth, and increasing population due to urbanization (Jiang (2009)). China has 21 percent of the world population, but its freshwater supply is only 6 percent of the world total (World Bank (2018)). A series of actions have been taken by the government to alleviate water shortage, such as the South-North Water Transfer Project, the water resources planning, legislation enforcement, and administration coherence (Ministry of Water Resources (2014)). Identifying factors that decrease water delivery efficiency offers policymaker valuable information to allocate financial resources and time to ease the water crisis.

The inefficiency in this paper refers to technical inefficiency which captures the shortfall of delivered water from the optimal quantity given the same labor, capital, and natural resource inputs. Literature in water utility analysis reveals that efficiency is affected by several structural features of a water utility, such as public versus private ownership, economies of scale, economies of scope, and regulation (Abbott and Cohen (2009); Aubert and Reynaud (2005); Carvalho and Marques (2014)). Also, recent research reveals that the operational environment in the water sector has a significant impact on technical efficiency, such as the influence of customer density, water source, water quality, peak factor, water pressure, etc. (Carvalho and Marques (2011); Li and Phillips (2017)). Besides, Li and Phillips (2017) identify the internal staff ratio in the Chinese water utilities which measures the percentage of employees in the Bianzhi list (loosely translated as "establishment of posts") in a utility. It essentially measures the impact of institutional condition on efficiency in a water utility. An employee in the establishment list benefits from this position in terms of salaries, pensions, insurance, and opportunities for promotion. 
The established post drives an employee's incentive to work. All the mentioned structural, institutional, and operational factors are also identified as environmental variables in the empirical analysis since they change output level but are not traditional inputs.

The common empirical approaches of efficiency analysis include data envelopment analysis (DEA), order-m probabilistic approach, and stochastic frontier analysis (Aubert and Reynaud (2005), Byrnes et al. (2010), Filippini et al. (2008), Zschille and Walter (2012), and Carvalho and Marques (2011)) ${ }^{1}$. Among these empirical methods, the stochastic production frontier is proposed in this paper, since it accounts for production shocks and allows for more flexible model setup, which separates production inefficiency from random noise ${ }^{2}$. The model also offers information on the partial impact of the environment variables on output.

The existing literature has examined the impact of environment variables on technical efficiency from different aspects in the Chinese water sector. However, the influence of environment variables on the marginal return of inputs is not touched before. For instance, Li and Phillips (2017) reveals the impact of institutional and operational condition on efficiency. Among the environment variables proposed by Li and Phillips (2017), the outsourcing ratio (conversely, the internal staff ratio) ${ }^{3}$ is of interest. Although the internal staffs benefit from the established posts which potentially drive their incentives to work, previous research realizes that the internal staff ratio has no significant impact on efficiency. This puzzle may be revealed by controlling for its impact on marginal product of labor and capital.

In order to capture the impact of environment variables on the marginal return on inputs, the empirical model is inspired by Yao et al. (2018b). In this model, the environment variable can change technical efficiency through the efficiency term and it can also shift the output level directly via coefficient functions. Combining the impact of environment variable from above two channels, the total effects are the sum of efficiency change and direct effect. Also, the model identifies whether the change in output shifts the production function (neutral effect) or changes the shape of it (non-neutral effect). To have a comprehensive understanding of water utilities, I include four other environmental variables in Li and Phillips (2017) besides the internal staff ratio which are customer density, non-revenue water rate, non-household user rate, and average piped water pressure.

The estimation results reveal that the internal staff ratio changes the marginal return on labor nonlinearly. Overall the staff ratio is negatively related to technical inefficiency. This paper contributes to the literature in two ways. Firstly, a semiparametric stochastic production frontier model with smooth

\footnotetext{
${ }^{1}$ A summary of the methodology used for productivity and efficiency studies are listed in the Appendix of Abbott and Cohen (2009).

${ }^{2}$ The flexible model setup also refers to the smooth coefficient functions in the stochastic production frontier model that will be introduced in the following context.

${ }^{3}$ Section 2 introduces the Bianzhi system and the internal staff ratio in details.
} 
coefficient is introduced to measure the impact of environment variable on the marginal productivity of labor and capital. This analysis is not touched before in the literature of water utilities. Secondly, this paper reveals the impact of Bianzhi (establishment) system on the water utility efficiency. The empirical results support the findings in Brødsgaard (2002) that the institutional reform improves efficiency in the public sectors.

The rest of the paper is organized as follows. Section 2 introduces the institutional characteristics of Bianzhi in China which emphasis on the Bianzhi system. In section 3, the empirical model is presented and the panel dataset about water utility is discussed. The estimation results are reported in section 4. Section 5 concludes the paper. The discussion on other environment variables are summarized in Appendix.

\subsection{Background and Literature Review}

Most water utilities in China are state-owned, but there is also some private participation in the water sector (Jiang and Zheng (2014)). The primary water sources are groundwater and surface water. As of 2017, the total yearly water supply is 604.3 billion $m^{3}$ and among which 494.5 billion $m^{3}$ is from surface water and 191.7 billion $m^{3}$ comes from groundwater. Among the available water resource, agriculture water usage accounts for $62.33 \%$, industry usage is $21.13 \%$, and household is $13.87 \%$ (Ministry of Water Resources (2017)). The Ministry of Water Resource of China is the department establish related laws and standards and manages water resources. Besides the Ministry of Water Resource, the administration authorities also include the Ministry of Housing and Urban-Rural Development and the Ministry of Land and Resources, since both groundwater and surface water are involved in the water supply process.

Recent literature has evaluated Chinese water sector from different perspectives, such as the institution, administration, and water pricing system (Li and Phillips (2017) and Jiang (2009)). Since price is the primary signal to balance the supply and demand of scarce water resource, the underpricing observed in the water sector is the culprits to blame for allocation inefficiency. In the recent work of Che and Shang (2015), it reveals that the water pricing reform has increased water price in domestic and industry sectors significantly. Another concern in the water sector is a lack of coherence among the administration authorities. Li and Phillips (2017) also suggest performance-based regulation to reduce ambiguities and improve efficiency.

The common approach to evaluate the performance of a water utility is to control for the environment variables. Carvalho and Marques (2011) also state that it is crucial to consider the influence of environment variables for efficiency analysis; otherwise it leads to unreliable inferences. According to Renzetti 
and Dupont (2004), factors that change the performance of a utility can be summarized into four categories: the scale of operations (Antonioli and Filippini (2001), Bhattacharyya et al. (1995), Byrnes et al. (2010), Correia and Marques (2011), and Filippini et al. (2008)), the physical environment (Antonioli and Filippini (2001), Carvalho and Marques (2011), Marques et al. (2014), Rogers et al. (2002), Zschille and Walter (2012), and Zschille and Walter (2012)), regulations and government policies (Filippini et al. (2008) and Marques et al. (2014)), and ownership (Bhattacharyya et al. (1995), Correia and Marques (2011), Carvalho and Marques (2011), Estache and Rossi (2002), Holland (2006), Lynk (1993), Marques et al. (2014), Picazo-Tadeo et al. (2009), and Renzetti and Dupont (2004)). The results on the above environment variables are mixed, since researches are conducted in different countries, such as Italy, the U.S., Portugal, Japan, Australia, etc.

The evaluation of water sector in China follows a similar path by controlling for the institutional and operational conditions, which includes customer density, water pressure in the delivery pipes, the non-household water usage, and outsourcing ratio ( $\mathrm{Li}$ and Phillips (2017)). Among these factors, the internal staff ratio is of great interest. This staff ratio is revealed to have no significant impact on the water supply efficiency in previous literature; however, it drives a staff's incentives to work differently based on whether he/she is in Bianzhi list. There are very few studies on the influence of Bianzhi on efficiency. Bianzhi is a unique institutional characteristic in the Chinese labor market.

"A direct translation of the term Bianzhi would be "the establishment" and it usually refers to the number of established posts in a unit, office or organization... Bianzhi refers to the authorized number of personnel (the number of established posts) in a Party or government administrative organ (jiguan), a service organization (shiye danwei) or a working unit (qiye).” Brødsgaard (2002)

The Ministry of Finance directly allocates fund to the established positions every year. Therefore, an employee in the establishment ("internal staff" in Li and Phillips (2017)) signs a formal contract and receives welfare subsidies. This employee is also provided with insurance and has promotion opportunities. In contrast, the employee that is not in the establishment ("outsource staff" in Li and Phillips (2017)) signs temporary contracts (possibly renewable), receives lower salaries, and is not eligible for any benefits received by the employees in establishment. The low wages potentially drive down the incentives to work. However, higher salaries and better welfare of internal staff do not guarantee above-average labor productivity. Since employees in the establishment list are less likely being laid off even with poor performance, it reduces the effort they devote to work. To my acknowledge, no research has been down to reveal the impact of establishment (Bianzhi) on the marginal product of labor in a water utility.

The common empirical estimation method of efficiency analysis in the water sector are data envelop- 
ment analysis (DEA), order-m probability approach, and stochastic frontier. DEA is a linear programming technique that evaluates technical inefficiency, which is a popular method in empirical water efficiency analysis (Abbott and Cohen (2009)). It has the advantage of modeling multiple inputs and outputs simultaneously and without requirement on the price of inputs and outputs. However, in the efficiency analysis of Carvalho and Marques (2011), they highlight that DEA is sensitive to outliers and proposed the order-m method. The order-m nonparametric method is firstly proposed by Cazals et al. (2002) which only uses part of the sample to obtain efficiency score for water utilities. Another nonparametric or semiparametric estimation method is the stochastic frontier model (cost or production frontiers). Aubert and Reynaud (2005) use a stochastic cost frontier approach to evaluate the Wisconsin water utilities under different regulatory regimes. Similar researches are conducted on water utilities in other countries, such as Portugal, Slovenia, and Germany (Correia and Marques (2011), Filippini et al. (2008), Zschille and Walter (2012)). The technical efficiency analysis on Chinese water utilities in Li and Phillips (2017) introduce the stochastic production frontier and evaluate the impact of different exogenous variables on the technical efficiency of water utilities.

The stochastic production frontier model is firstly motivated by the seminar work of Aigner et al. (1977) and Meeusen and van Den Broeck (1977), which includes a production function of inputs and a composite error term. The two components in the composite error are random noise and inefficiency term. The stochastic frontier model is popular among practitioners because it measures the magnitude of production inefficiency and its asymptotic properties are well examined. The parametric model requires distribution assumptions on both random noise and inefficiency term which is usually assumed a normal distribution on the random error and half normal or exponential distribution on the inefficiency term (Aigner et al. (1977), Meeusen and van Den Broeck (1977)). Besides, it also specifies the functional form of production functions, such as Cobb-Douglas and translog production functions (Battese and Coelli (1995)). Recent research relaxes functional form assumptions and introduces the nonparametric model while maintaining the distribution assumption on error terms (Aigner et al. (1977)). The issues arise in the nonparametric model is the so-called "curse of dimensionality" when the dimension of variables is large. Usually, the number of variables included in the urban utility analysis is large when controlling for both the traditional inputs (labor, capital, and raw material) and the exogenous variables (regulations and operational conditions).

In order to facilitate the influence of exogenous variables on the production function and to potentially alleviate the curse of dimensionality, the frontier model with smoothing variables is introduced (Li et al. (2002)). Recent work by Yao et al. (2018b) considers a smooth coefficient model that is different from traditional ones because the conditional mean of composite error is not zero. In their semiparametric 
model, the one-side inefficiency term exhibits scaling property where the inefficiency term is represented by the product between a scaling function and a random error. The smooth coefficient functions capture the influence of environment variables on production, and in the meantime, inefficiency term measures the indirect impact of environment variable on output.

\subsection{Model}

\subsubsection{The Semiparametric Smooth Coefficient Stochastic Frontier Model}

In this section, a stochastic production frontier model is introduced to estimate the magnitude of inefficiency in the water sector. Meanwhile, the impact of internal staff ratio on the marginal product of labor is also evaluated. A related work is found in Li and Phillips (2017), in which the frontier model consists of a Cobb Douglas production function and inefficiency term that depends on some environment variable linearly. I extend their work by introducing the smooth coefficient functions to measure the impact of the establishment system on productivity. Also, to facilitate the analysis on the environment variables and inefficiency, the efficiency term is set to be a function of the environment variable. The model setup can reveal the puzzle on the internal staff ratio.

A multi-step estimation is conducted based on the method in Yao et al. (2018b) as shown in equation (3.1). The proposed model is more flexible than the purely parametric ones, since it allows the coefficient function to vary with some covariates. This setup answers the question of whether the establishment system affects marginal return on labor and measures the magnitude of the change. Meanwhile, no functional form assumption is imposed on the smooth coefficient function, which avoids potential model misspecification. It also alleviates the so-called "curse of dimensionality" by modeling the traditional inputs and environment variables separately to reduce the dimension of variables.

$$
\ln Y_{i t}=\alpha\left(z_{i t}\right)+\beta_{L T}\left(z_{i t}\right) \cdot \ln \left(L T_{i t}\right)+\beta_{L N T}\left(z_{i t}\right) \cdot \ln \left(L N T_{i t}\right)+\beta_{K}\left(z_{i t}\right) \cdot \ln \left(K_{i t}\right)+\beta_{E}\left(z_{i t}\right) \cdot \ln \left(E_{i t}\right)+\epsilon_{i t} .
$$

where the output $Y_{i t}$ is total amount of delivered water; labor is categorized into technical staff $L T_{i t}$ and non-technical staff $L N T_{i t}$; $K_{i t}$ refers to capital in water utilities and $E_{i t}$ is energy usage; $z_{i t}$ represents the environment variables; $\beta(\cdot)$ is unknown coefficient function that varies with $z_{i t}$; $\epsilon_{i t}=v_{i t}-u_{i t}$ is composite error which includes the two-sided random error $v_{i t}$ and a one-sided inefficiency term $u_{i t} . v_{i t}$ is considered to be i.i.d. and distributed normally with $N\left(0, \sigma_{v}^{2}\right)$.

The inefficiency term $u_{i t}$ captures the short fall of actual delivered water from the possible maximum volume. Let $u_{i t}=u_{i} g\left(z_{i t} ; \eta\right)$ which exhibits "scaling" property (Wang and Schmidt (2002)). $u_{i} \sim$ 
$I I D\left|N\left(0, \sigma_{u}^{2}\right)\right|$ and the scaling function $g\left(z_{i t} ; \eta\right)=e^{\eta z_{i t}}$ is known up to parameter $\eta$. Define the conditional density of $\epsilon_{i t}$ to be $h\left(\epsilon_{i t} \mid z_{i t}, \theta_{0}\right)$, where the true parameter $\theta_{0}=\left(\sigma_{u}^{2}, \sigma_{v}^{2}, \eta\right)^{\prime}$. Denote the conditional mean and variance of composite error $\epsilon_{i t}$ as $E\left(\epsilon_{i t} \mid z_{i t}\right)=-\mu\left(z_{i t} ; \theta_{0}\right)=\sqrt{\frac{2}{\pi}} \sigma_{u} g\left(z_{i t} ; \eta\right)$ and $V\left(\epsilon_{i t} \mid z_{i t}\right)=$ $\sigma^{2}\left(z_{i t} ; \theta_{0}\right)=\sigma_{v}^{2}+\frac{\pi-2}{\pi} \sigma_{u}^{2} g^{2}\left(z_{i t} ; \eta\right)$. Equation (3.1) can be written in (3.2).

$\ln Y_{i t}=\alpha\left(z_{i t}\right)+\beta_{L T}\left(z_{i t}\right) \cdot \ln \left(L T_{i t}\right)+\beta_{L N T}\left(z_{i t}\right) \cdot \ln \left(L N T_{i t}\right)+\beta_{K}\left(z_{i t}\right) \cdot \ln \left(K_{i t}\right)+\beta_{E}\left(z_{i t}\right) \cdot \ln \left(E_{i t}\right)+v_{i t}-u_{i} e^{\eta z_{i t}}$.

The environment variables $z_{i t}$ measures the institutional and operational condition. This paper focuses on the internal staff ratio, but also evaluates other physical environment, such as customer density, nonrevenue water rate, non-household user rate, and average piped water pressure as in Li and Phillips (2017). Previous research conducted by Estache and Rossi (2002) reveals that the impact of public and private ownership on water companies is not significant in Asia countries, the measurement of ownership is not considered in the discussion.

The presence of inefficiency term in the composite error makes $E\left[\epsilon_{i t} \mid z_{i t}\right] \neq 0$, therefore the local least squares method on semiparametric smooth coefficient model in Li et al. (2002) is not feasible. The multi-step estimation method in Yao et al. (2018b) is proposed to estimate the coefficient functions and the conditional mean of inefficiency. The estimation procedure is briefly introduced in this section and the detailed discussion can be found in Yao et al. (2018b).

Let's denote $X_{i t}=\left(\ln \left(L T_{i t}\right), \ln \left(L N T_{i t}\right), \ln \left(K_{i t}\right), \ln \left(E_{i t}\right)\right)^{\prime}$ and $\beta\left(z_{i t}\right)=\left(\beta_{L T}\left(z_{i t}\right), \beta_{L N T}\left(z_{i t}\right), \beta_{K}\left(z_{i t}\right), \beta_{E}\left(z_{i t}\right)\right)$ to simplify notations. Since zero conditional mean of composite error is not satisfied, the first step is to obtain a model in which the error term has zero conditional mean. Firstly, a local linear approximation is performed on equation (3.2). The conditional mean of equation (3.2) is then subtracted from equation (3.2) which gives equation (3.3). The local linear estimators are denoted as $\hat{E}\left(\ln \left(Y_{i t}\right) \mid z_{i t}\right)$ and $\left.\hat{E}\left(X_{i t} \mid z_{i t}\right)\right)$.

$$
\ln \left(Y_{i t}\right)-E\left(\ln \left(Y_{i t}\right) \mid z_{i t}\right)=\left(X_{i t}-E\left(X_{i t} \mid z_{i t}\right)\right)^{\prime} \beta\left(z_{i t}\right)+\mu\left(z_{i t} ; \theta_{0}\right)+\epsilon_{i t}
$$

Let $\tilde{\epsilon}_{i t}=\epsilon_{i t}+\mu\left(z_{i t}\right)$ which shows $E\left(\tilde{\epsilon}_{i t} \mid X_{i t}, z_{i t}\right)=0$. Denote $\tilde{Y}_{i t}=\ln \left(Y_{i t}\right)-E\left(\ln \left(Y_{i t}\right) \mid z_{i t}\right)$ and $\tilde{X}_{i t}=\left(X_{i t}-E\left(X_{i t} \mid z_{i t}\right)\right)$. Equation (3.3) is transformed into equation (3.4), which can be estimated via local linear estimation. Let $\hat{b}_{0}=\hat{\beta}\left(z_{i t}\right), \hat{b}=\left(\hat{b}_{0}^{\prime}, \hat{b}_{1}^{\prime}\right)^{\prime}$, and $\tilde{W}_{i t}=\left(\tilde{X}_{i t}^{\prime},\left(\tilde{X}_{i t} \otimes\left(z_{i t}-z\right)\right)^{\prime}\right)^{\prime}$. The coefficient estimates in equation (3.4) are included in equation (3.5).

$$
\tilde{Y}_{i t}=\tilde{X}_{i t} \beta\left(z_{i t}\right)+\tilde{\epsilon}_{i t}
$$




$$
\hat{b}=\underset{b}{\operatorname{argmin}} \sum_{i=1}^{n} \sum_{t=1}^{T}\left(\tilde{Y}_{i t}-\tilde{W}_{i t} b\right)^{2} K\left(\frac{z_{i t}-z}{h}\right)
$$

Once $\hat{\beta}\left(z_{i t}\right)$ is estimated, it can be used to construct $\hat{\epsilon}_{i t}=\tilde{Y}_{i t}-\tilde{X}_{i t} \hat{\beta}\left(z_{i t}\right)-\mu\left(z_{i t} ; \theta\right)$ in which $-\mu\left(z_{i t} ; \theta\right)$ is a known function up to parameter $\theta$. Since the conditional density of $\epsilon_{i t}$ is $h\left(\epsilon_{i t} \mid z_{i t}, \theta_{0}\right)$ which is a known function up to parameter $\theta_{0}$, the parameter $\hat{\theta}$ can be estimated through pseudo-likelihood estimation method in equation $(3.6)^{4}$.

$$
\hat{\theta}=\underset{\theta}{\operatorname{argmax}} \ln \prod_{i=1}^{n} h\left(\hat{\epsilon}_{i}(\theta) ; z_{i}, \theta\right)
$$

The second step estimation is based on equation (3.7). Since $\hat{\theta}$ is estimated in equation $(3.6), \hat{\mu}\left(z_{i t}\right)$ is obtained. Let $\delta(z)=(\alpha(z), \beta(z))^{\prime}$. The estimates of coefficient function $\check{\theta}$ is estimated via local linear estimation. Therefore, the estimates of $\beta_{L T}\left(z_{i t}\right), \beta_{L N T}\left(z_{i t}\right), \beta_{K}\left(z_{i t}\right), \beta_{E}\left(z_{i t}\right)$, and $\alpha\left(z_{i t}\right)$ are obtained.

$$
\ln \left(Y_{i t}\right)+\mu\left(z_{i t} ; \theta\right)=\left(1, X_{i t}^{\prime}\right) \delta_{i t}+\tilde{\epsilon}_{i t}
$$

Since the last step of the estimation performs a local linear approximation on the coefficient functions, both the coefficients and their first-order derivatives are obtained, which can be used to analyze the marginal impact of the environment variable on output. In equation (3.2), environment variable can change the frontier directly through the $\alpha\left(z_{i t}\right)$ term and coefficient functions $\beta\left(z_{i t}\right)$, and it can also affect the actual water delivery via inefficiency term in $\epsilon_{i t}$. Followed Yao et al. (2018b), the direct effect is calculated from $\partial \alpha\left(z_{i t}\right) / \partial z_{i t}+\left\{\partial \beta_{L T}\left(z_{i t}\right) / \partial z_{i t}\right\} \ln \left(L T_{i t}\right)+\left\{\partial \beta_{L N T}\left(z_{i t}\right) / \partial z_{i t}\right\} \ln \left(L N T_{i t}\right)+$ $\left\{\partial \beta_{K}\left(z_{i t}\right) / \partial z_{i t}\right\} \ln \left(K_{i t}\right)+\left\{\partial \beta_{E}\left(z_{i t}\right) / \partial z_{i t}\right\} \ln \left(E_{i t}\right)$. The direct effect of $z_{i t}$ can be further decomposed in to neutral and nonneutral parts. It implies that the internal staff ratio can change the frontier neutrally through $\alpha\left(z_{i t}\right)$ by keeping inputs unaffected, and the neutral effect is captured by $\partial \alpha\left(z_{i t}\right) / \partial z_{i t}$. In contrast, the internal staff ratio can change the shape of the frontier through coefficient functions which is called nonneutral effect. It is calculated by $\left\{\partial \beta_{L T}\left(z_{i t}\right) / \partial z_{i t}\right\} \ln \left(L T_{i t}\right)+\left\{\partial \beta_{L N T}\left(z_{i t}\right) / \partial z_{i t}\right\} \ln \left(L N T_{i t}\right)+$ $\left\{\partial \beta_{K}\left(z_{i t}\right) / \partial z_{i t}\right\} \ln \left(K_{i t}\right)+\left\{\partial \beta_{E}\left(z_{i t}\right) / \partial z_{i t}\right\} \ln \left(E_{i t}\right)$. The efficiency changes brought by $z_{i t}$ is $\partial T E / \partial z_{i t}=$ $\partial \exp \left(-u e^{\eta z_{i t}}\right) / \partial z_{i t}$. When the sign of $\partial T E / \partial z_{i t}$ is positive, it indicates that technical inefficiency increases with $z_{i t}$. In contrast, a negative number means $z_{i t}$ reduces inefficiency level or improves production efficiency.

\footnotetext{
${ }^{4}$ The log-likelihood function is

$\ln \prod_{i=1}^{n} h\left(\hat{\epsilon}_{i}(\theta) ; z_{i}, \theta\right)=C-\frac{n(T-1)}{2} \ln \sigma_{v}^{2}-\frac{1}{2} \sum_{i=1}^{n} \ln \left(\sigma_{v}^{2}+\sigma_{u}^{2} \sum_{i=1}^{T} g^{2}\left(z_{i t} ; \eta\right)\right)+\sum_{i=1}^{n} \ln \left[1-\Phi\left(-\frac{\mu_{* i}}{\sigma_{* i}}\right)\right]+\frac{1}{2} \sum_{i=1}^{n}\left(\frac{\mu_{* i}}{\sigma_{* i}}\right)^{2}-\frac{\sum_{i=1}^{n} \sum_{t=1}^{T} \hat{\epsilon}_{i t}^{2}(\theta)}{2 \sigma_{v}^{2}}$
} 


\subsubsection{Data}

The data is obtained from Li and Phillips (2017) which manually collected data from the Chinese Yearbook of Urban Water Supply from 2009 to 2013. Because of missing data issue in the original dataset, the unbalanced panel data used in this paper contains 56 water utilities which leads to 136 total observation. The dataset covers all the variables in equation (3.2), which are one output, four inputs, and five environment variables. Output $Y_{i t}$ is measured as total delivered water volume in a year $(10,000$ $\left.m^{3}\right) . L T_{i t}$ is the total number of technical staff and the non-technical staff in a utility is obtained by subtracting the total number of employees from the number of technical staffs. Capital is essential in a water utility since the size of the infrastructure determines the volume of delivered water. Different measurements of capital are proposed in the literature, which include network length, stocking capacity, pumping capacity, and the ratio of net base rate to the price of capital (Aubert and Reynaud (2005)). In the work of Aubert and Reynaud (2005), it reveals that the estimation results are similar either using the physical characteristics or the operational assets as the measurement of capital. Therefore, capital is measured by the length of pipe $(1,000 \mathrm{~m})$ in this paper. The energy use in a water utility is proxied by electricity usage $(100,000 \mathrm{kwh})$. The urban water utilities treat the raw water in the following steps that consume electricity, pre-chlorination, coagulation and flocculation, sedimentation, and filtration. Usually, before water is delivered to customers, it is pressurized to improve delivery efficiency. Thus, electricity is crucial to the treatment process and it is considered as one of the inputs.

The environment variable of interest, the staff ratio $\left(\mathrm{Staff}_{i t}\right)$, is obtained by dividing the number of internal staff from the total number of employees. It is introduced to evaluate the impact of the establishment (Bianzhi) system on marginal product of labor and the technical efficiency. Customer density $\left(\right.$ Cusden $\left._{i t}\right)$ accounts for the economies of density as in Antonioli and Filippini (2001) and Li and Phillips (2017), which is the number of customers per unit length of a pipe. The non-revenue water $\left(\right.$ Nonrevr $\left._{i t}\right)$ calculates the percentage of non-billed water over total delivered water volume. Nonhousehold water usage rate $\left(\mathrm{Nonhhdr}_{i t}\right)$ affects delivery efficiency since the water usage in different sectors varies substantially. As of 2014, water usage of household is approximately $12.6 \%$, industry is $22.2 \%$, agriculture is $63.5 \%$ among total water usage (Ministry of Water Resources (2014)). The observed average non-house hold rate is slightly lower than the country's average. The last variable is the average water pressure in a pipe $\left(1\right.$ million pa) $\left(\right.$ Pressure $\left._{i t}\right)$. Table 3.1 reports the summary statistics. 


\subsection{Results}

The estimation results of the frontier model with emphasis on the internal staff ratio are reported in this section. The discussion on other operational environment variables is included in Appendix.

Table 3.2 reports estimation results of Equation (3.2) with all the $z_{i t}$ being the internal staff ratio $\left(\operatorname{Staff}_{i t}\right)$. It includes the $25 \mathrm{th}, 50 \mathrm{th}$, and 75 th percentiles of the coefficient functions $\hat{\alpha}\left(\operatorname{Staff}_{i t}\right)$, $\hat{\beta}_{L T}\left(\operatorname{Staff}_{i t}\right), \hat{\beta}_{L N T}\left(\operatorname{Staff}_{i t}\right), \hat{\beta}_{K}\left(\operatorname{Staff}_{i t}\right)$, and $\hat{\beta}_{E}\left(\operatorname{Staff}_{i t}\right)$. The estimated parameters are ${ }^{5} \hat{\theta}=\left({\hat{\sigma_{u}}}^{2},{\hat{\sigma_{v}}}^{2}, \hat{\eta}\right)^{\prime}=$ $\left(1.00^{* * *}, 1.00^{* * *}, 0.7956^{* * *}\right)^{\prime}$. As observed in Table 3.2, all the estimates have positive sign which is similar as the results in Li and Phillips (2017). It is also noticed that the marginal product of the non-technical staff $\beta_{L N T}\left(\right.$ Staff $\left._{i t}\right)$ is not significant. Li and Phillips (2017) highlight that it results from overstaffing.

The plots of coefficient functions with $95 \%$ confidence bound are included in Figure 3.1, in which all the coefficient plots exhibit nonlinearity. The upper left panel presents direct effect of the internal staff ratio $\alpha\left(\operatorname{Staff}_{i t}\right)$ which changes the production function neutrally. Overall, a water utility with more employees in establishment (Bianzhi) list, it has higher level of ${ }^{6} \alpha\left(\operatorname{Staff}_{i t}\right)$. The upper right panel shows the shape of coefficient function $\beta_{L T}\left(\operatorname{Staff}_{i t}\right)$. Although the marginal return on technical staff is non-linear, it has a decreasing trend with the change in $\operatorname{Staff}_{i t}$. A higher percentage of employees with established posts is associated with a relatively lower marginal return of technical workers. A technical worker is crucial to the operation of the water utility since the job duties of a technical worker cover installation of water pipes, operating water tanks. For that reason, the technical workers are usually in the established posts. Meanwhile, a worker with an established position has the incentives to devote less effort since the water utility, in general, does not layoff its worker in established position even with poor performance. Taken together, the marginal return of technical workers is lower with a higher ratio of established position in the water sector. The plot of $\beta_{L N T}\left(\mathrm{Staff}_{i t}\right)$ in the middle left has wide-range confidence bound which supports that the estimates are not significant. In the middle right plot, it is observed the marginal return on capital $\left(\beta_{E}\left(\operatorname{Staff}_{i t}\right)\right)$ is relatively higher when a water utility has lower staff ratio $(0.65-0.75)$ than other observations. In contrast, the higher staff ratio $(0.85-0.95)$ is associated with the higher return on energy usage in the lower left panel.

In order to quantify the effect of environment variable Staff $_{i t}$ on delivered water volume, the direct effect, efficiency changes, and overall effects are calculated with estimated partial derivatives of estimates. The average direct effect of $\operatorname{Staff}_{i t}$ is 1.5719 (with $61.76 \%$ of the estimates above zero) which is calculated from the formula $\partial \alpha\left(\operatorname{Staff}_{i t}\right) / \partial \operatorname{Staff}_{i t}+\left\{\partial \beta_{L T}\left(\operatorname{Staff}_{i t}\right) / \partial \operatorname{Staff}_{i t}\right\} \ln \left(L T_{i t}\right)+\left\{\partial \beta_{L N T}\left(\operatorname{Staff}_{i t}\right) / \partial \operatorname{Staff}_{i t}\right\} \ln \left(L N T_{i t}\right)+$ $\left\{\partial \beta_{K}\left(\operatorname{Staff}_{i t}\right) / \partial \operatorname{Staff}_{i t}\right\} \ln \left(K_{i t}\right)+\left\{\partial \beta_{E}\left(\operatorname{Staff}_{i t}\right) / \partial \operatorname{Staff}_{i t}\right\} \ln \left(E_{i t}\right)$. As Staff $i t$ increases by o.1 $(10 \%)$ which

\footnotetext{
$5 * * *, * * *$ represent the significant level at the $1 \%, 5 \%$, and $10 \%$ respectively.

${ }^{6} \alpha\left(\right.$ Staff $\left._{i t}\right)$ is comparable to the intercept in a linear function, where it changes the position of the production function but not the shape of it.
} 
means $10 \%$ more of the employees are in the Bianzhi establishment list, $\ln \left(Y_{i t}\right)$ increases by 0.1572 which raises delivered water volume by approximately $10158.24 \mathrm{~m}^{3}$. When decomposing the direct effect, it shows that the average neutral effect is $\partial \alpha\left(\operatorname{Staff}_{i t}\right) / \partial \operatorname{Staff}_{i t}=-0.0320$ (with $56.92 \%$ of the estimates below zero) and the average non-neutral effect is 1.6038 (with $47.69 \%$ of the estimates above zero). The average efficiency change effect is -0.0876 with all the estimates less than zero. Among the observations, $30 \%$ of the estimates are significant at $1 \%$ level; $10 \%$ are significant at $5 \%$ level; $18 \%$ are significant at $10 \%$ level.

Since the influence is non-linear, the average change does not give enough information. To have a better ideal of the changes in output that is associated with staff ratio, the direct effect, efficiency changes, and total effects are plotted against Staff $_{i t}$ in Figure 3.2. Among the 136 observations in the sample, 52 of them has the staff ratio that equals to one. The plot of direct effect fluctuates around zero. In contrast, the efficiency changes are below zero and has an upward trend. Firstly, it reveals the existence of production inefficiency since all the estimates of efficiency change effects are significant. Secondly, the technical inefficiency decreases with the internal staff ratio but at a decreasing rate. It illustrates that production efficiency improves with the more established posts in a water utility. Besides, the direct effect and efficiency changes are of different scale, the overall effects of staff ratio are similar to the direct effect.

\subsection{Conclusion}

Improving water delivery efficiency is a direct and effective way to ease water shortages in China. The literature reveals that many exogenous factors can potentially change technical efficiency in a water utility. These variables, also known as environment variables, measure the institutional and operational conditions, such as the customer density faced by a water utility, the percentage of billed water, the demand of water in different sectors, the pressure in water pipes, etc.

Among these facilitating variables, one institutional measure is of great interest, which is the measurement of establishment (Bianzhi) system. It separates established positions from others since an employee in the established post (also known as internal staff) has advantages in terms of salaries, subsidies, insurance, pensions, and promotion opportunities. Besides, the established position offers a labor contract that is close to a permanent one. Therefore, the employees in the establishment system usually will not be laid off even with poor performance. This system drives down the incentives to work hard for both the staff in and out the establishment system. The impact of the establishment system on the marginal return on labor is not examined before in the water utilities, and previous literature indicates the percentage of 
internal staff in a utility has no significant impact on the technical efficiency (Li and Phillips (2017)).

To account for the influence of the internal staff ratio on the marginal product of labor, a semiparametric stochastic production frontier model with smooth coefficient in Yao et al. (2018b) is introduced. Because of the existence of smooth coefficient, it captures the partial impact of environment variables on the output. Meanwhile, the inefficiency term of the model varies with the environment variable, which not only examines the existence of inefficiency but also measures the magnitude of it.

The empirical results reveal that a higher percentage of internal staff tends to lower the marginal product of technical staff. At the meantime, the relatively large internal staff ratio reduces technical inefficiency but at a decreasing rate. 
Table 3.1

Summary Statistics

\begin{tabular}{llllll}
\hline Variable & Description & Mean & STD & Min & Max \\
\hline$Y_{i t}$ & Delivered water volume & 11824.69 & 21064.93 & 182.5 & 87161 \\
$L T_{i t}$ & Number of technical staff & 122.27 & 175.66 & 3 & 851 \\
$L N T_{i t}$ & Number of non-technical staff & 521.57 & 595.74 & 19 & 3428 \\
$E_{i t}$ & 2704.36 & 3738.29 & 8.1 & 15107 \\
$K_{i t}$ & Electricity usage & 1110.54 & 1688.04 & 3.9 & 8788.28 \\
Staff $_{i t}$ & Length of pipes & 0.93 & 0.12 & 0.55 & 1 \\
Cusden $_{i t}$ & Staff ratio & 0.08 & 0.07 & 0.01 & 0.51 \\
Nonrevr $_{i t}$ & Customer density & 0.18 & 0.09 & 0.00 & 0.48 \\
Nonhhdr $_{i t}$ & Non-revenue water ratio & 0.54 & 0.17 & 0.14 & 1 \\
Pressure $_{i t}$ & Non-household user rate & 0.32 & 0.28 & 0.15 & 3.2 \\
\hline Number of observations & Average piped water pressure & 0.32 & & & \\
\hline
\end{tabular}


Table 3.2

Estimation of the Semiparametric Smooth Coefficient Stochastic Frontier with Staff $i t$

\begin{tabular}{|c|c|c|c|c|}
\hline & $\mathrm{Q}(25 \%)$ & $\mathrm{Q}(50 \%)$ & $\mathrm{Q}(75 \%)$ & Mean \\
\hline$\alpha\left(\operatorname{Staff}_{i t}\right)$ & $\begin{array}{l}1.9313^{* * *} \\
(0.5381)\end{array}$ & $\begin{array}{l}3.1446^{* * *} \\
(0.7825)\end{array}$ & $\begin{array}{l}3.1598^{* * *} \\
(0.7859)\end{array}$ & $\begin{array}{l}2.7310^{* * *} \\
(0.6748)\end{array}$ \\
\hline$\beta_{L T}\left(\operatorname{Staff}_{i t}\right)$ & $\begin{array}{l}0.1623^{*} \\
(0.0912)\end{array}$ & $\begin{array}{l}0.2332^{* *} \\
(0.1081)\end{array}$ & $\begin{array}{l}0.2332^{* *} \\
(0.1081)\end{array}$ & $\begin{array}{l}0.2296^{* *} \\
(0.106)\end{array}$ \\
\hline$\beta_{L N T}\left(\operatorname{Staff}_{i t}\right)$ & $\begin{array}{l}0.1577 \\
(0.1058)\end{array}$ & $\begin{array}{l}0.2744 \\
(0.1885)\end{array}$ & $\begin{array}{l}0.2744 \\
(0.1885)\end{array}$ & $\begin{array}{l}0.2335 \\
(0.1746)\end{array}$ \\
\hline$\beta_{K}\left(\operatorname{Staff}_{i t}\right)$ & $\begin{array}{l}0.4380^{* * *} \\
(0.1421)\end{array}$ & $\begin{array}{l}0.4772^{* * *} \\
(0.174)\end{array}$ & $\begin{array}{l}0.4772^{* * *} \\
(0.174)\end{array}$ & $\begin{array}{l}0.4760^{* * *} \\
(0.1697)\end{array}$ \\
\hline$\beta_{E}\left(\operatorname{Staff}_{i t}\right)$ & $\begin{array}{l}0.1994 \\
(0.2382)\end{array}$ & $\begin{array}{l}0.1994 \\
(0.2382)\end{array}$ & $\begin{array}{l}0.3868^{* *} \\
(0.1596)\end{array}$ & $\begin{array}{l}0.2765 \\
(0.2067)\end{array}$ \\
\hline
\end{tabular}



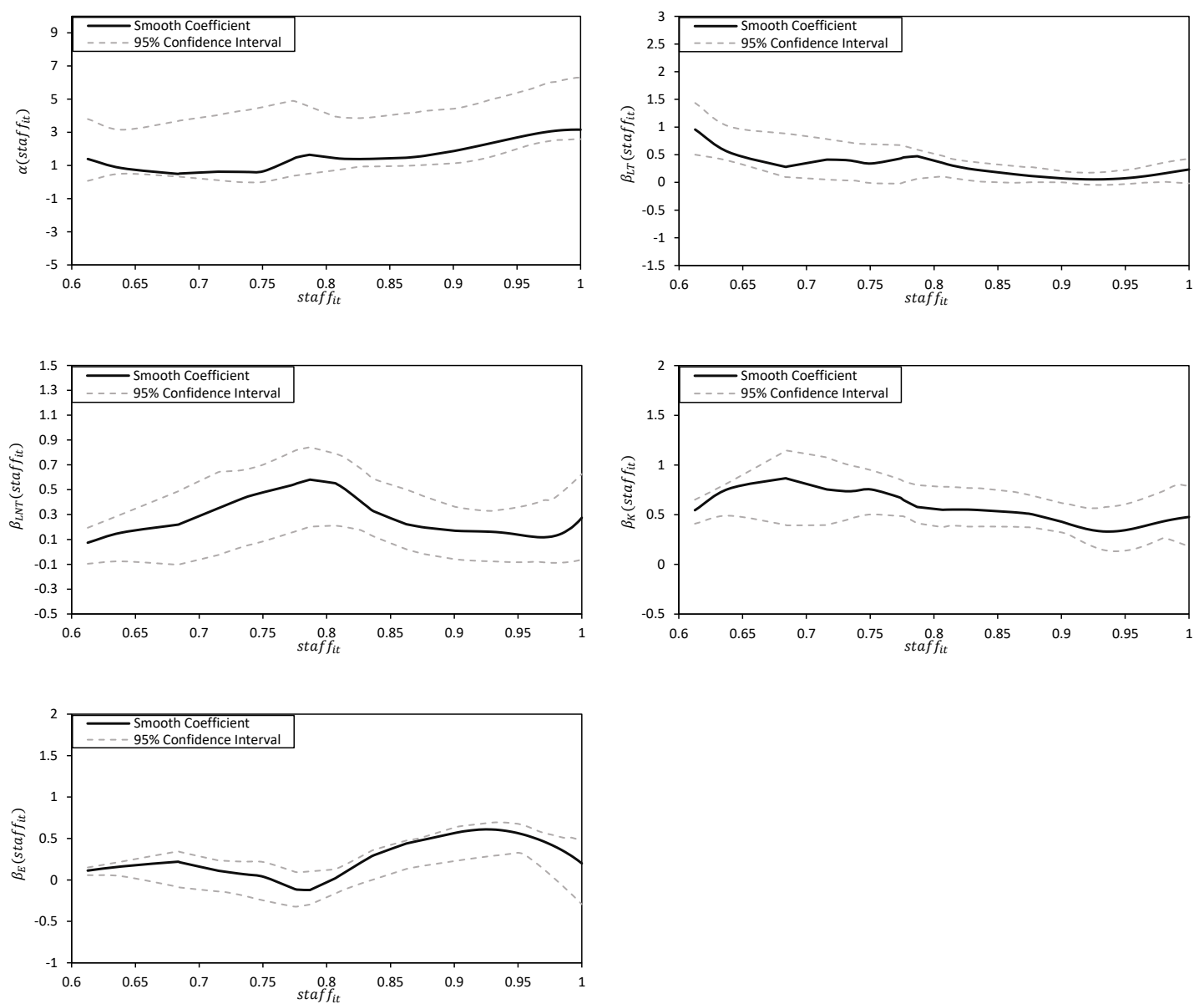

Figure 3.1

Plots of $\alpha\left(\operatorname{Staff}_{i t}\right), \beta_{L T}\left(\operatorname{Staff}_{i t}\right), \beta_{L N T}\left(\operatorname{Staff}_{i t}\right), \beta_{K}\left(\operatorname{Staff}_{i t}\right)$, and $\beta_{E}\left(\operatorname{Staff}_{i t}\right)$ against Staff $i t$ 

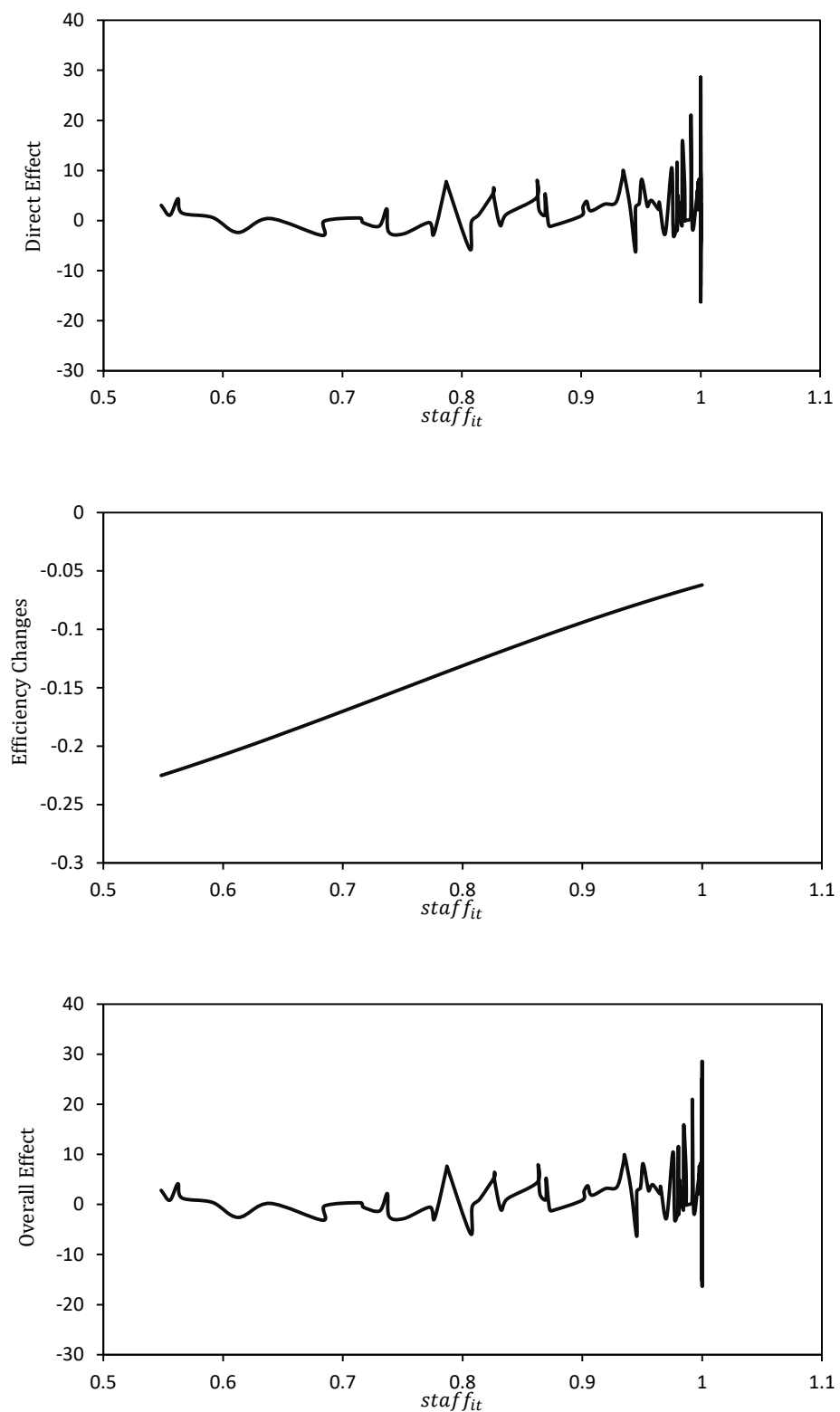

Figure 3.2

Plots of direct effect, efficiency changes, and overall effects against Staff $_{i t}$ 


\subsection{Appendix}

In this section, it presents the semiparametric estimation of coefficient functions in equation 3.2 when controlling for different environment variables, such as customer density $\left(\operatorname{Cusden}_{i t}\right)$, non-revenue water ratio $\left(\right.$ Nonrevr $\left._{i t}\right)$, non-household user rate $\left(\operatorname{Nonhhdr}_{i t}\right)$, and average piped water pressure $\left(\right.$ Pressure $\left._{i t}\right)$. The coefficient estimates with 25th, 50th, and 75th percentiles are reported in Table 3.3. Taken together the results from Table (3.2) and Table (3.3), the estimates of $\alpha\left(z_{i t}\right)$ are significant across all the estimations and the magnitude of $\alpha\left(z_{i t}\right) \mathrm{s}$ are similar and close to 2. Besides, the coefficient function of capital is significant at each quantile across all the panels in Table(3.3). It is also observed that the mean value of the estimates is positive in each panel of Table 3.3, which is consistent with the results in Table 3.2.

Panel (a) in Table 3.3 includes estimation results of equation (3.2) when controlling for the influence of customer density. It is noticed that $\beta_{L T}\left(\right.$ Cusden $\left._{i t}\right), \beta_{L N T}\left(\right.$ Cusden $\left._{i t}\right)$, and $\beta_{E}\left(\right.$ Cusden $\left._{i t}\right)$ are not significant, which indicates the customer density has no direct impact of the marginal return of labor and energy usage. The marginal return on capital is nonlinear as shown in Figure 3.3. The efficiency change is U-shaped and below zero which shows that higher customer density reduces technical inefficiency but at a lower rate. The efficiency changes are significant at $1 \%$ level for all the observations. That is to say, increased customer density improves water delivery efficiency. It is also known as "economies of density" in the literature (Li and Phillips (2017), Picazo-Tadeo et al. (2009)).

The results of non-household user rate are summarized in Table 3.3 panel (c), Figure 3.7, and Figure 3.8. The efficiency changes in Figure 3.8 is significant at $1 \%$ level across the estimates. A higher nonhousehold ratio increases production efficiency. When the ratio approaches 1 , the rate of increase slows down. Since water demand in the industry or business sector usually maintains at a stable level, the water delivery efficiency in those sectors is higher than in household use.

When controlling for the impact of average piped water pressure in the model, it is noticed that the efficiency changes in Figure 3.10 is below zero and the estimates are overall significant at $1 \%$ level. It indicates that higher water pressure reduces delivery inefficiency but at a decreasing rate. The leakage and velocity are related to water pressure. When water pressure is within the normal range, higher water pressure leads to higher velocity which satisfies customer demand sufficiently. However, when water 
pressure increases above a certain level, it increases the leakage rate and reduces the volume of delivered water. Therefore, when the water pressure is close to the right end in the second panel in Figure 3.10, it is observed the rate of efficiency improvement slows down. 
Table 3.3

Estimation of the Semiparametric Smooth Coefficient Stochastic Frontier with Environment Variables

\begin{tabular}{|c|c|c|c|c|c|}
\hline $\begin{array}{l}\text { Environment } \\
\text { variable }\left(z_{i t}\right)\end{array}$ & Coefficients & $\mathrm{Q}(25 \%)$ & $\mathrm{Q}(50 \%)$ & $\mathrm{Q}(75 \%)$ & Mean \\
\hline \multirow[t]{6}{*}{ Cusden $_{i t}$} & $\alpha\left(z_{i t}\right)$ & $\begin{array}{l}1.6545^{* *} \\
(0.8264)\end{array}$ & $\begin{array}{l}1.7735^{* * *} \\
(0.4544)\end{array}$ & $\begin{array}{l}1.8775^{* * *} \\
(0.6365)\end{array}$ & $\begin{array}{l}2.2039 \\
(2.2375)\end{array}$ \\
\hline & $\beta_{L T}\left(z_{i t}\right)$ & $\begin{array}{l}-0.0499 \\
(0.1145)\end{array}$ & $\begin{array}{l}0.0036 \\
(0.0624)\end{array}$ & $\begin{array}{l}0.1843 \\
(0.1216)\end{array}$ & $\begin{array}{l}-0.0460 \\
(0.5106)\end{array}$ \\
\hline & $\beta_{L N T}\left(z_{i t}\right)$ & 0.0699 & 0.0811 & $0.2245^{*}$ & $\begin{array}{l}-0.3916 \\
(17973)\end{array}$ \\
\hline & $\beta_{K}\left(z_{i}\right.$ & $\begin{array}{l}(0.2134) \\
0.6438^{* * *}\end{array}$ & $\begin{array}{l}(0.1944) \\
0.8201^{* * *}\end{array}$ & $\begin{array}{l}(0.1329) \\
0.9201^{* * *}\end{array}$ & $\begin{array}{l}(1.7913) \\
0.1524\end{array}$ \\
\hline & & $(0.2031)$ & $(0.1883)$ & $(0.1846)$ & $(2.2995)$ \\
\hline & $\beta_{E}\left(z_{i t}\right)$ & $\begin{array}{l}0.1005 \\
(0.0981)\end{array}$ & $\begin{array}{l}0.1536 \\
(0.2168)\end{array}$ & $\begin{array}{l}0.2382 \\
(0.2457)\end{array}$ & $\begin{array}{l}1.1940 \\
(3.2209)\end{array}$ \\
\hline \multirow[t]{8}{*}{ Nonrevr $_{i t}$} & $\alpha\left(z_{i t}\right)$ & $\begin{array}{l}0.6192 \\
(0.5490)\end{array}$ & $\begin{array}{l}1.5638^{* * *} \\
(0.6037)\end{array}$ & $\begin{array}{l}2.0172^{* * *} \\
(0.3290)\end{array}$ & $\begin{array}{l}1.1768^{*} \\
(0.6904)\end{array}$ \\
\hline & $\beta_{L T}\left(z_{i t}\right)$ & $\begin{array}{l}0.0410 \\
(0.0788)\end{array}$ & $\begin{array}{l}0.0680 \\
(0.0684)\end{array}$ & $\begin{array}{l}0.1652^{*} \\
(0.0919)\end{array}$ & $\begin{array}{l}0.0810 \\
(0.1155)\end{array}$ \\
\hline & $\beta_{L N T}\left(z_{i t}\right)$ & $0.2205^{* *}$ & $0.4470^{* * *}$ & $0.4731^{* * *}$ & $0.2770^{*}$ \\
\hline & & $(0.0920)$ & $(0.1262)$ & $(0.0901)$ & $(0.1601)$ \\
\hline & $\beta_{K}\left(z_{i t}\right)$ & $0.3135^{* *}$ & $0.4168^{* * *}$ & $0.547^{* * *}$ & $0.4248^{* *}$ \\
\hline & & $(0.1254)$ & $(0.1318)$ & $(0.1385)$ & $(0.1727)$ \\
\hline & $\beta_{E}\left(z_{i t}\right)$ & $0.1607^{* *}$ & $0.4313^{* * *}$ & $0.6709^{*}$ & $0.4938^{* * *}$ \\
\hline & & & $(0.0700)$ & $(0.40$ & $(0.1727)$ \\
\hline \multirow[t]{9}{*}{ Nonhhdr $_{i t}$} & $\alpha\left(z_{i t}\right)$ & $\begin{array}{l}1.5592^{*} \\
(0.8045)\end{array}$ & $\begin{array}{l}1.9178^{* * *} \\
(0.3553)\end{array}$ & $\begin{array}{l}2.3658^{* * *} \\
(0.4632)\end{array}$ & $\begin{array}{l}2.2114^{* * *} \\
(0.5263)\end{array}$ \\
\hline & $\beta_{L T}\left(z_{i t}\right)$ & -0.0601 & $0.1981^{* * *}$ & $0.3468^{* * *}$ & 0.1306 \\
\hline & & $(0.1029)$ & $(0.0632)$ & $(0.0622)$ & $(0.0900)$ \\
\hline & $\beta_{L N T}\left(z_{i t}\right)$ & -0.0626 & $0.2270^{* *}$ & $0.3058^{* * *}$ & 0.1653 \\
\hline & & $(0.1013)$ & $(0.0993)$ & $(0.0927)$ & $(0.1128)$ \\
\hline & $\beta_{K}\left(z_{i t}\right)$ & $0.3481^{* * *}$ & $0.5587^{* * *}$ & $0.7022^{* * *}$ & $0.5112^{* * *}$ \\
\hline & & $(0.0925)$ & $(0.1039)$ & $(0.0843)$ & $(0.1549)$ \\
\hline & $\beta_{E}\left(z_{i t}\right)$ & $0.2076^{*}$ & $0.2771^{* * *}$ & $0.5226^{* * *}$ & $0.3859^{* * *}$ \\
\hline & & $(0.1212)$ & $(0.0789)$ & $(0.1468)$ & $(0.1233)$ \\
\hline \multirow[t]{8}{*}{ (d) } & $\alpha\left(z_{i t}\right)$ & $\begin{array}{l}2.3866^{* * *} \\
(0.3979)\end{array}$ & $\begin{array}{l}2.8239^{* * *} \\
(0.4604)\end{array}$ & $\begin{array}{l}3.1609^{* * *} \\
(0.5779)\end{array}$ & $\begin{array}{l}3.0424^{* * *} \\
(07420)\end{array}$ \\
\hline & $\beta_{L T}\left(z_{i t}\right)$ & $0.1870^{* *}$ & $0.2465^{* * *}$ & $0.3058^{* * *}$ & 0.1139 \\
\hline & & $(0.0733)$ & $(0.0669)$ & $(0.0727)$ & $(0.1471)$ \\
\hline & $\beta_{L N T}\left(z_{i t}\right)$ & 0.1251 & 0.1709 & 0.1820 & $\begin{array}{l}0.1852 \\
(0.2663)\end{array}$ \\
\hline & $\beta_{K}\left(z_{i t}\right)$ & $\begin{array}{l}(0.1190) \\
0.3403^{* * *}\end{array}$ & $0.5255^{* * *}$ & $\begin{array}{l}(0.1179) \\
0.6094^{* * *}\end{array}$ & $\begin{array}{l}(0.2663) \\
0.5489^{* * *}\end{array}$ \\
\hline & & $(0.0968)$ & $(0.1059)$ & $(0.1327)$ & $(0.1905)$ \\
\hline & $\beta_{E}\left(z_{i t}\right)$ & 0.0586 & $0.1669^{*}$ & $0.4057^{* * *}$ & 0.1869 \\
\hline & & $(0.1310)$ & $(0.0986)$ & $(0.0889)$ & $(0.1930)$ \\
\hline
\end{tabular}

$* * *, * *, *$ represent the significant level at the $1 \%, 5 \%$, and $10 \%$ respectively. 

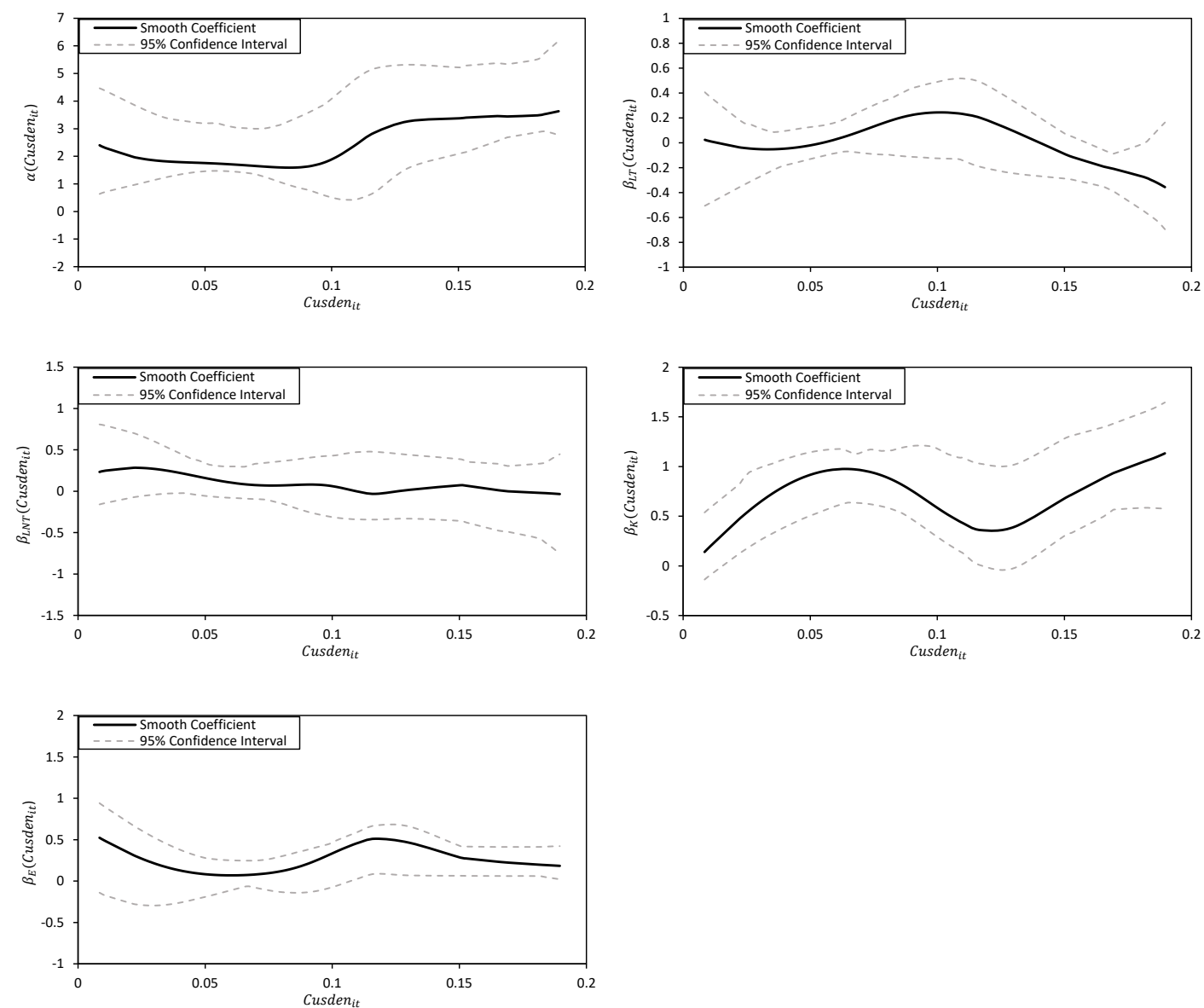

Figure 3.3

Plots of $\alpha\left(\operatorname{Cusden}_{i t}\right), \beta_{L T}\left(\operatorname{Cusden}_{i t}\right), \beta_{L N T}\left(\operatorname{Cusden}_{i t}\right), \beta_{K}\left(\operatorname{Cusden}_{i t}\right)$, and $\beta_{E}\left(\operatorname{Cusden}_{i t}\right){\text { against } \operatorname{Cusden}_{i t}}$ 

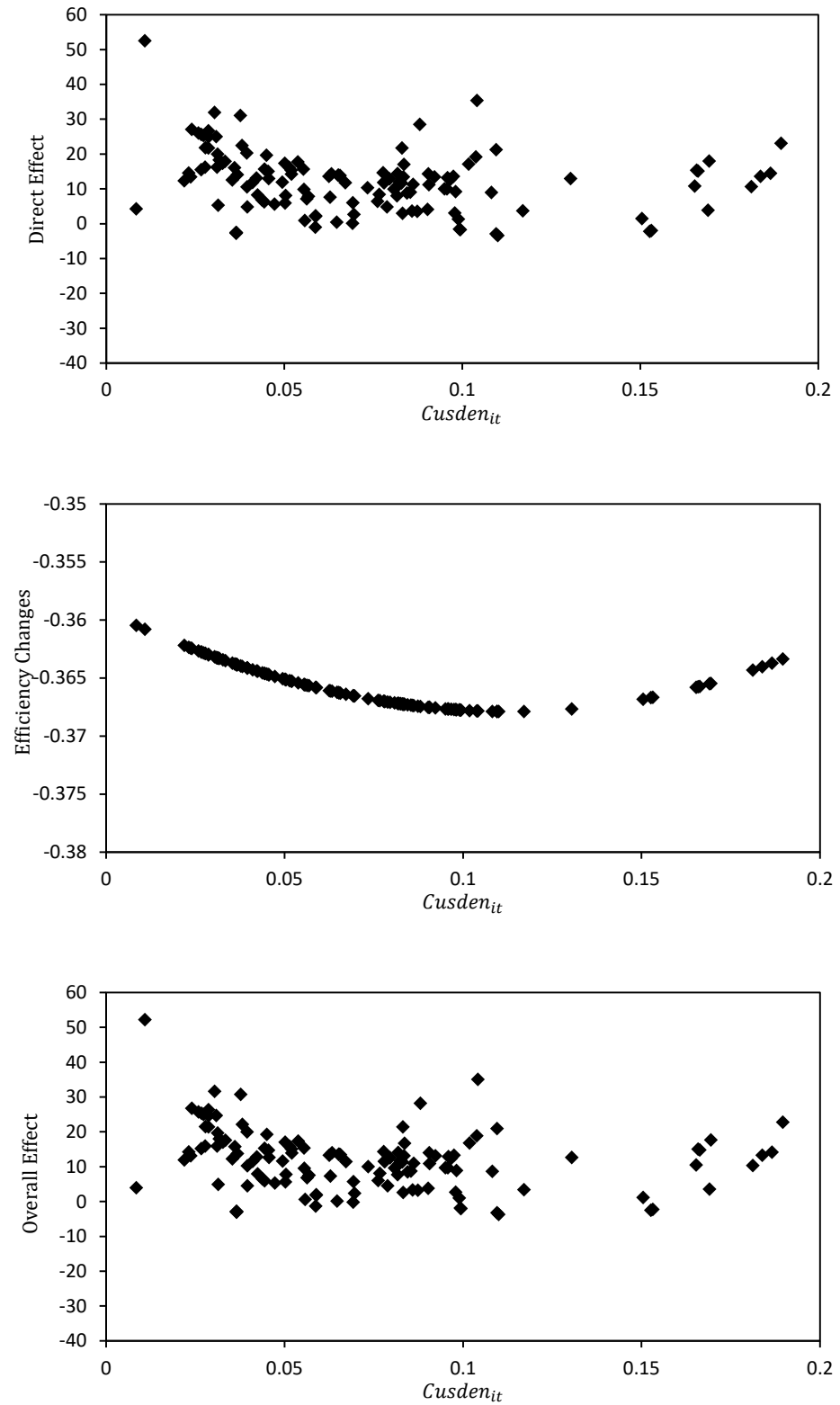

Figure 3.4

Plots of direct effect, efficiency changes, and overall effects against Cusden $_{i t}$ 

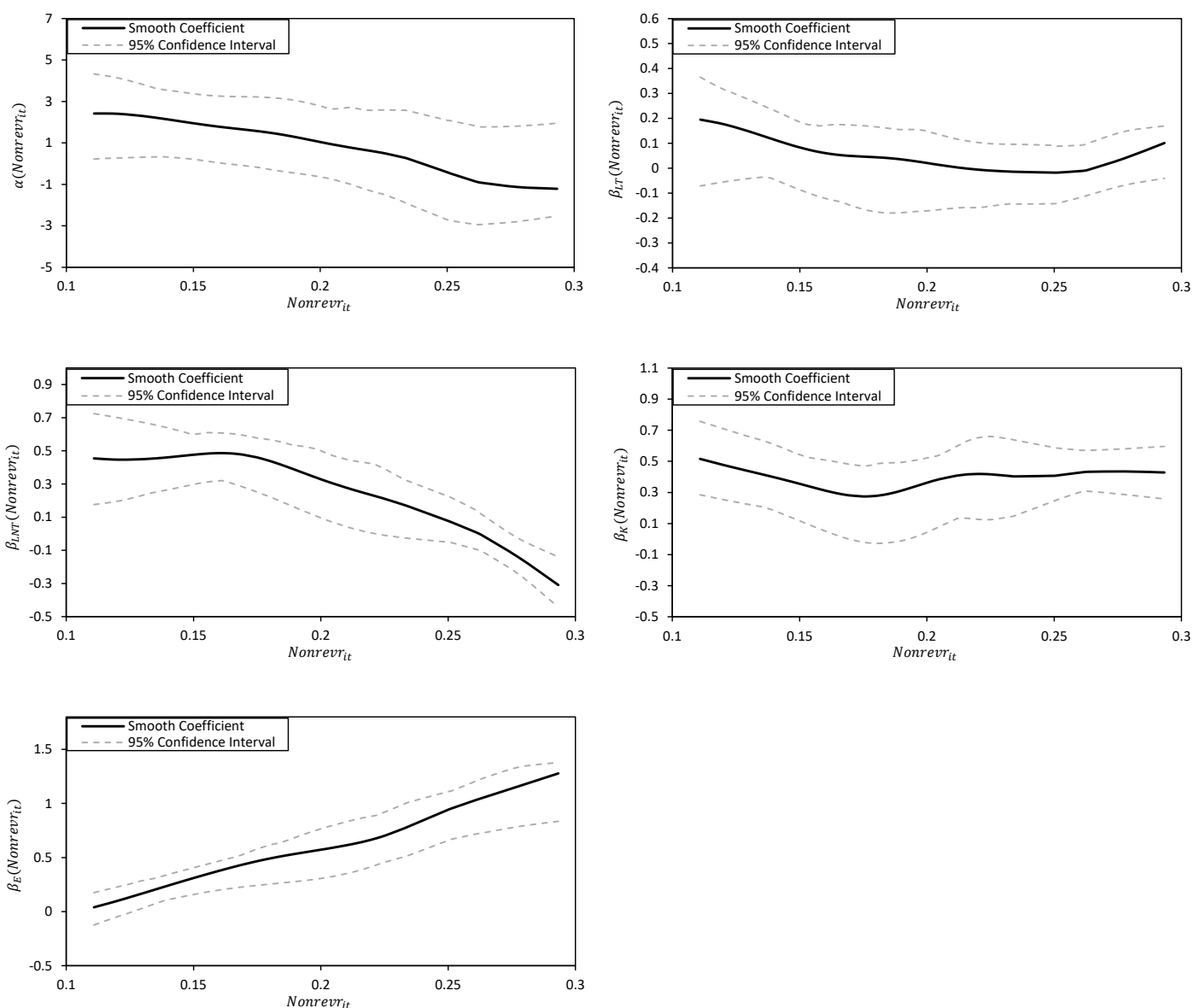

Figure 3.5

Plots of $\alpha\left(\right.$ Nonrevr $\left._{i t}\right), \beta_{L T}\left(\right.$ Nonrevr $\left._{i t}\right), \beta_{L N T}\left(\right.$ Nonrevr $\left._{i t}\right), \beta_{K}\left(\right.$ Nonrevr $\left._{i t}\right)$, and $\beta_{E}\left(\right.$ Nonrevr $\left._{i t}\right)$ against Nonrevr $_{i t}$ 

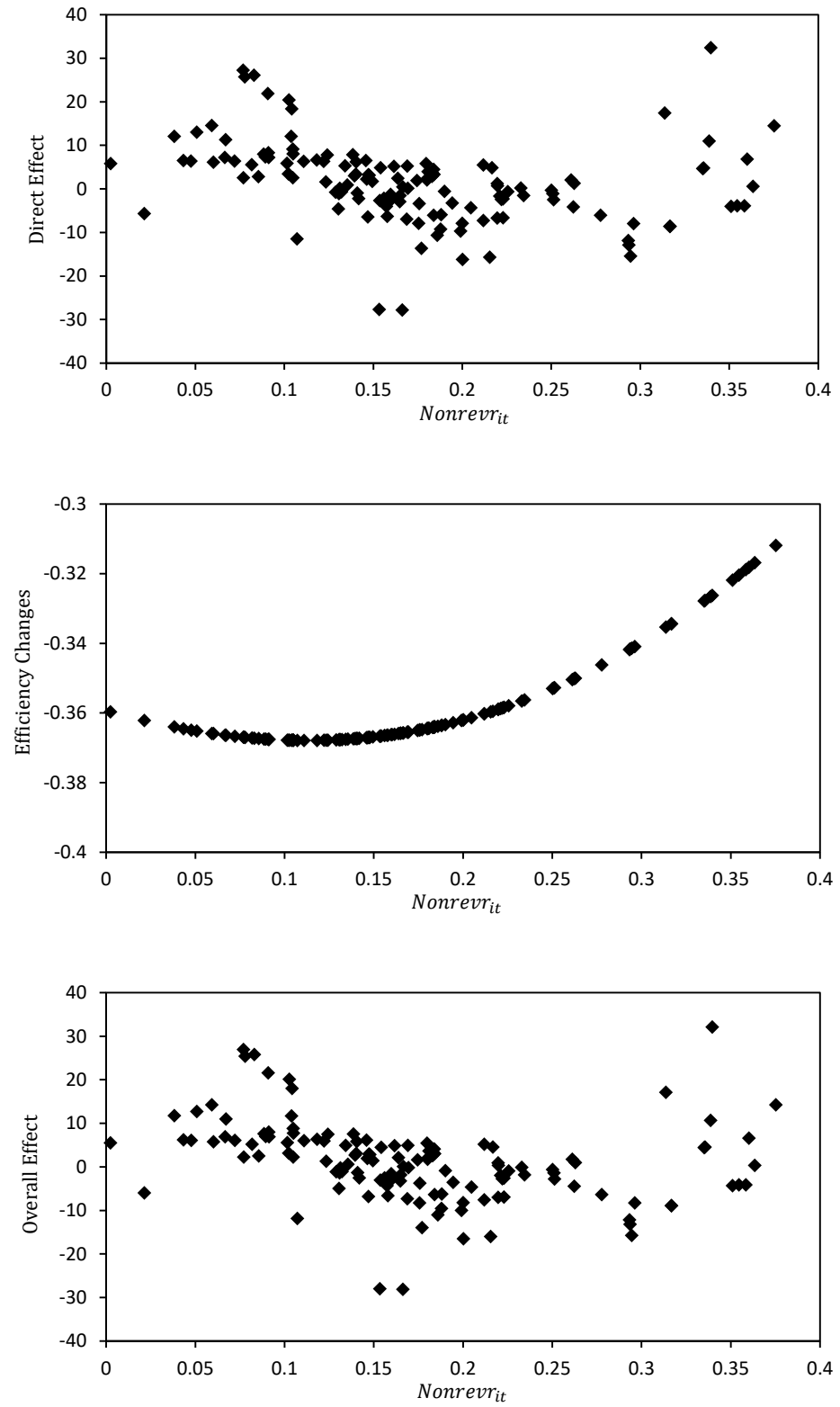

Figure 3.6

Plots of direct effect, efficiency changes, and overall effects against Nonrevr ${ }_{i t}$ 

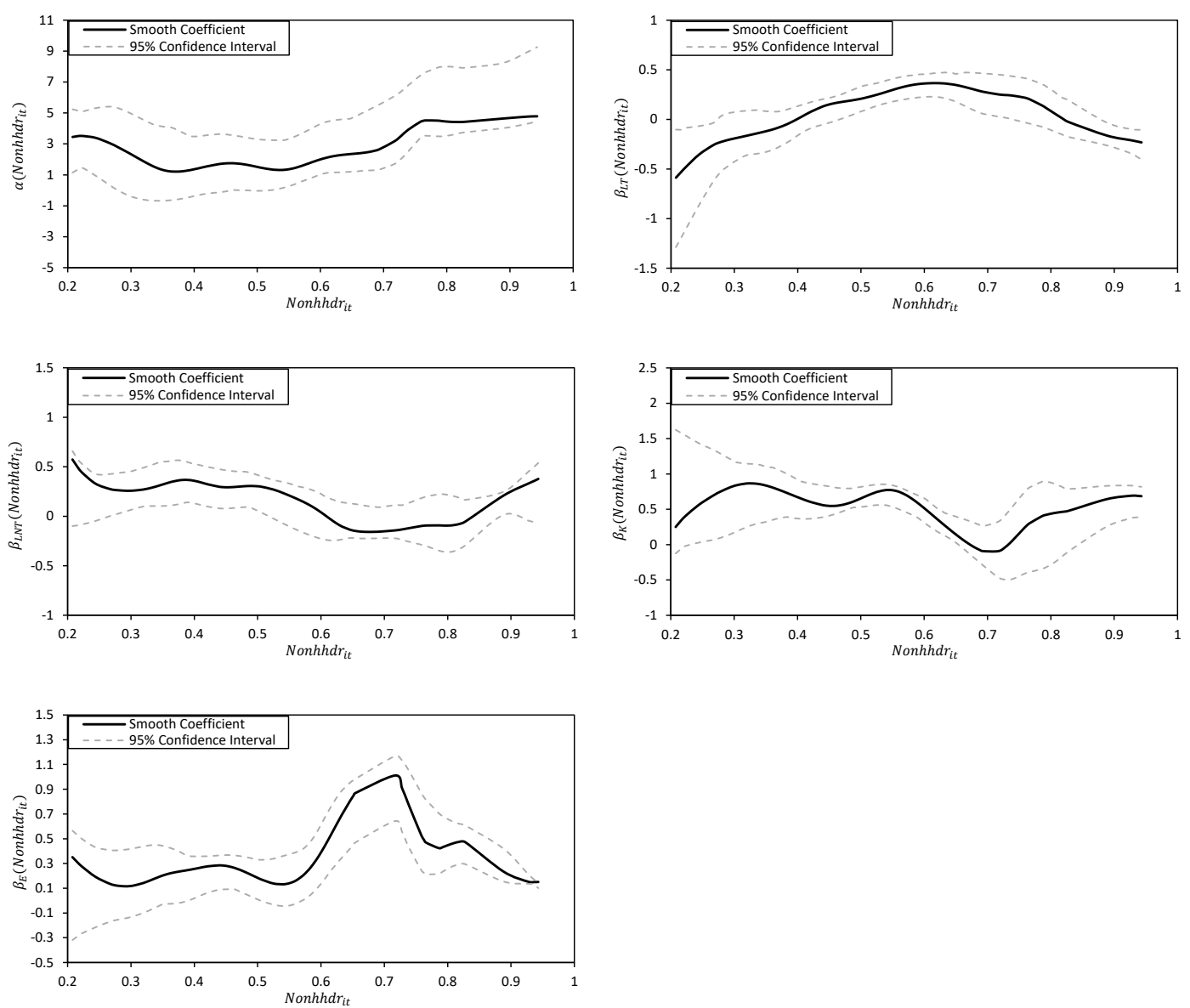

Figure 3.7

Plots of $\alpha\left(\operatorname{Nonhhdr}_{i t}\right), \beta_{L T}\left(\operatorname{Nonhhdr}_{i t}\right), \beta_{L N T}\left(\operatorname{Nonhhdr}_{i t}\right), \beta_{K}\left(\operatorname{Nonhhdr}_{i t}\right)$, and $\beta_{E}\left(\operatorname{Nonhhdr}_{i t}\right)$ against Nonhhdr $_{i t}$ 

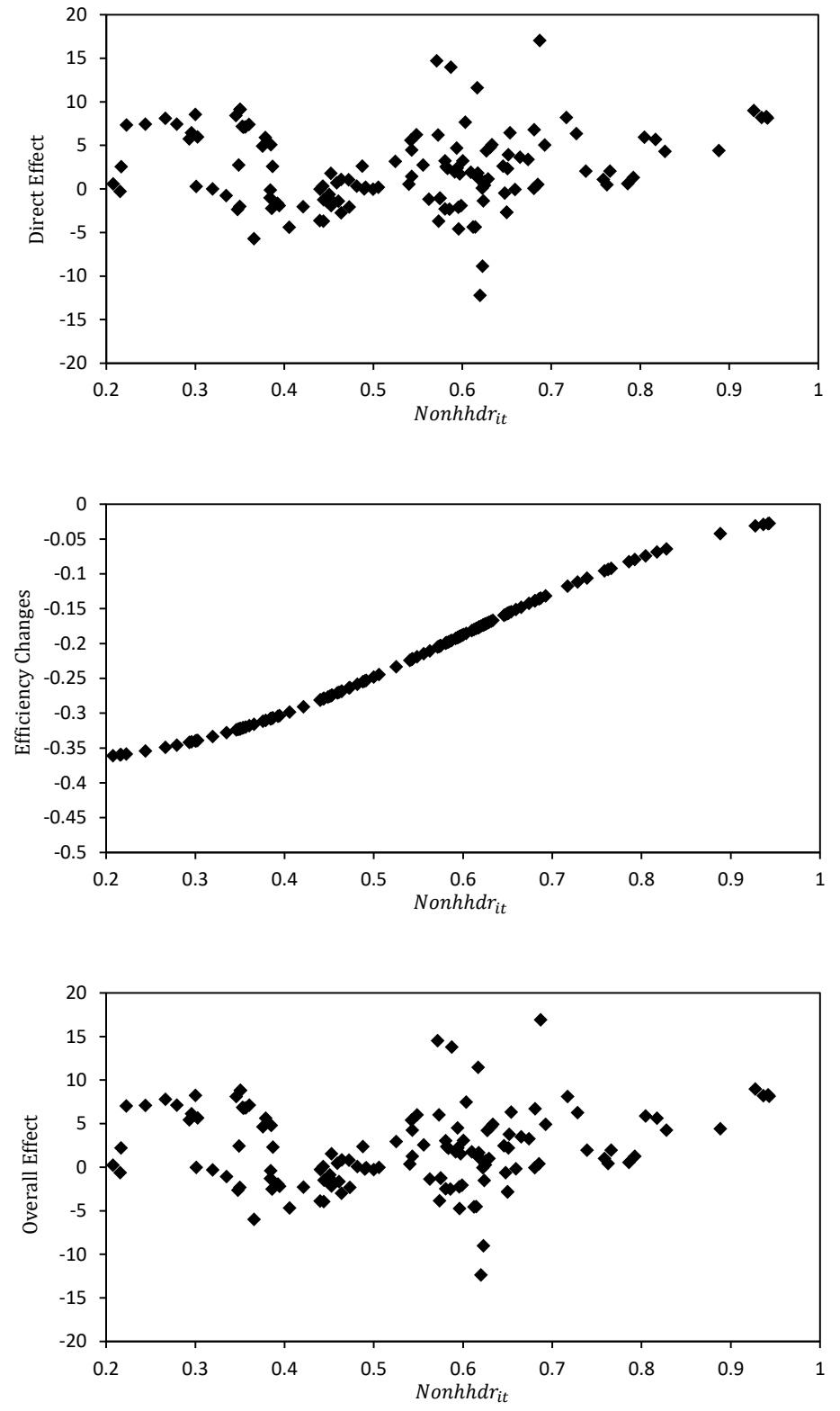

Figure 3.8

Plots of direct effect, efficiency changes, and overall effects against Nonhhdr ${ }_{i t}$ 

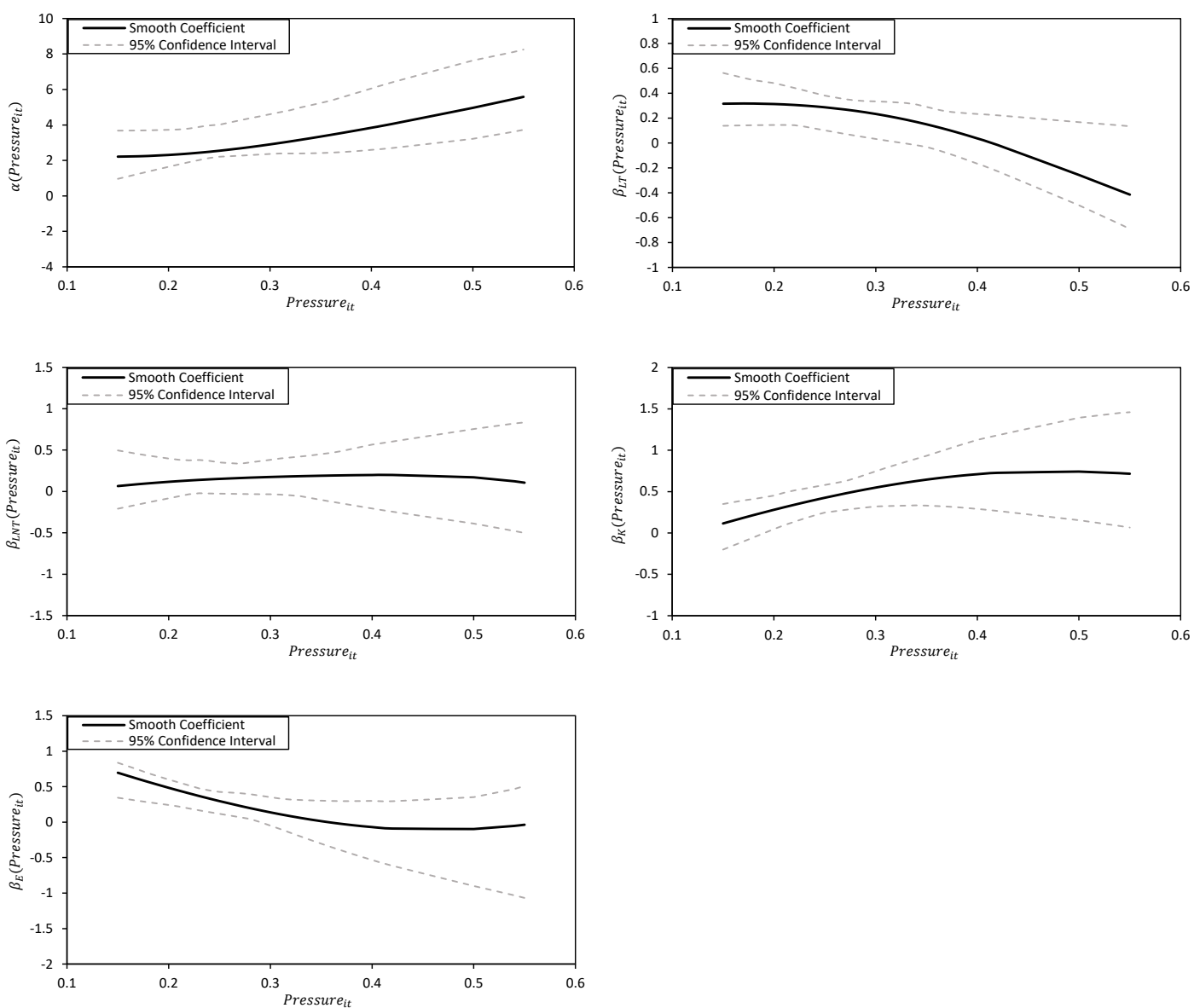

Figure 3.9

Plots of $\alpha\left(\right.$ Pressure $\left._{i t}\right), \beta_{L T}\left(\right.$ Pressure $\left._{i t}\right), \beta_{L N T}\left(\right.$ Pressure $\left._{i t}\right), \beta_{K}\left(\right.$ Pressure $\left._{i t}\right)$, and $\beta_{E}\left(\right.$ Pressure $\left._{i t}\right)$ against Pressure $_{i t}$ 

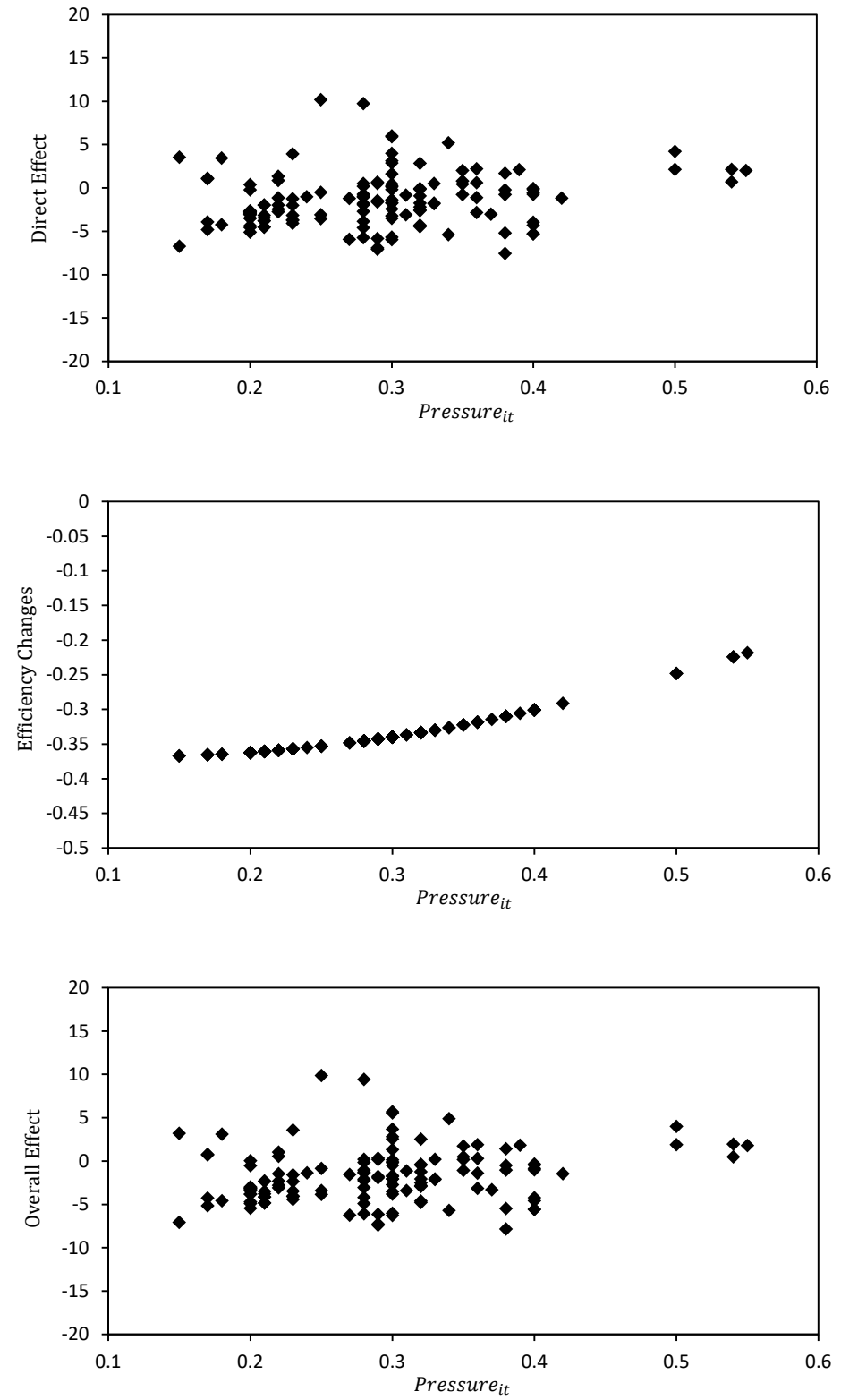

Figure 3.10

Plots of direct effect, efficiency changes, and overall effects against Pressure ${ }_{i t}$ 


\section{Bibliography}

Abbott, M., Cohen, B., 2009. Productivity and efficiency in the water industry. Utilities Policy 17 (3-4), 233-244.

Aigner, D., Lovell, C. A. K., Schmidt, P., 1977. Formulation and estimation of stochastic frontiers production function models. Journal of Econometrics 6, 21-37.

Alvarez, A., Amsler, C., Orea, L., Schmidt, P., 2006. Interpreting and testing the scaling property in models where inefficiency depends on firm characteristics. Journal of Productivity Analysis 25, 201212 .

Antonioli, B., Filippini, M., 2001. The use of a variable cost function in the regulation of the Italian water industry. Utilities Policy 10 (3-4), 181-187.

Arellano, M., 2003. Panel Data Econometrics. Oxford University Press, Oxford.

Aubert, C., Reynaud, A., 2005. The Impact of Regulation on Cost Efficiency: An Empirical Analysis of Wisconsin Water Utilities. Journal of Productivity Analysis 23 (3), 383-409.

Baltagi, B. H., 2013. Econometric Analysis of Panel Data, 2nd Edition. Wiley, New York.

Battese, G. E., Coelli, T. J., 1995. A model for technical inefficiency effects in a stochastic frontier production function for panel data. Empirical Economics 20 (1), 325-332.

Bhattacharyya, A., Harris, T. R., Narayanan, R., Raffiee, K., 1995. Specification and estimation of the effect of ownership on the economic efficiency of the water utilities. Regional Science and Urban Economics 25 (6), 759-784.

Brødsgaard, K. E., 2002. Institutional Reform and the Bianzhi System in China. The China Quarterly $170,361-386$.

Bushnell, J. B., Wolfram, C., 2009. Chapter Title: The Guy at the Controls: Labor Quality and Power Plant Efficiency.

Byrnes, J., Crase, L., Dollery, B., Villano, R., 2010. The relative economic efficiency of urban water utilities in regional New South Wales and Victoria. Resource and Energy Economics 32 (3), 439-455.

Cai, Z., Fan, J., Li, R., 2000. Efficient Estimation and Inferences for Varying-Coefficient Models. Journal of the American Statistical Association 95 (451), 888-902.

Carvalho, P., Marques, R. C., 2011. The influence of the operational environment on the efficiency of water utilities. Journal of Environmental Management 92 (10), 2698-2707.

Carvalho, P., Marques, R. C., 2014. Computing economies of vertical integration, economies of scope and economies of scale using partial frontier nonparametric methods. European Journal of Operational Research 234 (1), 292-307.

Caudill, S. B., Ford, J. M., Gropper, D. M., 1995. Frontier estimation and firm-specific inefficiency measure in the presence of heteroskedasticity. Journal of Business \& Economic Statistics 13 (1), 105111. 
Cazals, C., Florens, J.-P., Simar, L., 2002. Nonparametric frontier estimation: a robust approach. Journal of Econometrics 106 (1), 1-25.

Chan, H. R., Chupp, B. A., Cropper, M. L., Muller, N. Z., 2018. The impact of trading on the costs and benefits of the Acid Rain Program. Journal of Environmental Economics and Management 88, 180-209.

Che, Y., Shang, Z., 2015. Water Pricing in China: Impact of Socioeconomic Development. Springer, Cham, pp. 97-115.

Correia, T., Marques, R. C., 2011. Performance of Portuguese water utilities: how do ownership, size, diversification and vertical integration relate to efficiency? Water Policy 13 (3), 343-361.

Delgado, M. S., Ozabaci, D., Sun, Y., Kumbhakar, S. C., 2018. Smooth Coefficient Models With Endogenous Environmental Variables.

Ellerman, A. D., 2003. Lessons from Phase 2 compliance with the U.S. Acid Rain Program.

EPA, 2005. Acid Rain Program 2005 Progress Report. Tech. rep.

URL www.epa.gov/airmarkets

Estache, A., Rossi, M. A., 2002. How Different Is the Efficiency of Public and Private Water Companies in Asia? The World Bank Economic Review 16 (1), 139-148.

Fan, Y., Li, Q., Weersink, A., 1996. Semiparametric estimation of stochastic production frontier models. Journal of Business and Economic Statistics 14, 460-468.

Färe, R., Grosskopf, S., Noh, D.-W., Weber, W., 2005. Characteristics of a polluting technology: theory and practice. Journal of Econometrics 126 (2), 469-492.

Färe, R., Grosskopf, S., Pasurka, C. A., 2007. Pollution abatement activities and traditional productivity. Ecological Economics 62 (3-4), 673-682.

Färe, R., Grosskopf, S., Pasurka, C. A., 2013. Tradable permits and unrealized gains from trade. Energy Economics 40, 416-424.

Färe, R., Grosskopf, S., Pasurka, C. A., 2014. Potential gains from trading bad outputs: The case of U.S. electric power plants. Resource and Energy Economics 36 (1), 99-112.

Färe, R., Grosskopf, S., Pasurka, C. A., Weber, W. L., 2012. Substitutability among undesirable outputs. Tech. Rep. 1.

Feng, J., Huang, Z., Zhang, R., 2012. Estimation on varying-coefficient partially linear model with different smoothing variables. Communications in Statistics - Theory and methods 41, 516-529.

Filippini, M., Hrovatin, N., Zorić, J., 2008. Cost efficiency of Slovenian water distribution utilities: an application of stochastic frontier methods. Journal of Productivity Analysis 29 (2), 169-182.

Greene, W. H., 1980. Maximum likelihood estimation of econometric frontier functions. Journal of Econometrics 13 (1), 27-56.

Hampf, B., 2014. Separating environmental efficiency into production and abatement efficiency: a nonparametric model with application to US power plants. Journal of Productivity Analysis 41 (3), 457473.

Hampf, B., Rødseth, K. L., 2015. Carbon dioxide emission standards for U.S. power plants: An efficiency analysis perspective. Energy Economics 50, 140-153.

Hancevic, P. I., 2016. Environmental regulation and productivity: The case of electricity generation under the CAAA-1990. Energy Economics 60, 131-143.

Henderson, D. J., Carroll, R. J., Li, Q., 2008. Nonparametric estimation and testing of fixed effects panel data model. Journal of Econometrics 144, 257-275. 
Henderson, D. J., Ullah, A., 2005. A nonparametric random effects estimator. Economics Letters 88, 403-407.

Heshmati, A., Kumbhakar, S., Sun, K., 2014. Estimation of productivity in Korean electric power plants: A semiparametric smooth coefficient model. Energy Economics 45, 491-500.

Holland, S. P., 2006. Privatization of Water-Resource Development. Environmental \& Resource Economics 34 (2), 291-315.

Horowitz, J. L., Mammen, E., 2004. Nonparametric estimation of an additive model with a link function. The Annals of Statistics 32 (6), 2412-2443.

Horrace, W. C., Parmeter, C. F., 2011. Semiparametric deconvolution with unknown error variance. Journal of Productivity Analysis 35 (2), 129-141.

Hsiao, C., 2014. Analysis of Panel Data, 3rd Edition. , Econometric Society Monographs, New York.

Jiang, Y., 2009. China's water scarcity. Journal of Environmental Management 90 (11), 3185-3196.

Jiang, Y., Zheng, X., 2014. Private Sector Participation and Performance of Urban Water Utilities in China. Economic Development and Cultural Change 63 (1), 155-189.

Kleit, A. N., Terrell, D., 2001. Measuring Potential Efficiency Gains from Deregulation of Electricity Generation: A Bayesian Approach. Review of Economics and Statistics 83 (3), 523-530.

Knittel, C. R., 2002. Alternative Regulatory Methods and Firm Efficiency: Stochastic Frontier Evidence from the U.S. Electricity Industry. Review of Economics and Statistics 84 (3), 530-540.

Kumbhakar, S. C., Ghosh, S., Mcguckin, J. T., 1991. A Generalized Production Frontier Approach for Estimating Determinants of Inefficiency in U.S. Dair Farms. Journal of Business $\{\&\}$ Economic Statistics 9 (3), 279-286.

Lee, Y. K., Mammen, E., Park, B. U., 2012a. Flexible generalized varying coefficient regression models. Annals of Statistics 40, 1906-1933.

Lee, Y. K., Mammen, E., Park, B. U., 2012b. Projection-type estimation for varying coefficient regression models. Bernoulli 18, 177-205.

Li, F., Phillips, M. A., 2017. The Influence of the Regulatory Environment on Chinese Urban Water Utilities. Water Resources Management 31 (1), 205-218.

Li, Q., Huang, C. J., Li, D., Fu, T.-T., 2002. Semiparametric Smooth Coefficient Models. Journal of Business \& Economic Statistics 20 (3), 412-422.

Li, Q., Racine, J., 2007. Nonparametric econometrics: theory and practice. Princeton University Press, Princeton, NJ.

Li, Q., Stengos, T., 1996. On the root-n-consistent semiparametric estimation of partially linear models. Journal of Econometrics 71, 389-397.

Lin, X., Carroll, R. J., 2006. Semiparametric estimation in general repeated measures problems. Journal of the Royal Statistical Society (Series B), 68-88.

Lin, Z., Li, Q., Sun, Y., 2014. A consistent nonparametric test of parametric regression functional form in fixed effects panel data models. Journal of Econometrics 178 (PART 1), 167-179.

Linton, O. B., 1997. Efficient estimation of additive nonparametric regression models. Biometrika 84, 469-473.

Linton, O. B., Nielsen, J. P., 1995. A kernel method of estimating structured nonparametric regression based on marginal integration. Biometrika 82, 93-100. 
Lynk, E., 1993. Privatisation, Joint Production and the Comparative Efficiencies of Private and Public Ownership: The UK Water Industry Case.

Mammen, E., Linton, O. B., Nielsen, J. P., 1999. The existence and asymptotic properties of a backfitting projection algorithm under weak conditions. Annals of Statistics 27, 1443-1490.

Marques, R. C., Berg, S., Yane, S., 2014. Nonparametric Benchmarking of Japanese Water Utilities: Institutional and Environmental Factors Affecting Efficiency. Journal of Water Resources Planning and Management 140 (5), 562-571.

Martins-Filho, C., Yao, F., 2009. Nonparametric regression estimation with general parametric error covariance. Journal of Multivariate Analysis 100, 309-333.

Martins-Filho, C., Yao, F., 2015. Semiparametric Stochastic Frontier Estimation via Profile Likelihood. Econometric Reviews 34 (4), 413-451.

Meeusen, W., van Den Broeck, J., 1977. Efficiency estimation from Cobb-Douglas production functions with composed error. International Economic Review 18, 435-444.

Ministry of Water Resources, C., 2014. Statistic Bulletin of China Water Activities. Tech. rep., Ministry of Water Resources.

Ministry of Water Resources, C., 2017. Bulletin of China Water Resources. Tech. rep.

Napolitano, S., Schreifels, J., Stevens, G., Witt, M., LaCount, M., Forte, R., Smith, K., 2007. The U.S. Acid Rain Program: Key Insights from the Design, Operation, and Assessment of a Cap-and-Trade Program. The Electricity Journal 20 (7), 47-58.

Ozabaci, D., Henderson, D. J., Su, L., 2014. Additive Nonparametric Regression in the Presence of Endogenous Regressors. Journal of Business \& Economic Statistics 32 (4), 555-575.

Park, B. U., Mammen, E., Lee, Y. K., Lee, E. R., 2015. Varying Coefficient Regression Models: A Review and New Developments. International Statistical Review 83, 36-64.

Parmeter, C. F., Wang, H. J., Kumbhakar, S. C., 2017. Nonparametric estimation of the determinants of inefficiency. Journal of Productivity Analysis 47 (3), 205-221.

Pechan, E. H., Gagnon, A. C., Acurex Environmental Corporation, Edward Aul \& Associate Inc., 1993. Emission Factor Documentation For AP-42 Section 1.1 Bituminous And Subbituminous Coal Combustion EPA Project Officer. Tech. rep.

Picazo-Tadeo, A. J., Sáez-Fernández, F. J., González-Gómez, F., 2009. The role of environmental factors in water utilities' technical efficiency. Empirical evidence from Spanish companies. Applied Economics $41(5), 615-628$.

Porter, M. E., van der Linde, C., 1995. Toward a New Conception of the Environment-Competitiveness Relationship. Journal of Economic Perspectives 9 (4), 97-118.

Renzetti, S., Dupont, D., 2004. The Performance of Municipal Water Utilities: Evidence on the Role of Ownership. Journal of Toxicology and Environmental Health, Part A 67 (20-22), 1861-1878.

Roca-Pardinas, J., Sperlich, S., 2010. Feasible estimation in generalized structured models. Statistics and Computing 20, 367-379.

Rogers, P., Silva, R. D., Policy, R. B. W., 2002, U., 2002. Water is an economic good: How to use prices to promote equity, efficiency, and sustainability. Water Policy 4 (1), 1-17.

Ruckstuhl, A. F., Welsh, A. H., Carroll, R. J., 2000. Nonparametric Function Estimation of the Relationship between Two Repeatedly Measured Variables. Statistica Sinica 10, 51-71.

Stevenson, R. E., 1980. Likelihood functions for generalized stochastic frontier estimation. Journal of Econometrics 13 (1), 57-66. 
$\mathrm{Su}, \mathrm{L} .$, Ullah, A., 2006. Profile likelihood estimation of partially linear panel data models with fixed effects. Economics Letters 92, 75-81.

Sun, Y., Carroll, R. J., Li, D., 2009. Semiparametric estimation of fixed effects panel data varying coefficient models. Advances in Econometrics 25, 101-130.

Ullah, A., Roy, N., 1998. Nonparametric and Semiparametric Econometrics of Panel Data: Econometrics of Victoria, Victoria, British Columbia. In: Handbook of Applied Economic Statistics. Marcel Dekker, New York, pp. 579-604.

Wang, H.-J., Schmidt, P., 2002. One-step and two-step estimation of the effects of exogenous variables on technical efficiency levels. Journal of Productivity Analysis 18, 129-144.

Wang, L., Yang, L., 2007. Spline-backfitted kernel smoothing of nonlinear additive autoregression model. Annals of Statistics 35, 2474-2503.

Wang, N., 2003. Marginal nonparametric kernel regression accounting for within-subject correlation. Biometrika 90 (1), 43-52.

World Bank, 2018. China: A Watershed Moment for Water Governance.

Xue, L., Yang, L., 2006. Estimation of semiparametric additive coefficient model. Journal of Statistical Planning and Inference 136, 2506-2534.

Yang, L., Park, B. U., Xue, L., Hardle, W., 2006. Estimation and testing for varying coefficients in additive models with marginal integration. Journal of the American Statistical Association 101, 1212-1227.

Yao, F., Lu, Q., Sun, Y., Zhang, J., 2018a. Efficient Estimation in Varying Coefficient Panel Data Model with Different Smoothing Variables and Fixed Effects.

Yao, F., Zhang, F., Kumbhakar, S. C., 2018b. Semiparametric Smooth Coefficient Stochastic Frontier Model With Panel Data. Journal of Business \& Economic Statistics, 1-17.

Zhang, R., Li, G., 2007. Averaged estimation of functional-coefficient regression models with different smoothing variables. Statistics \& Probability Letters 77, 455-461.

Zschille, M., Walter, M., 2012. The performance of German water utilities: a (semi)-parametric analysis. Applied Economics 44 (29), 3749-3764. 